San Jose State University

SJSU ScholarWorks

Mineta Transportation Institute Publications

$4-2020$

\title{
Local Government Policy and Planning for Unmanned Aerial Systems
}

Tyler Spence

San Jose State University, spenct18@erau.edu

Francesca Favaro

San Jose State University, francesca.favaro@sjsu.edu

Kally Yeung

San Jose State University

Follow this and additional works at: https://scholarworks.sjsu.edu/mti_publications

Part of the Aviation Safety and Security Commons

\section{Recommended Citation}

Tyler Spence, Francesca Favaro, and Kally Yeung. "Local Government Policy and Planning for Unmanned Aerial Systems" Mineta Transportation Institute Publications (2020). https://doi.org/10.31979/ mti.2020.1823

This Report is brought to you for free and open access by SJSU ScholarWorks. It has been accepted for inclusion in Mineta Transportation Institute Publications by an authorized administrator of SJSU ScholarWorks. For more information, please contact scholarworks@sjsu.edu. 


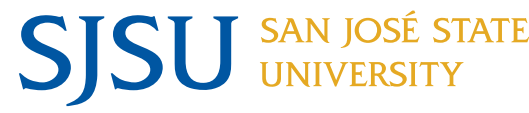

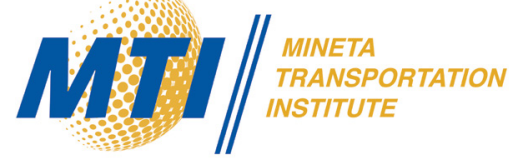

Local Government Policy and Planning for Unmanned Aerial Systems

Tyler Spence, Ph.D.

Francesca Favaro, Ph.D.

Student Co-Author: Kally Yeung
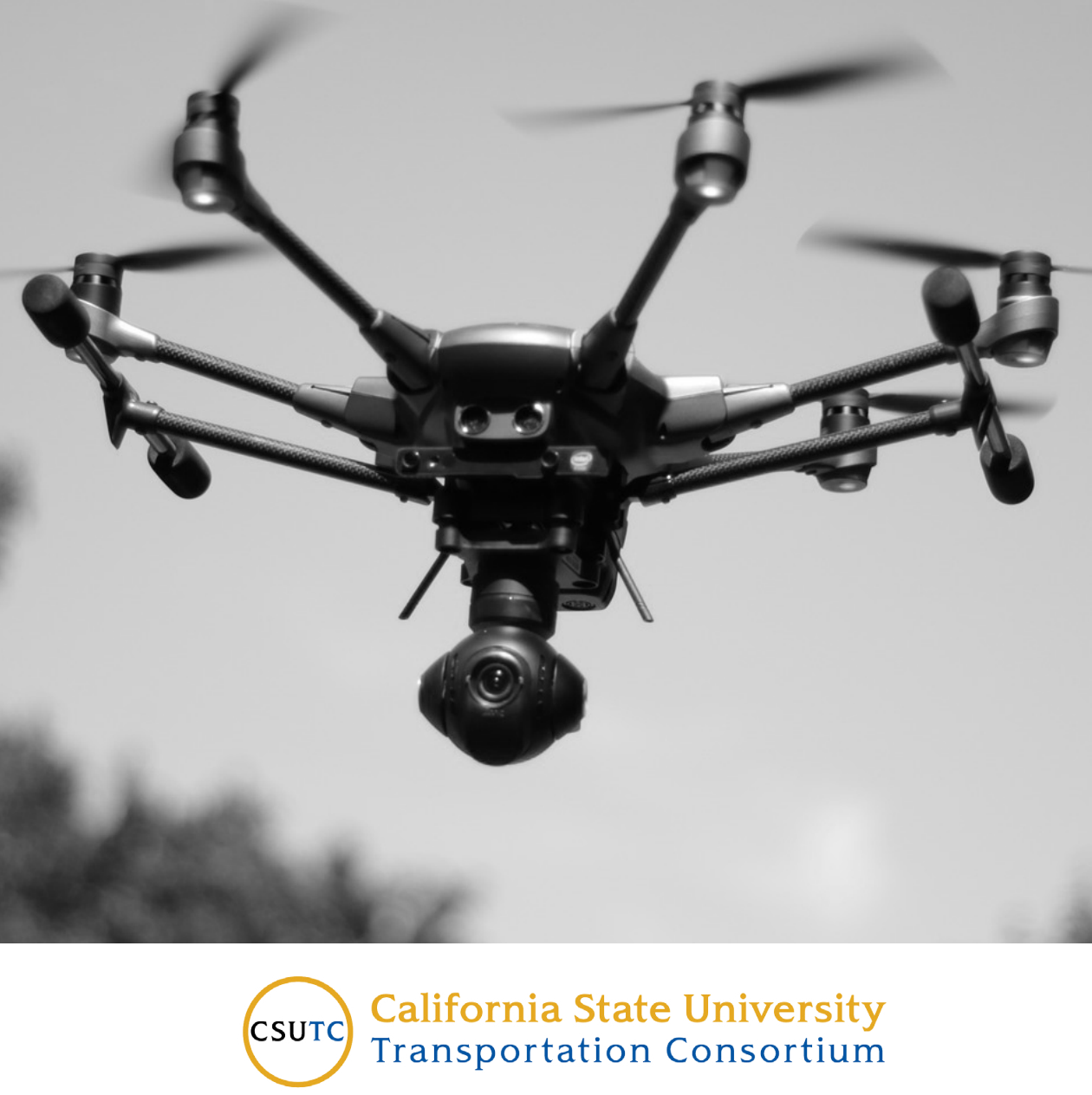


\section{MINETA TRANSPORTATION INSTITUTE}

Founded in 199I, the Mineta Transportation Institute (MTI), an organized research and training unit in partnership with the Lucas College and Graduate School of Business at San José State University (SJSU), increases mobility for all by improving the safety, efficiency, accessibility, and convenience of our nation's transportation system. Through research, education, workforce development, and technology transfer, we help create a connected world. MTI leads the four-university. MTI leads the four-university California State University Transportation Consortium funded by the State of California through Senate Bill I.

MTl's transportation policy work is centered on three primary responsibilities:

\section{Research}

MTI works to provide policy-oriented research for all levels of government and the private sector to foster the development of optimum surface transportation systems. Research areas include: bicycle and pedestrian issues; financing public and private sector transportation improvements; intermodal connectivity and integration; safety and security of transportation systems; sustainability of transportation systems; transportation / land use / environment; and transportation planning and policy development. Certified Research Associates conduct the research. Certification requires an advanced degree, generally a Ph.D., a record of academic publications, and professional references. Research projects culminate in a peer-reviewed publication, available on TransWeb, the MTI website (http://transweb.sjsu.edu).

\section{Education}

The Institute supports education programs for students seeking a career in the development and operation of surface transportation systems. MTI, through San José State University, offers an AACSBaccredited Master of Science in Transportation Management and graduate certificates in Transportation Management, Transportation Security, and High-Speed Rail Management that serve to prepare the nation's transportation managers for the 2 I st century. With the active assistance of the California Department ofTransportation (Caltrans), MTI delivers its classes over a state-of-the-art videoconference network throughout the state of California and via webcasting beyond, allowing working transportation professionals to pursue an advanced degree regardless of their location. To meet the needs of employers seeking a diverse workforce, MTl's education program promotes enrollment to under-represented groups.

\section{Information and Technology Transfer}

MTI utilizes a diverse array of dissemination methods and media to ensure research results reach those responsible for managing change. These methods include publication, seminars, workshops, websites, social media, webinars, and other technology transfer mechanisms. Additionally, MTI promotes the availability of completed research to professional organizations and journals and works to integrate the research findings into the graduate education program. MTl's extensive collection of transportation- related publications is integrated into San José State University's world-class Martin Luther King, Jr. Library.

\section{Disclaimer}

The contents of this report reflect the views of the authors, who are responsible for the facts and accuracy of the information presented herein. This document is disseminated in the interest of information exchange. The report is funded, partially or entirely, by a grant from the State of California. This report does not necessarily reflect the official views or policies of the State of California or the Mineta Transportation Institute, who assume no liability for the contents or use thereof. This report does not constitute a standard specification, design standard, or regulation. 
REPORT 20-07

\title{
LOCAL GOVERNMENT POLICY AND PLANNING FOR UNMANNED AERIAL SYSTEMS
}

\author{
Tyler Spence, Ph.D. \\ Francesca Favaro, Ph.D. \\ Student Co-Author: Kally Yeung
}

April 2020

A publication of

Mineta Transportation Institute

Created by Congress in 1991

College of Business

San José State University

San José, CA 95192-0219 


\section{TECHNICAL REPORT DOCUMENTATION PAGE}

1. Report No. 20-07

4. Title and Subtitle

Local Government Policy and Planning for Unmanned Aerial Systems
2. Government Accession No.

3. Recipient's Catalog No.

5. Report Date

April 2020

6. Performing Organization Code

7. Authors

Tyler Spence, Ph.D. - 0000-0002-2029-3440

Francesca Favaro, Ph.D. - 0000-0003-0239-0770

9. Performing Organization Name and Address

Mineta Transportation Institute

College of Business

San José State University

San José, CA 95192-0219

12. Sponsoring Agency Name and Address

State of California SB1 2017/2018

Trustees of the California State University

Sponsored Programs Administration

401 Golden Shore, 5th Floor

Long Beach, CA 90802

15. Supplemental Notes

10.31979/mti.2020.1823

16. Abstract

This research identifies key state and local government stakeholders in California for drone policy creation and implementation, and describes their perceptions and understanding of drone policy. The investigation assessed stakeholders' positions, interests, and influence on issues, with the goal of providing potential policy input to achieve successful drone integration in urban environments and within the national airspace of the United States. The research examined regulatory priorities through the use of a two-tiered Stakeholder Analysis Process. The first tier consisted of a detailed survey sent out to over 450 local agencies and jurisdictions in California. The second tier consisted of an in-person focus group to discuss survey results as well as to gain deeper insights into local policymakers' current concerns. Results from the two tiers of analysis, as well as recommendations, are provided here.

\section{Key Words}

Unmanned aircraft systems; drones; local government agencies; policy analysis; stakeholders

\section{Distribution Statement}

No restrictions. This document is available to the public through The National Technical Information Service, Springfield, VA 22161
19. Security Classif. (of this report) Unclassified
20. Security Classif. (of this page) Unclassified
21. No. of Pages

85
22. Price 


\title{
Copyright $\odot 2020$ \\ by Mineta Transportation Institute \\ All rights reserved
}

\author{
Mineta Transportation Institute \\ College of Business \\ San José State University \\ San José, CA 95192-0219
}

Tel: (408) 924-7560

Fax: (408) 924-7565

Email: mineta-institute@sjsu.edu

transweb.sjsu.edu 


\section{ACKNOWLEDGMENTS}

The authors would like to thank MTI Executive Director Dr. Karen Philbrick, as well as Dr. Hilary Nixon, Director of Research and Technology Transfer, for extensive help and support during the proposal submission and study. The authors would like to thank Lauren Torrisi, Dylan Ershain, and Nazanin Nader for help throughout the data collection process. The authors would also like to thank Editing Press, for editorial services, as well as MTI staff, including Research Support Assistant Joseph Mercado and Executive Administrative Assistant Jill Carter.

The contents of this report reflect the views of the authors, who are responsible for the facts and accuracy of the information presented herein. This report does not necessarily reflect the official views or policies of the U.S. government, the State of California, or the Mineta Transportation Institute, who assume no liability for the contents or use thereof. This report does not constitute a standard specification, design standard, or regulation. 


\section{TABLE OF CONTENTS}

$\begin{array}{ll}\text { Executive Summary } & 1\end{array}$

$\begin{array}{ll}\text { I. Introduction } & 3\end{array}$

$\begin{array}{ll}\text { II. Literature Review } & 6\end{array}$

$\begin{array}{lr}\text { III. Methodology } & 12\end{array}$

IV. Discussion of Results 15

Tier One Data Analysis: Survey 15

Tier Two Data Analysis: Focus Group 30

$\begin{array}{ll}\text { V. Concluding Summary of Findings } & 49\end{array}$

Appendix A: Survey Questions

Appendix B: Focus Group Handout $\quad 56$

$\begin{array}{ll}\text { Abbreviations and Acronyms } & 63\end{array}$

$\begin{array}{lc}\text { Endnotes } & 64\end{array}$

$\begin{array}{ll}\text { Bibliography } & 75\end{array}$

$\begin{array}{ll}\text { About the Authors } & 83\end{array}$

$\begin{array}{lr}\text { Peer Review } & 85\end{array}$ 


\section{LIST OF FIGURES}

1. Projected Growth of the UAS Market Size to 2021

2. Example of a Structured Survey Question Implemented in Qualtrics 16

3. Breakdown of Respondents' Type of Jurisdiction 17

4. Breakdown of Respondents' Development Population Size 17

5. Breakdown of Respondents' Type of Development 18

6. Breakdown of Ratings for "Drone Regulation as a Topic of Interest" 18

7. Breakdown of Foreseen Time Horizon for Relevance of Drone Regulation Topic 19

8. Breakdown of Use and Availability by Application 20

9. Perceived Threats Ranked by the Level of Concern 21

10. Summary of Findings for Respondents' Jurisdictions with respect to Access, Policy-making, and the Need for Subject Matter Experts 22

11. Regulation Awareness Breakdown 23

12. Expectations for Regulatory Approach $\quad 24$

13. Breakdown of Regulatory Aspects and Restrictions by Likelihood of Consideration

14. Legislation Forecast for Different Types of Location Restrictions 26

15. Forecasted UAS Activity and Type of Use 27

16. Estimated Timeframes for the Adoption of Drone Delivery 28

17. Likelihood Estimate Distribution for 10-year Timeframe Applications in Urban Air Mobility $\quad 29$

18. View of the Focus Group Setting 31

19. Example Organization of a Sticky Notes Exercise 39

20. Overview of Finalized Board for Exercise 1

21. Identified Categories for Exercise 1 40 
22. Overview of Finalized Board for Exercise 2

23. Identified Categories for Exercise 2

24. Overview of Finalized Board for Exercise 3

25. Identified Categories for Exercise 3 


\section{LIST OF TABLES}

1. Crosstab for the Variables "Level of Interest" and "Foreseen Time Horizon" 19

2. Participants' Jurisdiction and Position Held 30

3. General Discussion Question Order 32

4. Debate Question Series $\quad 35$

5. Sticky Notes Exercise 1: Summary of Answers 41

6. Sticky Notes Exercise 2: Summary of Answers 44

7. Sticky Notes Exercise 3: Summary of Answers 47 


\section{EXECUTIVE SUMMARY}

Unmanned Aircraft Systems or Vehicles (UAS/UAVs), also commonly referred to as "drones," are increa singly used for a variety of applications. Civil and commercial UAS applications, especially at low altitudes, span a wide range of sectors. Present applications include inspection, surveying, monitoring, and emergency management, with package delivery and mobility applications due in the near future-important aspects for every local community. The State of California provides an opportunity to explore how a wide variety of communities are attempting to mitigate potential downsides of UAS in their communities. California is a key location for studying the evolution of UAS operations and the adaptive processes by local governments for incorporating UAS policies due to the wide variability in urban, suburban, rural and transition environments, as well as to the presence of Silicon Valley, a hub of technological development and programs focused on UAS activities.

The project made use of the Stakeholder Analysis Process (SAP), using a mixed-methods approach that combined quantitative responses, in order to gauge the generalizable intent of the policymakers (tier-one analysis), with qualitative responses from semi-structured or free-response interviews or focus groups for thematic analysis (tier-two analysis).

The first-tier data collection involved the creation of a survey to be distributed to local agencies in the State of California. The survey aimed at exploring particular areas of concern on the topic of drone usage and regulation, including:

- Usage, type, and accessibility of UAS for different departments

- Interest in local level regulation of UAS operations

- Timeline for major UAS deployment and need of regulation

- Privacy and environmental concerns and restrictions

- Need for technical expertise

- Federal regulations and best regulatory paths forward

The second-tier data collection was carried out at the individual level through an inperson focus group of experts who provided detailed responses through the use of a semi-structured interview framework. The structure and flow of the discussion during the focus group were flexible and largely based on the responses from the group, with the researchers prompting the attendees on key topics of interest that were identified during the first tier of analysis. Survey and focus group activities showed trends and conclusions that were in agreement with each other. The following list highlights some of the major takeaways that are analyzed in this report:

- While the majority of the participants recognized the importance of UAS technology and the associated concerns for integration, they showed only moderate/little interest in overall regulation of UAS. 
- The authors observed a defeatist attitude towards communication between federal and local agencies concerning regulations; there was a consensus on the feeling, "why keep track of federal regulations if, by the time we decide to act, those will be changed again?"

- Many answers provided by survey-takers and focus group participants pointed to the need for specialized training, at the local level, regarding which aspects of drone usage to regulate and how; participants were particularly concerned with how to enforce such a regulatory structure.

- Participants urged for more restrictive licensing, with the purpose of tracking users. Potential regulation of purchase permits was explored and brought forward by the focus group participants (especially the law enforcement representatives), whose vision of future drone regulation drew a parallel with gun control laws.

- While the approach to overall regulation was labeled as "reactive" (i.e., developing policy only in response to problems as they arise), there were specific suggestions where a proactive attitude was maintained. A primary concern noted about rogue operations was the need to ensure that usage of UAS could be restricted to appropriate locations only (e.g., non-congested areas). However, the concern of the participants was that if restrictions become so burdensome that operators cannot legally use their aircraft anywhere, alternative locations for operations have to be considered that still allow for user needs to be met. Specifically, participants in law enforcement suggested the need to ensure adequate spaces across the region where users could meet for flying UAS, as well as for exchanging tips and best practices for operations.

- With respect to use and preferred applications, law enforcement showed the highest rates of current use and drone availability, followed by fire emergency response and road inspection. There was consensus that all the investigated applications could represent good use of drone technology. 


\section{INTRODUCTION}

Unmanned Aircraft Systems (UAS) or Vehicles (UAVs), also commonly referred to as "drones," are increasingly being used for a variety of applications. Civil and commercial UAS applications, especially at low altitudes, span a wide range of sectors. Present applications include inspection, surveying, monitoring, and emergency management, with package delivery and mobility applications due in the near future-all important aspects for every local community. The National Aeronautics and Space Administration (NASA) estimates that the entire small UAS (sUAS) fleet in the U.S.- combining both hobbyist and commercial uses-will reach 3 to 6 million vehicles by 2021 (see Figure 1). ${ }^{1}$ As of 2018, there were a reported 110,000 UAS registered with the Federal Aviation Administration (FAA), a 2.5-fold increase since 2016, the first full year of the registration system. ${ }^{2}$ At its current growth rate, the UAS market is projected to grow from its current market value of $\$ 2$ billion to more than $\$ 17$ billion by $2024 .^{3}$

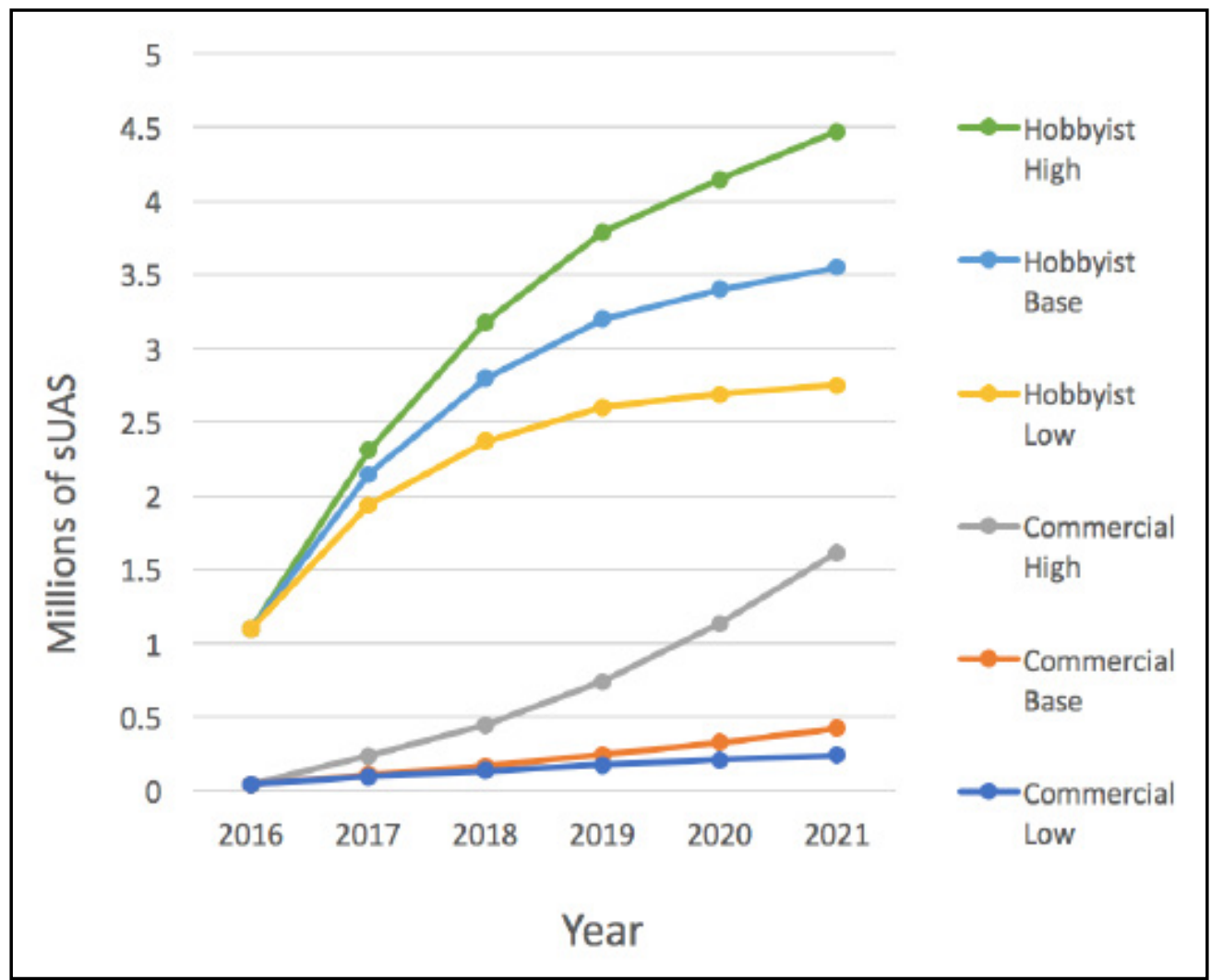

Figure 1. Projected Growth of the UAS Market Size to 2021

Source: Schaufele, Roger, Li Ding, Nick Miller, H. Anna Barlett, Michael Lukacs, and Disais Bhadra, "FAA Aerospace Forecast, Fiscal Years 2017-2037," 2017 (accessed October 11, 2019),

https://www.faa.gov/data_research/aviation/aerospace_forecasts/media/FY2017-37_FAA_Aerospace_Forecast.pdf

The future integration of this technology within cities requires careful planning and research into airspace integration strategies, public safety risk management, and operational frameworks. NASA has proposed a vision, the Unmanned Traffic Management Concept of Operations (UTM ConOps), which will allow such deployment within the regulatory, operational, and technical environments but requires involvement among the users and 
mangers of the National Airspace System, including federal agencies (e.g., the Federal Aviation Administration [FAA] and the U.S. Department of Transportation [DoT]) and local bureaucracies (e.g., state departments, county supervisors, local legislature). ${ }^{4}$

Currently, the United States is among the safest airspace systems in the world, averaging a 91.5 percent compliance rating to international standards-the global average is 61.4 percent-and maintaining a United States passenger airline fatality-free record since 2009. ${ }^{5}$ However, the nationwide growth of UAS operations from hobbyists and commercial industry sectors has sparked fear among aviation safety experts that unregulated growth could diminish that safety record by increasing the number of unmarked and unidentifiable objects in the vicinity of manned aircraft operations. ${ }^{6}$ These fears have led to concerns that mass use of these UASs, particularly small ones by recreational users and other operators unfamiliar with the National Airspace System (NAS), could lead to disasters that would impact unsuspecting passengers in commercial airlines and reduce the status of the FAA as a global leader in aviation safety and efficiency. ${ }^{7}$ There have already been instances of UAS being sighted in airport vicinities, and several have been suspected of hitting passenger aircraft. ${ }^{8}$ The estimates about the potential numbers of UAS in airport vicinities are largely speculative, because the data are collected through eyewitness reports and the FAA often cannot verify a report; further, there is a lack of valid and reliable forecasting models, and research has demonstrated the challenges in pilots' identification of UAS. ${ }^{9}$ Being able to identify the total number of UAS in the overall NAS as well as the total number of UAS operating in individual airport vicinities is important for understanding the necessary safety protocols and aircraft capacity limitations, and for enabling policies-ranging from airport operational aspects to standard traffic flows for mitigating congestion delays (e.g., departure procedures, standard arrivals, holding patterns, and preferred routings) - that are to be properly analyzed, maintained, and updated based on actual use data.

The nationwide growth of UAS operations, both from hobbyists and from commercial industry sectors, has increased risk, to the extent that a lack of clear regulatory frameworks for operational growth could diminish the safety record of aircraft operations in the United States NAS. ${ }^{10}$ UAS share the use of the NAS with manned aircraft, but while the latter category is characterized by highly trained operators and heavily regulated operations, many UAS users are unfamiliar with the traditional training and knowledge required by manned aircraft operators. UAS operators are not required to go through the traditional pilot training routes to gain access to the NAS, and the changed regulatory processes, through defined remote pilot certification and operational rules of Title 14 Part 107 and Part 101 of the Code of Federal Regulations for (i.e., part of the Federal Aviation Regulations) have increased entry access to the NAS compared to what previously required for specialized operational training. ${ }^{11}$

The need to address a lack of policy clarity for UAS operations has been examined by aviation experts and policymakers at all levels of government. ${ }^{12}$ The need for a better regulatory approach is particularly apparent in settings where the use of UAS compromises efficiency and safety, and local governments may be in a better position to experience and foresee the local benefits and threats of locally-operating UAS technology than the federal government alone. 
The primary objective of this research was thus to conduct a policy analysis on how local legislatures are approaching the topic of drone integration within their jurisdictions. Results of the research include a description of the perceptions of the identified stakeholders' understanding of drone policy including their positions, interests, and influence on issues. Furthermore, the research examines regulatory priorities and provides stakeholder and expert-informed data through systematic collection of information from debates between and among different local, state, and federal agencies towards successful UAS integration in urban environments and within the national airspace. Towards this goal, the research analyzes the priorities and concerns of various local agencies including mayoral offices, county supervisors, airports, roads districts, public utilities committees, state parks, and business groups. Among the broader impact objectives, this research also serves an educational role, providing local agencies with more direct access to aviation technical expertise, and it aims at furthering discussion on the future of urban air mobility for the transportation of both goods and people. 


\section{LITERATURE REVIEW}

Local agencies have a vested interest in regulating UAS operation and the authority to make reasonable restrictions regarding the time, manner, and place of operation. This authority may include the authority to pass land use, zoning, privacy and trespassing laws, and it also includes law enforcement. However, local enforcement cannot supersede or conflict with federal regulations or areas where the federal government has authority. ${ }^{13}$ Because of the designated regulatory supremacy by the federal government, local authorities are limited in the areas of laws and ordinances that can be enforced in order to determine consequences for operators who violate privacy or recklessly endanger persons or property with a drone.$^{14}$ Local legislation may specifically address UAS, but it more commonly focuses on the underlying rights to privacy and protection from reckless endangerment applicable to multiple subjects, without specifically referring to UAS. Local ordinances may also address environmental concerns such as noise and disruption to wildlife. For example, California restricts the use of UAS within state parks; ${ }^{15}$ although the regulation mentions that general use is allowed (unless in the presence of wildlife), the burden is on the user to recognize and understand all of the operational limitations at a desired location.

Federal regulations establishing a remote pilot license were issued in 2016, as Title 14, Chapter I, Part 107 of the Code of Federal Regulations (and commonly known as "Part 107"). ${ }^{16}$ Under Part 107, regulations limit UAS operations to within the operator's line of sight, to below 400 feet, to daytime only, and away from people not directly involved in the operation. However, it is possible to request a Certificate of Waiver or Authorization (COW and COA, respectively) from the FAA to waive these conditions. To date, more than 2,900 waivers have been granted, ${ }^{17}$ indicating the growth of operations. Moreover, the FAA currently lacks the capacity to enforce all Part 107 rules and ensure strict abidance, and it has asked local law enforcement to help ensure the safety of the public. ${ }^{18}$ Since the introduction of the initial rules for operating small UAS in the NAS, little has changed on the federal level, while local communities have witnessed a variety of problems of integration of UAS in the national airspace. As a result, many local and state departments and agencies have issued their own regulations to limit the use of drone technology. The Oceanside, CA police department has implemented a handheld device called a "drone killer" that can electronically disable a UAS on the spot. ${ }^{19}$ Recent examples of efforts by local law enforcement and emergency personnel to raise community awareness for UAS compliance include the California Department of Forestry and Fire Protection (Cal Fire) and the California Highway Patrol (CHP), who have used social media to try to prevent unauthorized UAS operators in wildfire areas and have taken measures to raise awareness of the hazards of operation for anyone other than an authorized responder. The CHP took the step of publicizing the arrest and citation of an individual flying a UAS near wildfire aircraft operations, who stated he did not know his actions were illegal. ${ }^{20}$

Unfortunately, uncertainty has hindered local governments' efforts to regulate UAS use. Local governments have often either found that rules they implemented to protect their communities are being overturned by federal courts, or they have been hesitant to act because of uncertainty about whether they can implement a particular policy at all. The first court case regarding the authority of local legislation over UAS was decided in 
September 2017 where the local UAS legislation to limit all UAS flights below 400 feet and implement a local registration system by the government of Newton, MA was found to have been preempted by FAA regulations..$^{21}$ In 2015, the FAA issued a fact sheet that provided guidance, from the FAA perspective, to state and local governments describing areas open to regulation and areas that would be preempted by federal supremacy. ${ }^{22}$ Only recently recognizing such interaction with the lower levels of government, the FAA created a new partnership program between state and local governments and industry to "foster a meaningful dialogue on the balance between local and national interests related to UAS integration, and provide actionable information to the USDOT on expanded and universal integration of UAS into the National Airspace System."23

Possible applications of UAS include environmental monitoring, emergency services, surveillance (e.g., laser optical microphones, high powered cameras, infrared cameras, and facial recognition software), aerial mapping, delivery of goods, and photography and filming ${ }^{24}$ However, when used by public agencies, UAS operations by local level governments faced backlash from the communities over issues of privacy, NIMBY (Notin-my-Backyard) concerns, noise, and operational restraints. ${ }^{25}$ Privacy has been routinely cited by community residents as a concern with the public use of UAS. ${ }^{26}$ Between 2012 and 2015, 500 UAS-related laws and regulations concerning privacy were introduced and adopted among several states (California was not among these states). ${ }^{27}$ Privacy violations often occurred because of continuous video-recording by the equipment onboard the UAS while in flight. ${ }^{28}$ Privacy incidents in California included a temporary ban on UAS manufactured by the company DJI by both the City and County of San Francisco over ongoing fears that the aircraft were transmitting sensitive U.S. infrastructure information to China. ${ }^{29}$ Similarly, tensions over a lack of privacy arose among residents of the Land Park neighborhood of Sacramento, CA, in response to secret UAS flights conducted at night around the neighborhood by the Sacramento Housing and Redevelopment Agency. ${ }^{30}$

In addition to privacy concerns, security and safety concerns have also arisen over the operation of UAS technology. Drug smugglers and human traffickers have used UAS to spy on official ports of entry at the U.S.-Mexico border near San Diego, undermining federal agents' efforts to halt these activities. ${ }^{31}$ In 2017 in Santa Clara County, CA, a UAS carrying methamphetamines crashed inside a jail perimeter, raising alarms about overflights in controlled areas. ${ }^{32}$

\section{Public Perception of UAS Technology}

The advent of UAS that are available to the public to purchase and fly for recreation or hire has initiated a growing and dynamic industry, despite the numerous regulations and somewhat negative public perception of this relatively new technology. Advantages of UAS technology are that the aircraft are capable of supporting big data due to their informationgathering ability and a variety of camera and sensor technologies that can be attached. ${ }^{33}$ In addition, UAS operations save time, are more cost-efficient, and are more effective for job completion than conventional methods of data collection or payload delivery. ${ }^{34,35}$ While commercial operators and firms involved with data collection and analytics are happy with the rapid evolution of UAS technology as well as with the ability to apply for COAs that waive some of the regulations, some non-UAS-using community residents are less 
optimistic about the technology, especially regarding its possession by certain government agencies. ${ }^{36}$ Federal, local, and state government use of UAS technology is not a new development; domestic federal agencies such as the border patrol, NASA, and various law enforcement agencies have been using UAS for their own applications for around 15 years. The concern, especially regarding local law enforcement agencies, is the use of UAS technology by these agencies for surveillance. ${ }^{37}$ The same advanced sensors, cameras, microphones, and software that commercial operators use on their UAS can be configured or specialized for agency-owned UAS for the purpose of real-time surveillance, in some instances without the requirement of a warrant. ${ }^{38}$

However, despite the potential for law and government agencies to use UAS technology to infringe on individual privacy, public opinion is quite polarized. ${ }^{39}$ In several surveys that ask about UAS use and regulation, it was generally found that respondents were supportive of the U.S. federal, state, and local governments' use of UAS but were cautious about the total extent to which UAS could be used without careful regulation. ${ }^{40}$ While a 2018 survey found that certain groups were more predisposed to have an affinity or dislike towards government UAS use depending on their level of education and level of trust in the government among other demographic variables, overall it appeared that there was favorable support for the use of UAS technology including the ability for governments to have access to and use UAS ${ }^{41}$ The ability to use UAS for the purpose of surveillance or other privacy infringement resulted in public concerns about law enforcement intent, even with sUAS. ${ }^{42}$ Public demonstrations have occurred in cities such as Los Angeles and Seattle in response to local governments' approval of law enforcement UAS programs. ${ }^{43}$ Law enforcement has used publicly navigable airspace to conduct evidence gather missions against marijuana growers and companies suspected of violating EPA regulations by surveying areas of the premises not protected from observation from a public vantage point. ${ }^{44}$ The ability for UAS to readily observe private property has raised concerns because data collected by these devices may be able to be used for multiple purposes without explicit limitations through regulation..$^{45}$ Additional action that may prevent the abuse of UAS technology by government agencies could be accomplished by an approval process or the incorporation of software limitations that delete sensitive information in real time, censor certain pixel arrangements like faces, or record which files have been accessed. ${ }^{46}$

Recreational users have raised concerns about UAS regulations ${ }^{47}$ The FAA has faced challenges to regulation that limit recreational UAS users due to organized resistance from model hobbyists and other recreational users through community groups such as the Academy for Model Aeronautics (AMA). ${ }^{48}$ In one successful action by recreational users, the burden was eased for recreational UAS users in 2017 when federal courts overturned the requirement for recreational users to register their UAS, declaring registration requirements beyond the scope of Congressional law and asserting that the law would need to be amended appropriately to allow such action by the FAA. ${ }^{49}$ Despite the efforts of these advocacy groups and the large number of registered recreational UAS users, public support for UAS varies by operation. ${ }^{50}$ UAS recreational users and hobbyists, business operators, and real estate operators all received less than 50 percent support from the public. Public support was not negative among all users, however; the general public tended to show favorable support for farming and conservation efforts, with approval from 75-80 percent of the public, while the greatest support from the public was the use of UAS 
for search and rescue and firefighting operations, with approval from over 90 percent of the public and opposition less than 5 percent. ${ }^{51}$ One of the recurring issues impacting public perceptions of UAS is the confusion and lack of knowledge the public has regarding legal UAS operations; some indicators such as gender (males appear to be more supportive), age (as age increases support for UAS decreases), and familiarity with UAS have been found to correlate with overall support and a reduction in concern for factors such as privacy invasion. ${ }^{52}$

\section{California State Legislation}

The legality of UAS use in the state of California is constantly changing and differs from jurisdiction to jurisdiction; this observation is also true of other states in the country. ${ }^{53}$ One constant, however, is that in addition to Part 107 enacted by the FAA, there are several statewide laws in the civil code that are exclusive to California. These provisions include Civil Code 43.101, which states that an emergency responder is not liable for damages caused to a UAS that was interfering with emergency response-which implies that, in the eyes of the state, action by government officials to down a UAS is a permissible in some circumstances. ${ }^{54} \mathrm{~A}$ statewide law was introduced in 2016 as an amendment to the California State Penal Code Title 10 Section 402, stipulating that UAS operations that interfere with emergency personnel could be charged as misdemeanors. ${ }^{55}$ Another relevant California state law is Civil Code 1708.8, which defines two instances in which liability for invasion of privacy can be assessed: trespass which can include aerial trespass above the land, and taking a picture or recording without consent, including any knowing dissemination of such pictures or recordings. ${ }^{56}$ This third law addresses the privacy concerns the public has about UAS; however, there are numerous circumstances that absolve distributers of liability under this code (e.g., a distributor is not in violation of the code if the picture or recording had already been previously publicly distributed), a leniency which may make some people uneasy. ${ }^{57}$ Finally, in 2018, Senate Bill 1186 was passed, requiring local law enforcement agencies to have a surveillance use policy, approved by their local government and made accessible to the public, before implementing a UAS program. ${ }^{58}$ This law has been implemented in order to assuage fears of overly discretionary surveillance by local law enforcement of private property (as in the aforementioned court cases in which officers used aircrafts to obtain evidence against marijuana growers); this could potentially make it much more difficult for law enforcement to abuse advanced UAS surveillance technology to gather evidence against people on private property that would only otherwise be obtained by a physical intrusion requiring a warrant. ${ }^{59}$

In addition to statewide laws, there are several local ordinances that restrict the use of drones. Los Alamitos and all national parks have placed an outright ban on UAS. ${ }^{60}$ Areas of San Diego, Santa Clara County Parks, Santa Cruz District Parks, San Francisco Parks, and Sacramento County Parks all have restrictions limiting in which parks UAS are allowed to be flown. ${ }^{61}$ These laws are mostly intended to prevent hobbyists from operating UAS in public areas that have non-operationally involved people nearby such as fishers, hikers, or event attendees at stadiums or other venues which potentially puts bystanders at risk of unsuspecting harm by the UAS. ${ }^{62}$ Hobbyists, however, argue that these laws prevent them from being able to enjoy their UAS, and they feel as if the government is infringing upon their rights. ${ }^{63}$ 
The State of California proposed to establish UAS legislation in 2015 for privacy and 2016 for interference with first responders during an emergency. ${ }^{64} \mathrm{At}$ the local and state level of government, more oversight of local agencies such as law enforcement will be enacted into policy to prevent abuses of UAS technology and to establish what the use of these UAS will be once acquired by a particular agency. ${ }^{65}$

The variations in regulations have impacted jurisdictions differently for UAS operations within local communities. The City of San Diego, for instance, is adapting federal UAS regulations into its municipal code in order to strike a balance between the safety of the general public and the increased usage of sUAS. ${ }^{66}$ The city also gave local authorities the power to ticket people violating the FAA's UAS guidelines ${ }^{67}$

In addition to regulating recreational and commercial UAS in communities, local government agencies have also shown an increasing interest in using UAS technology for operational activities. The Los Angeles Fire Department has acquired UAS to aid in building entry and finding lost persons. ${ }^{68}$ They have received special authorization through a COA for conducting UAS operations but must still seek permission from the FAA for any operation not specified by the agreement whenever they need to fly UAS. ${ }^{69}$ In the City and County of San Francisco, five departments have sought independent permission to fly UAS from the FAA: namely, the Fire Department, the Port of San Francisco, the Recreation and Park Department, the Public Utilities Commission, and the Office of the Controller. ${ }^{70}$

State firefighters have attempted to use UAS owned by the National Guard to fight wildfires since 2013; however, acquiring these assets requires complex approval mechanisms and has resulted in a delayed deployment process. ${ }^{71}$ In the County of El Dorado in California, UAS have been used by law enforcement to record high-definition, detailed video tours of crime scenes, which were played for juries in several higher-profile cases; similar videos were previously recorded from staffed helicopter operations, and UAS ultimately offset the cost in a single use..$^{72}$ In 2018, the Sacramento Housing and Redevelopment Agency operated a UAS at night during a 90-day operation over two specific housing communities in the hopes of preventing crime; while it did catch illegal dumping and trespassing, nearby residential neighborhoods noticed the operations, questioning the program's legality and expressing their displeasure to their city council. ${ }^{73}$ In a different California county, Pacer County Mosquito Control used UAS for the identification, detection, and elimination of mosquito populations. The Mosquito Control agency found UAS operations to be more efficient in applying pesticides and detecting mosquito larvae to reduce the environmental footprint, to increase the safety of employees, and to cost less in equipment and labor. ${ }^{74}$

\section{Future Legislation}

The FAA and NASA are currently developing the UAS Traffic Management (UTM) system in the NAS with the goal of continued safety to prevent traffic conflicts between conventionally manned aircraft and UAS. ${ }^{75}$ In the next ten years, an Unmanned Traffic Management (UTM) system could reach the point where integration of UAS into the NAS is successful for some low-altitude operations; in 2014, NASA stated a goal of 15 years (by 2029) for achieving a UTM system that could safely incorporate high-density operations ${ }^{76}$ In addition to UTM work by NASA, but in conjunction with a focus on the integration of 
autonomous aircraft, Airbus has proposed a related framework they termed Air Traffic Management (ATM) ${ }^{77}$ Airbus addressed a perceived gap in the UTM framework with private electronic automation companies having a place in determining flight path approvals for the integration of UAS into the airspace. This vision would ultimately eliminate the need for staffed air traffic control centers; human controllers could be moved to management positions of automated control systems. ${ }^{78}$ Identified operating principles required for a successful airspace structure include priorities on safety and security of autonomous aircraft, access to airspace below 500 feet above the ground, flexibility for new technology for manned and unmanned aircraft, and international coordination and standardization that include UAS standards and recommended practices. ${ }^{79}$

In May 2019, the FAA implemented the rules passed by the U.S. Congress in the FAA Reauthorization Act of 2018 and superseded the previous recreational rules that had been in effect (i.e., rules under Part 101 of the FARs and established through Section 336 of the FAA Modernization and Reform Act of 2012). ${ }^{80}$ Changes included a requirement for users to register their UAS as well as to pass an online test similar to that taken by commercially certified UAS operators. ${ }^{81}$ A further part of this legislation is the FAA's application-based Low Altitude Authorization and Notification Capability (LAANC) system that allows for an automated approval of UAS operations into controlled airspace, which could only previously be done through COAs; this should help reduce the number of operators seeking special approval to fly in a certain airspace and allow operators to fly their UAS legally with relative ease and quicker access than through the human-verified COA process. ${ }^{82}$ The LAANC system is a system developed by NASA and the FAA as an initial step toward a realized UTM system and integration of UAS into the NAS; unmanned aircraft share their location using GPS coordinates for the purpose of collision avoidance and efficient traffic flow. ${ }^{83}$ As the UTM system is developed and commercial operations begin to proliferate, hobbyists and recreational users may face more burdens to access entry to the airspace, as the FAA is considering adding a requirement of GPS receiver and transmitter installation on their UAS as well as mandatory flight proficiency checks in addition to the online tests currently required. ${ }^{84}$ Ultimately, the regulatory landscape is rapidly evolving and there are many assumptions about the future vision of UAS' integration into society (e.g., applications for urban air mobility for personal transportation within city centers), but the structures and frameworks established now will set progress in motion for how that vision will look in the future. 


\section{METHODOLOGY}

This project employed a two-tiered data collection process that allowed it to effectively synthesize both quantitative and qualitative data from experts and policymakers. As described in the Introduction, the primary goal of the present project was to conduct a policy analysis on the future of drone integration and regulation in the State of California. To achieve such a goal, we employed a Stakeholder Analysis Process (SAP).

SAP is an academic tool that has been commonly used for policy analyses where an understanding of the beliefs of the policymakers and influencers on a particular topic is essential. This method has been used for attempting to evaluate potential policy evolutions in a number of fields including health, technology, environment, and management. ${ }^{85}$ SAP can be used to investigate, within an interactive framework, the views that various actors hold towards policy-making and decision-making, and to explore perspectives, vision, intentions, and interrelations between such actors. ${ }^{86}$ To do so, SAP often employs a mixed-methods approach that combines quantitative responses, in this study from Likert-scale survey questions in order to gauge generalizable intent of the policymakers across the State of California with qualitative responses from semi-structured or freeresponse interviews or focus groups, in this study for thematic analysis of specific local government representatives with UAS experiences. This is the structure adopted for the present research, with a first-tier data collection process involving a structured 16-question survey, and a second-tier data collection process involving a focus group with selected stakeholders from the State of California.

The first-tier data collection process involved the creation of a survey to be distributed to local agencies in the State of California. Given the complex and partially undefined regulatory landscape surrounding the deployment of drones within the national airspace, it was important for the authors to clarify the role that each agency played or was planning to play. This meant understanding the starting point of all the players involved, including their expectations of outcomes, perceived fears/threats and concerns, current viewpoints, and assessment of the extent to which there is already a current regulatory approach. A 16-question Likert-type questionnaire was thus created and distributed to the local-level and county-level government agency employees who were currently involved with drone usage and integration within their legislation and/or responsible for policy implementation. The survey took approximately ten minutes to complete and was implemented in Qualtrics software. Key topic areas included respondents' beliefs about the need for interaction between local, state, and federal levels of government, and the level of regulation that would likely emerge. Respondents' views about the needs for regulations, the threats to society, and likelihood for local regulatory involvement beyond federal mandates were also investigated. The details surrounding the survey structure are presented later, together with the presentation of the results. Contact information for public officials could largely be obtained through public records. This was an important factor that led the researchers to select the survey format as the first-tier process to investigate the local government stance on the use and integration of drone technology. A list of email addresses organized by county and city jurisdiction was created to efficiently disseminate links to the survey to interested mayoral offices, county supervisors, airports and roads districts, public utilities committees, state parks, and business groups. The survey remained open for four 
months, and responses were solicited three times from the overall distribution list that was created for the project. Analysis of the responses was then largely based on variation of mean responses. A few demographic characteristics about the community of the local government employee respondents were requested to enable an estimation of variation based on the type of community the official represented, such as urban, suburban, or rural environments (details presented in the analysis of results section). A similar study that collected responses from local officials in Indiana ${ }^{87}$ showed the importance of tackling multiple types of jurisdictions, with different development settings and population characteristics. This was also the case in the present project, with the varied demographics characteristic reported later in the analysis results section.

The second-tier data collection process employed an in-person focus group with selected officials from the State of California. This phase concentrated on more individual-level data from experts who provide detailed responses to questions posed in a semi-structured discussion environment. The "focus group" process has been identified and used as a suitable tool for data collection for policy research, ${ }^{88}$ and it expands upon the basis of SAP as identified by Brugha and Varvasovskzky ${ }^{89}$ and Varvasovskzky and McKee. ${ }^{90}$ As an example, Varavasovszky and McKee studied alcohol policy in Hungary ${ }^{91}$ seeking to identify policy actors on the alcohol issue, understand their positions, and ultimately provide policy input through a systematic analysis of semi-structured interviews with identified policymakers. We opted to adopt a similar structure, and shared the similar goal of identifying the key local government subject experts involved with policy-making that targeted novel topics - in our case drone deployment. We thus solicited participation from local policymakers and business leaders who were identified as stakeholders in the drone industry during the first tier of data collection. The focus group activities were led by the researchers of this project based on a semi-structured template, with the responses and flow of the discussion being flexible and largely based on the responses from the group. Details on the structure of the focus group are provided later in the analysis section. At a general level, the results obtained from the survey data analysis were used to identify key topics that needed to be explored further. This is a common practice in the SAP, making the process semi-iterative around issues that can be explored in both tiers of data analysis. This feature also leads to the ability to gather more specific insights on the most frequently identified issues.

Finally, it is important to mention that the above-described process worked well, given the particular location of the research team in California. San José State University (SJSU) is located in the heart of Silicon Valley and in one of the largest cities in the U.S. It is a prime location to obtain feedback from a variety of stakeholders and policymakers for insights on the future of drone policy at local levels. SJSU is surrounded by many different airports, has some of the most congested airspace in the country, and contains many of the companies leading the revolution in drone technology. Moreover, there are varying political landscapes and diverse areas that have varying needs for drone activity, ranging from urban air mobility applications to agricultural use, thus making California an ideal location for this research. 
The overall project was completed in one year of work. A key step was having a complete analysis of the survey data before setting up the activities and structure for the focus group. Intermediate preliminary results (while the survey was still open and before the last solicitation for responses) were also presented at the 2019 California Transportation Planning Conference; feedback from the audience helped to shape focus areas for the in-person workshop. 


\section{DISCUSSION OF RESULTS}

The presentation of the results is divided between the two tiers explained in the methodology section. A summary of the overall findings is provided in Section 5.

\section{TIER ONE DATA ANALYSIS: SURVEY}

\section{Structure and Overview}

The 16-question survey was implemented in Qualtrics and was sent to a mailing list including 58 counties and 416 cities in California, for a total of 1,658 email addresses collected on publicly available websites for officials operating in offices with drone-related activities. A total of 214 responses were collected, with 22 individuals reporting additional contact information for consideration for the second tier of data collection. The survey targeted the following categories of local level offices/agencies:

- Mayoral offices

- County supervisors

- Airports and roads districts

- Public utilities committees

- State parks

The questions, which are included in Appendix A, presented a combination of Likert-scale ranked options in the areas of:

1. Usage and accessibility to UAS for different department (law enforcement, fire, inspection)

2. Interest in self-regulation of UAS operations

3. Timeline for major UAS deployment and need of regulation

4. Privacy concerns

5. Environmental concerns

6. Need for more technical expertise

7. Knowledge of federal regulations

8. Restriction of usage

9. Estimated volume of business 
10. Commercial versus private usage

11. Best regulatory paths

In those questions that required a specific rating, Likert scales with 5 categories were chosen, yielding a simple and yet detailed system for assessing the respondents' stances on specific matters. All questions were multiple-choice; see Figure 2 for an example. The only open-ended question was the last one, wherein additional comments from the respondent were solicited. The survey took an average time of 10 minutes to complete.

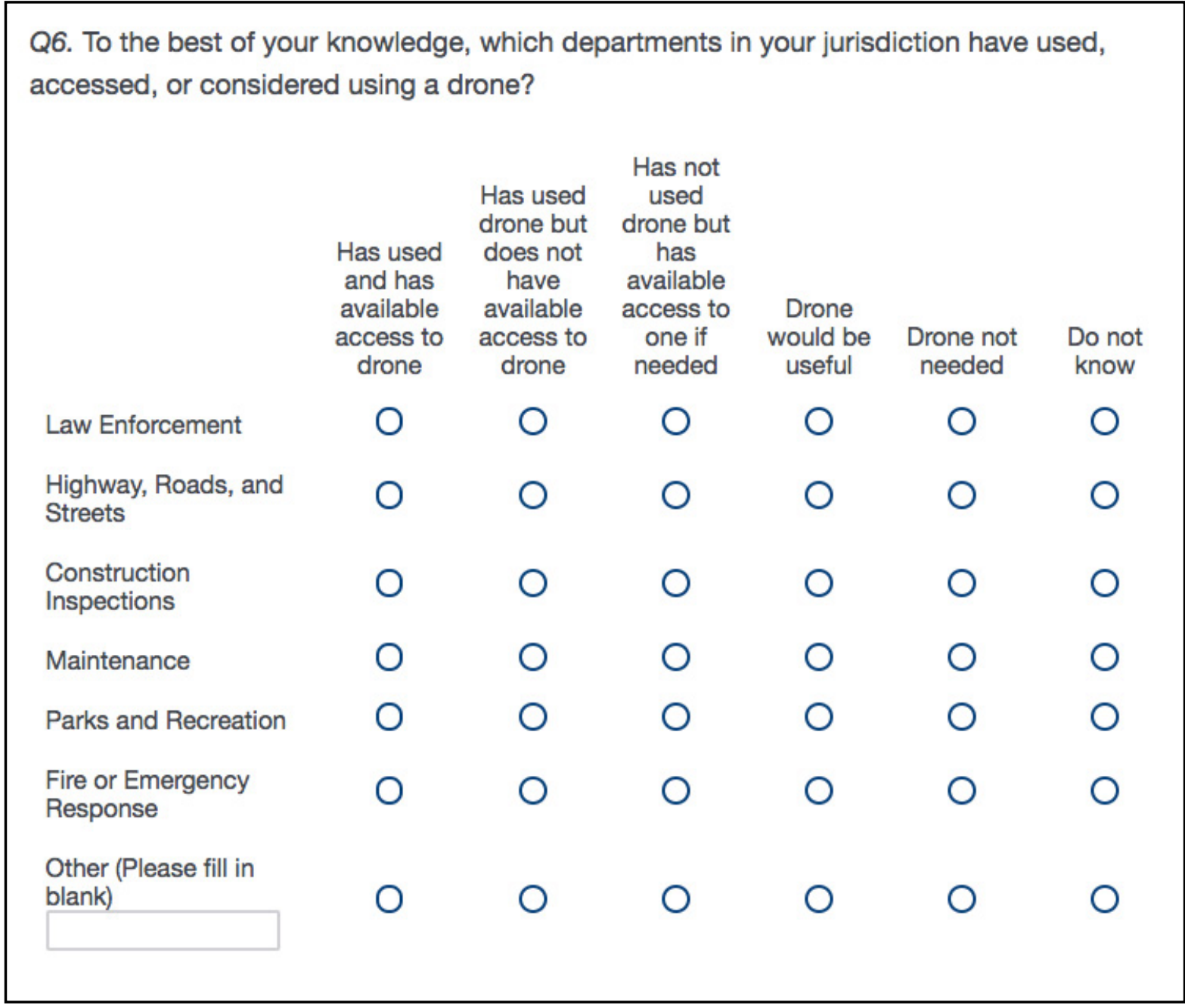

Figure 2. Example of a Structured Survey Question Implemented in Qualtrics

\section{Respondents' Demographics}

Figures 3,4 , and 5 report on the demographics of the respondents. The majority of respondents $(67.3 \%)$ came from a city. With respect to the population size, a majority $(83.2 \%)$ of respondents' jurisdictions had population below 250,000. The smaller developments between 10,000 to 49,999 inhabitants had mostly a mixed rural/suburban type of development, while urban developments corresponded to populations higher than 100,000 . 


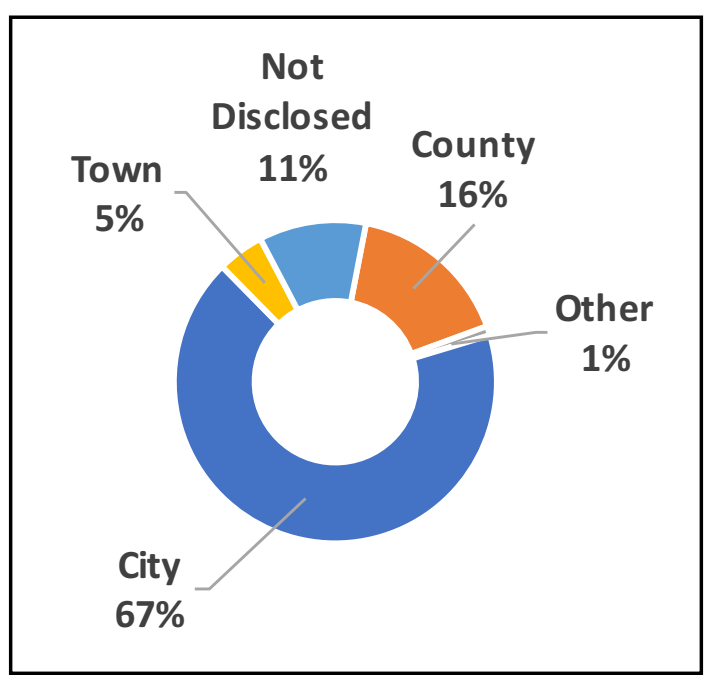

Figure 3. Breakdown of Respondents' Type of Jurisdiction

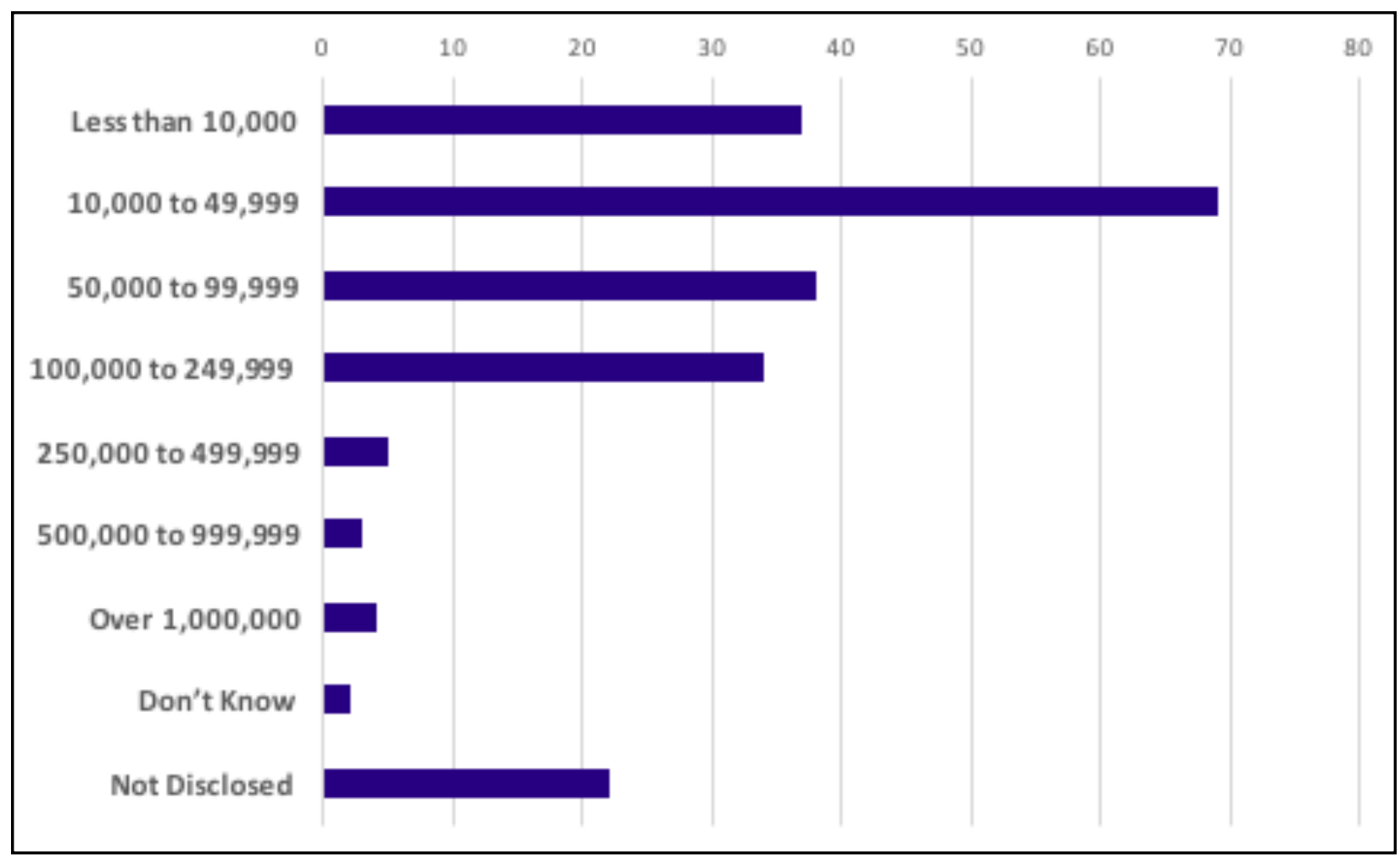

Figure 4. Breakdown of Respondents' Development Population Size 


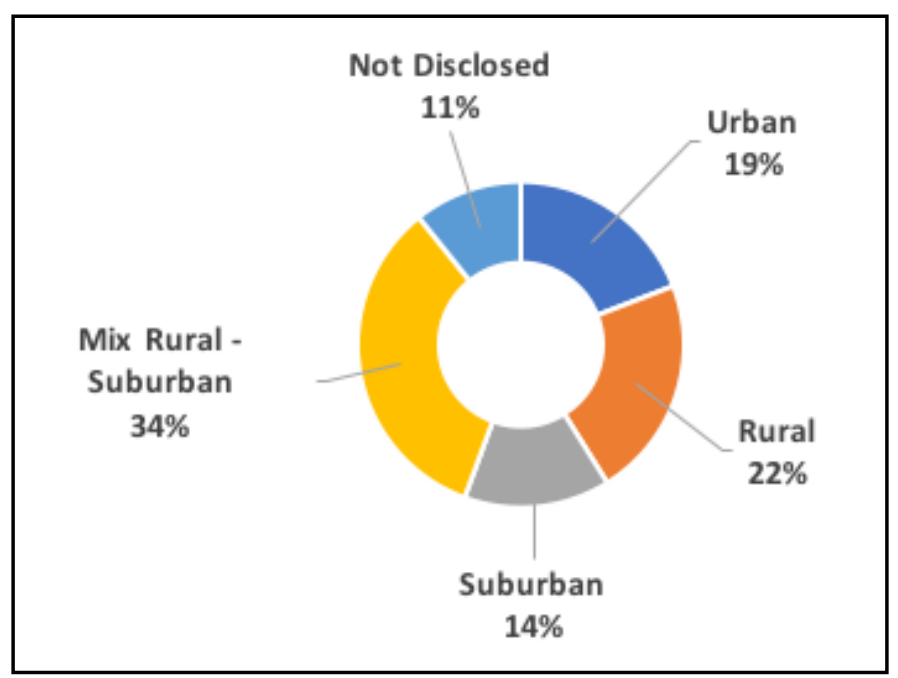

Figure 5. Breakdown of Respondents' Type of Development

\section{Overview of Survey Results}

Question: Is the use and regulation of drones a topic of interest in your office?

The first question in the survey gauged the overall interest of the specific office of the respondent in the topic of drone regulation. This question was accompanied by the request to assess a time-horizon for how soon drone regulation would become a topic of interest within their jurisdiction. Figure 6 shows the breakdown of replies for interest. The majority (58\%) showed only moderate to no interest in the overall regulation of UAS technology.

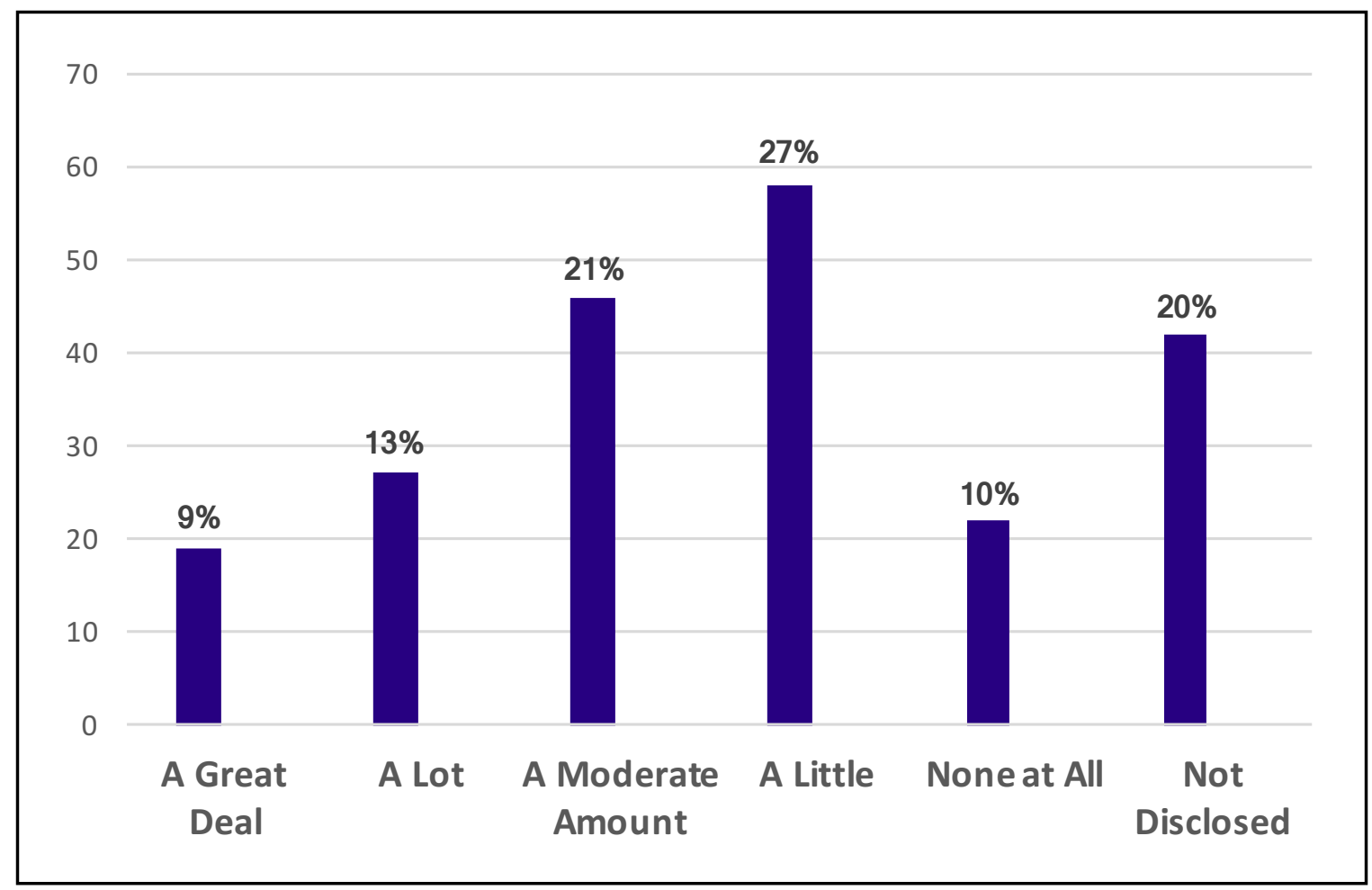

Figure 6. Breakdown of Ratings for "Drone Regulation as a Topic of Interest" 
Question: In how many years do you think the use of drones and regulation of this activity will become a relevant topic with resources allocated in your office?

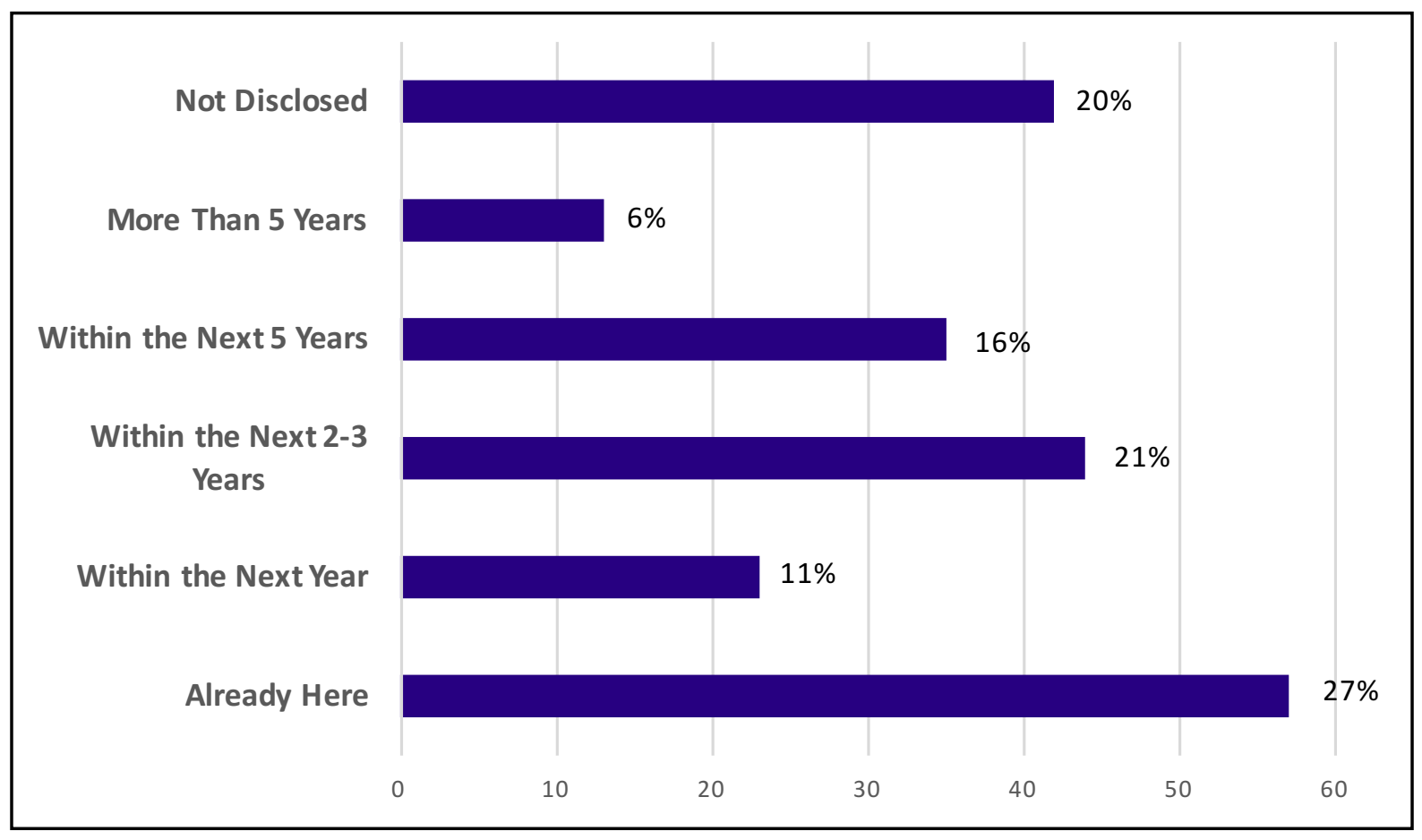

Figure 7. Breakdown of Foreseen Time Horizon for Relevance of Drone Regulation Topic

A plurality of the participants (38\%) recognized that the technology and associated concerns are already here or are about to surface in the next year. This is an interesting point when compared to the mild interested shown from Figure 6. In particular, respondents who rated the technology as "already here" or "within one year" comprise $43 \%$ of the ones with moderate or higher interest in UAS use and technology. Moreover, respondents in the category of "no [interest] at all" in drone regulations still believed it to be relevant within the next 5 years. Table 1 provides the crosstab between the two questions. There is statistical significance between the two variables "level of interest" and "foreseen time horizon" (p-value $<0.01$ ).

Table 1. Crosstab for the Variables "Level of Interest" and "Foreseen Time Horizon"

\begin{tabular}{lrrrrrr}
\hline $\begin{array}{l}\text { Level of Interest/Foreseen } \\
\text { Time-Horizon }\end{array}$ & $\begin{array}{c}\text { None } \\
\text { at all }\end{array}$ & A little & $\begin{array}{c}\text { A moderate } \\
\text { amount }\end{array}$ & A lot & A great deal & Total \\
\hline Already here & $0.0 \%$ & $19.0 \%$ & $41.3 \%$ & $0.3 \%$ & $57.9 \%$ & $26.6 \%$ \\
Within the next year & $13.6 \%$ & $6.9 \%$ & $13.0 \%$ & $22.2 \%$ & $21.1 \%$ & $10.7 \%$ \\
Within the next 2-3 years & $22.7 \%$ & $27.6 \%$ & $30.4 \%$ & $18.5 \%$ & $21.1 \%$ & $20.6 \%$ \\
Within the next 5 years & $45.5 \%$ & $34.5 \%$ & $10.9 \%$ & $0.0 \%$ & $0.0 \%$ & $16.4 \%$ \\
More than 5 years & $18.2 \%$ & $12.1 \%$ & $4.3 \%$ & $0.0 \%$ & $0.0 \%$ & $6.1 \%$ \\
\hline
\end{tabular}

*Note: the "not disclosed" data are not reported. 
Question: To the best of your knowledge, which departments in your jurisdiction have used, accessed, or considered using a drone?

The survey continued by exploring current usage of drones by different departments within the jurisdiction of interest. Figure 8 provides a breakdown of the most common applications, together with respondents' reported availability of access to drones and expectations regarding their usefulness. Law enforcement showed the highest current use, followed by fire emergency response and road inspection. There was consensus that all the listed applications could make good use of the technology, as assessed by the category "drone would be useful" shown in Figure 8.

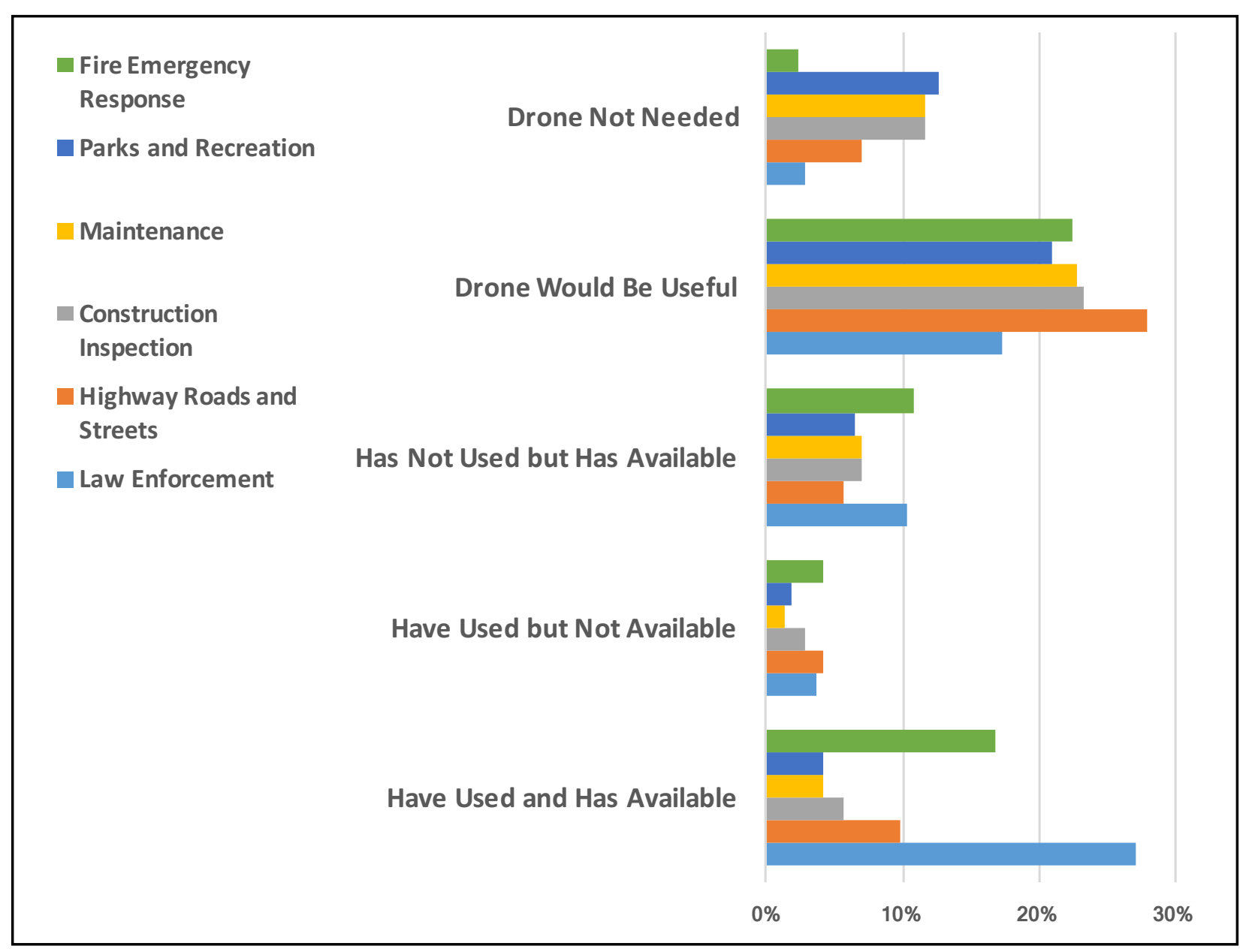

Figure 8. Breakdown of Use and Availability by Application 
Question: How do you rank the level of concern for each item listed below regarding drone use in your jurisdiction by either recreational or commercial operators?

Furthermore, the survey investigated the main areas of concern from local agencies with regard to drone usage. The queried concerns all had a possible impact in hampering public acceptance as well as efficient integration of this technology in the local communities, as highlighted in our literature review. Figure 9 shows the results for perceived threats ranked by level of concern. Privacy was the primary concern of respondents overall, followed by safety concerns, with noise and visual pollution being the least worrisome. (This particular result led to important discussions during the focus group portion of the project, with security concerns also being explored in more detail. $\left.{ }^{1}\right)$ The ranking represented in Figure 9 was obtained through a weighted average process, whereby the frequency of replies in each category was weighted by a ranked level of concern (from 0 for no concern, to 4 for a lot of concern). The higher the overall score, the higher the level of concern.

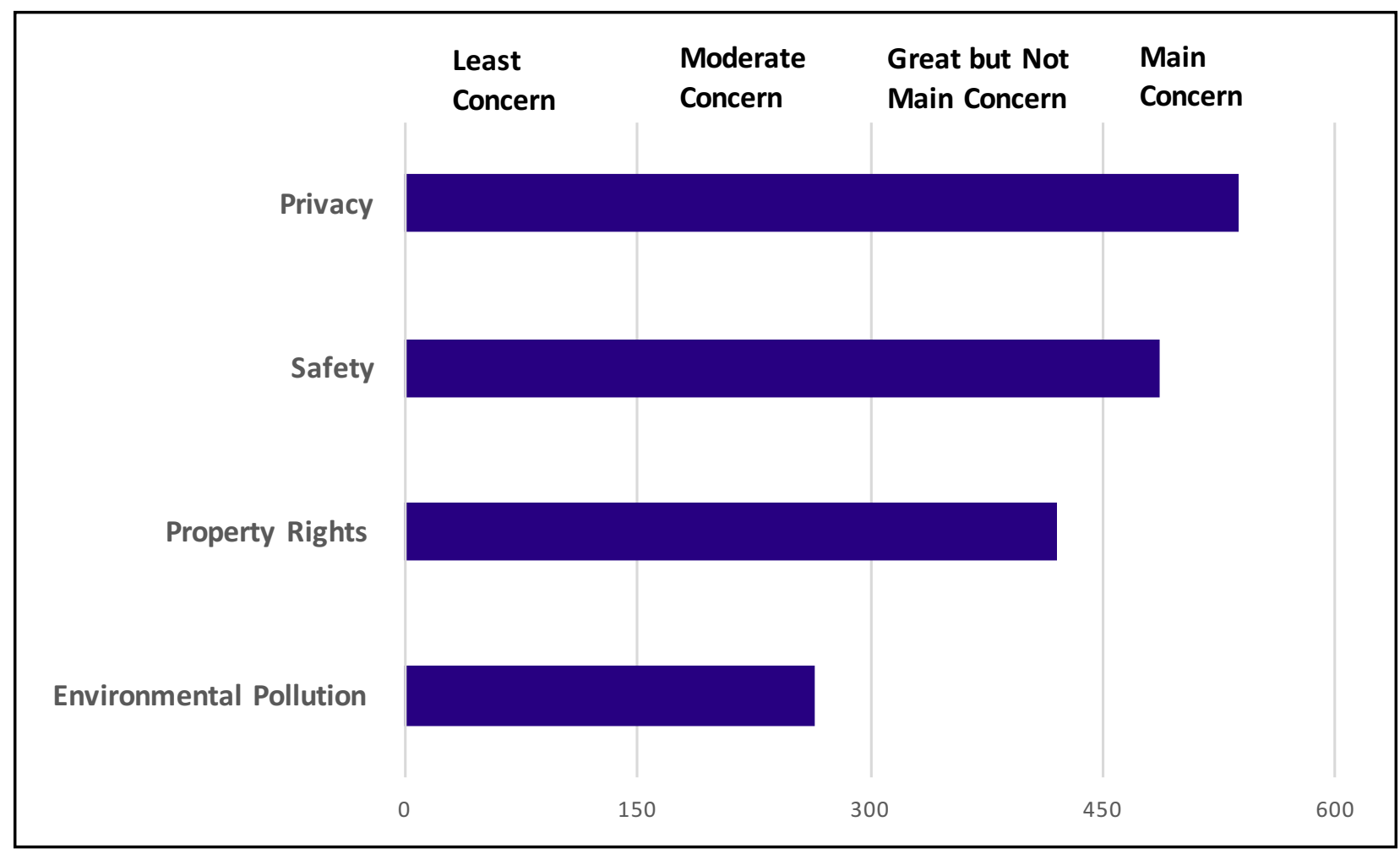

Figure 9. Perceived Threats Ranked by the Level of Concern

\footnotetext{
1 The focus group was actually held three days after the Gilroy shooting of July 28,2019 , so that security concerns were raised by many participants, and discussions on how to better leverage drone technology were brought forward.
} 
Question: For each item listed below, choose the appropriate category as it relates to UAS policy planning and operations for your office (access, policymaking, hiring experts).

Figure 10 provides an overview of three more areas of assessment for the current status of UAS use and regulation within local jurisdictions in California. Survey takers were asked to assess their involvement with actual policy-making, access to UAS, and likelihood of hiring specific subject matter experts. For this third question, many respondents asserted they did not foresee the need to hire aviation technical staff $(58 \%)$ or consultants $(36 \%)$ in the future, with $43 \%$ of respondents further indicating that they planned on dealing with drone regulations at a later time in the future.

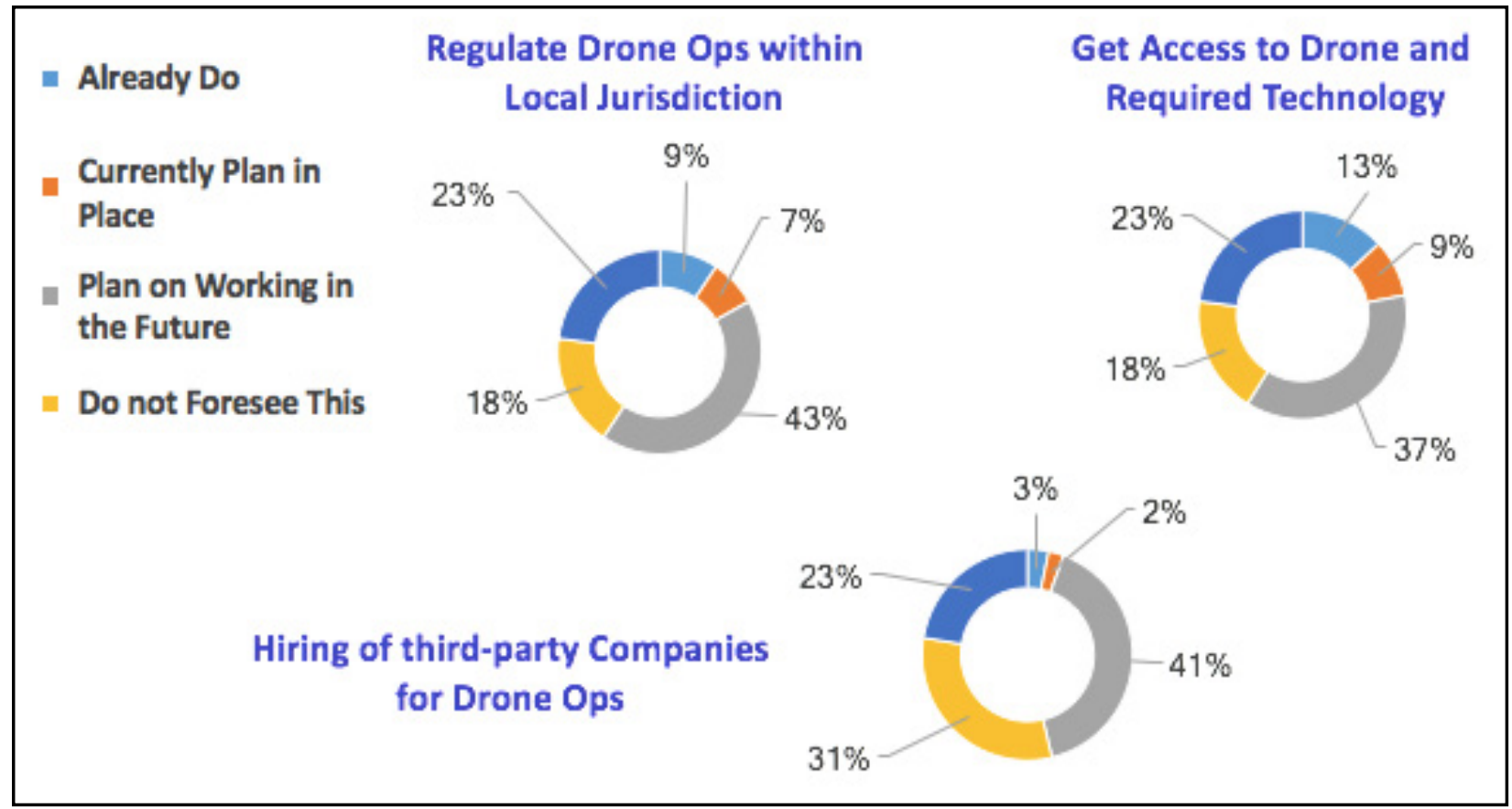

Figure 10. Summary of Findings for Respondents' Jurisdictions with respect to Access, Policy-making, and the Need for Subject Matter Experts

Local agencies seemed more inclined to hire third-party companies and start-ups than to seek the help of aviation consultants and subject matter experts from academia. (This was an interesting factor to discuss during the focus group, in particular in relation to the respondents' knowledge of the current regulatory landscape.) 
Question: Are you aware of the current federal aviation regulations (FAR) regarding the use of drones?

Figure 11 shows the breakdown for level of awareness of current federal regulations. Only $19 \%$ of respondents indicated full awareness of the federal regulations currently in place. Moreover, $42 \%$ of respondents indicated some level of awareness but expressed a need for help in interpretation, or additional study of the details.

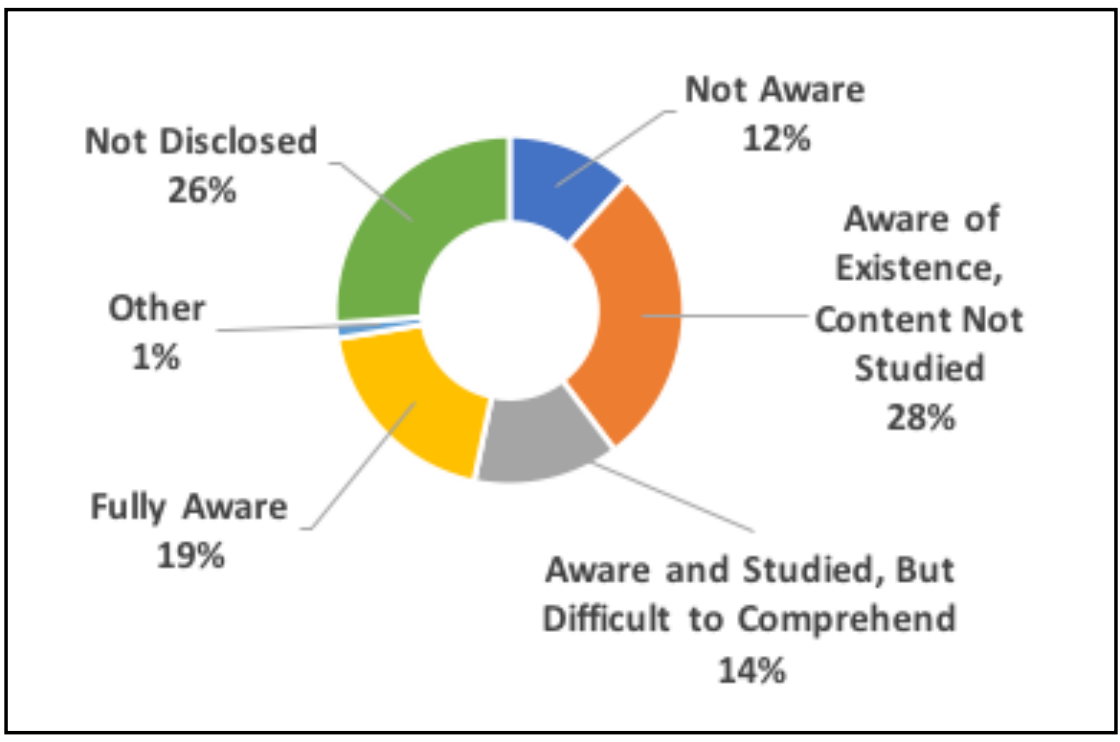

Figure 11. Regulation Awareness Breakdown 
Question: What is the expected framework for local legislation of drone use in the future?

The question concerning the level of awareness on current regulations was followed by an assessment of the preferred regulatory approach. Answers were variable (Figure 12), with a high number of respondents either not providing an answer to the particular question or selecting the "I don't know" option. Of those who replied, a plurality (33\%) believed that local legislation would most likely be implemented in response to problems, with only $20 \%$ expecting legislation to be implemented proactively.

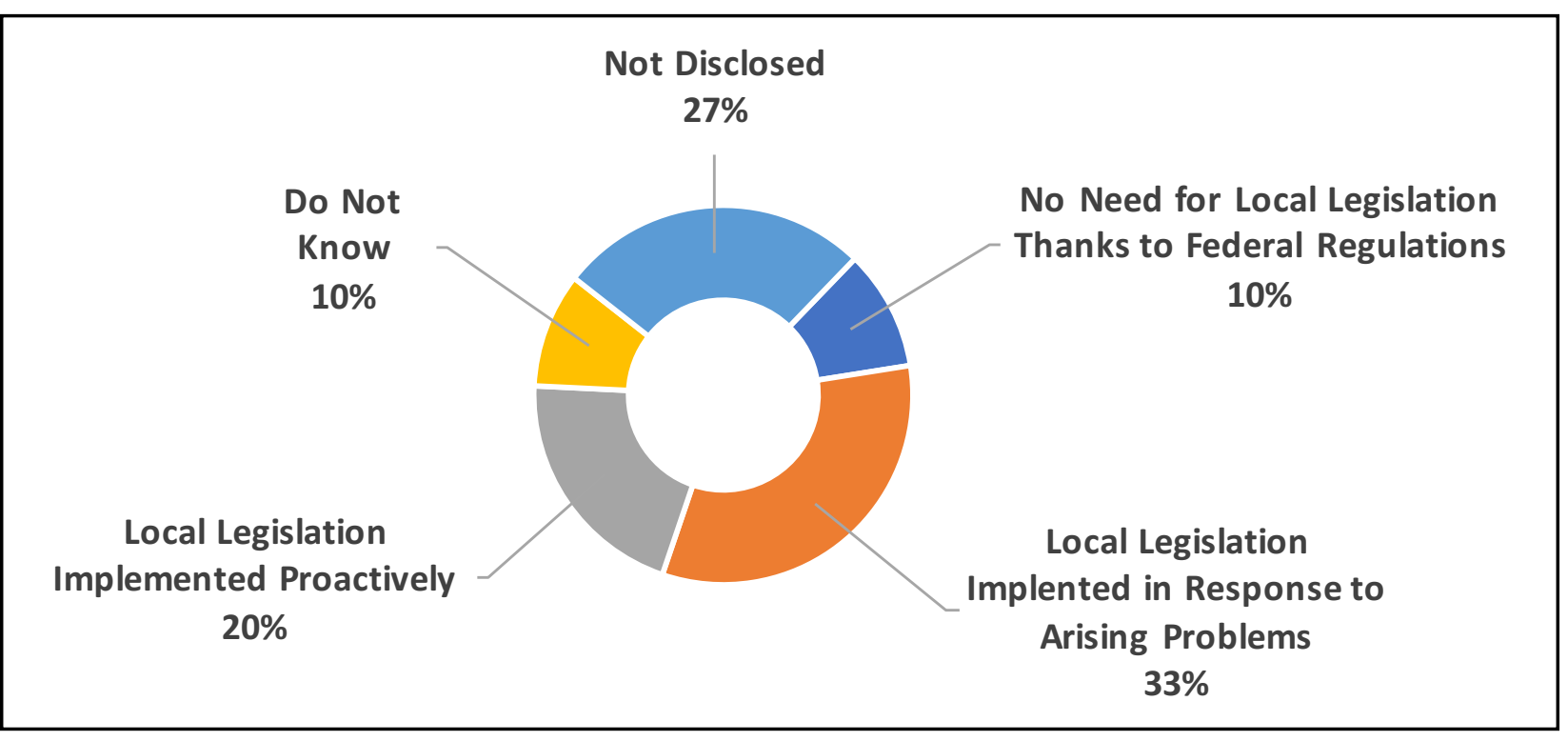

Figure 12. Expectations for Regulatory Approach 
Question: Select the answer that best describes how you see your office involved in potential regulation of drones for each issue below

With respect to current regulatory aspects, location restrictions (i.e., where UAS cannot fly) were observed to be the only area in which local legislation is already involved. A plurality of survey takers does not anticipate a need to track users $(42 \%)$ or UAVs $(36 \%)$ (Figure 13). Also seen in Figure 13 is there were $=$ observable similarities in the frequencies of responses for the "not foreseen" and the "no current plan but likely in the future" categories. Note that each survey taker could only select one option, so that there are the same number of responses for local agencies that do not foresee getting involved in any regulatory aspect and for those that think that all areas are important to tackle, although later on in the future. The fact that some participants recognized the likelihood of tackling all regulatory aspects in the future but not at the present time could point to limited resources and/or similar reasons behind the reluctance to start regulatory planning for drone applications at the local level. This is a factor that was discussed and investigated during the focus group activities.

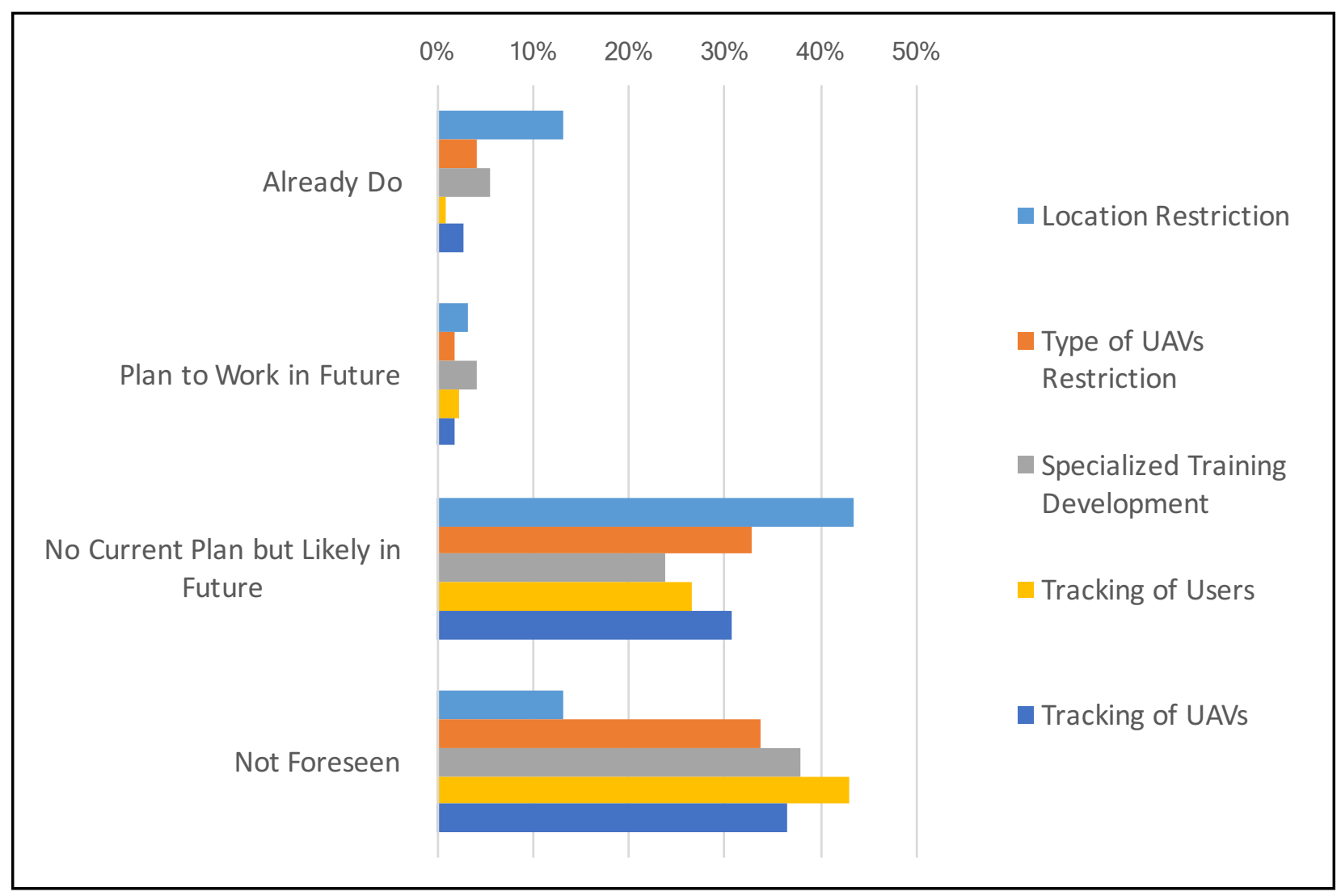

Figure 13. Breakdown of Regulatory Aspects and Restrictions by Likelihood of Consideration 
Question: Consider the following locations below and describe any expectations regarding local legislation or regulation to restrict drone use in your jurisdiction

Locations restrictions are currently predominant in local legislation, with California restricting the usage of drones within state parks. ${ }^{13}$ The survey analyzed what type of property was most likely to be subject to local restrictions. A plurality of respondents $(44 \%)$ agree that local legislation may be necessary for all restriction types mentioned, especially for public property (either open space or other; see categories in Figure 14). Sixteen percent of participants thought there should be no regulation on private property in the first place, with most of the existing legislation related to public property, both open space and other.

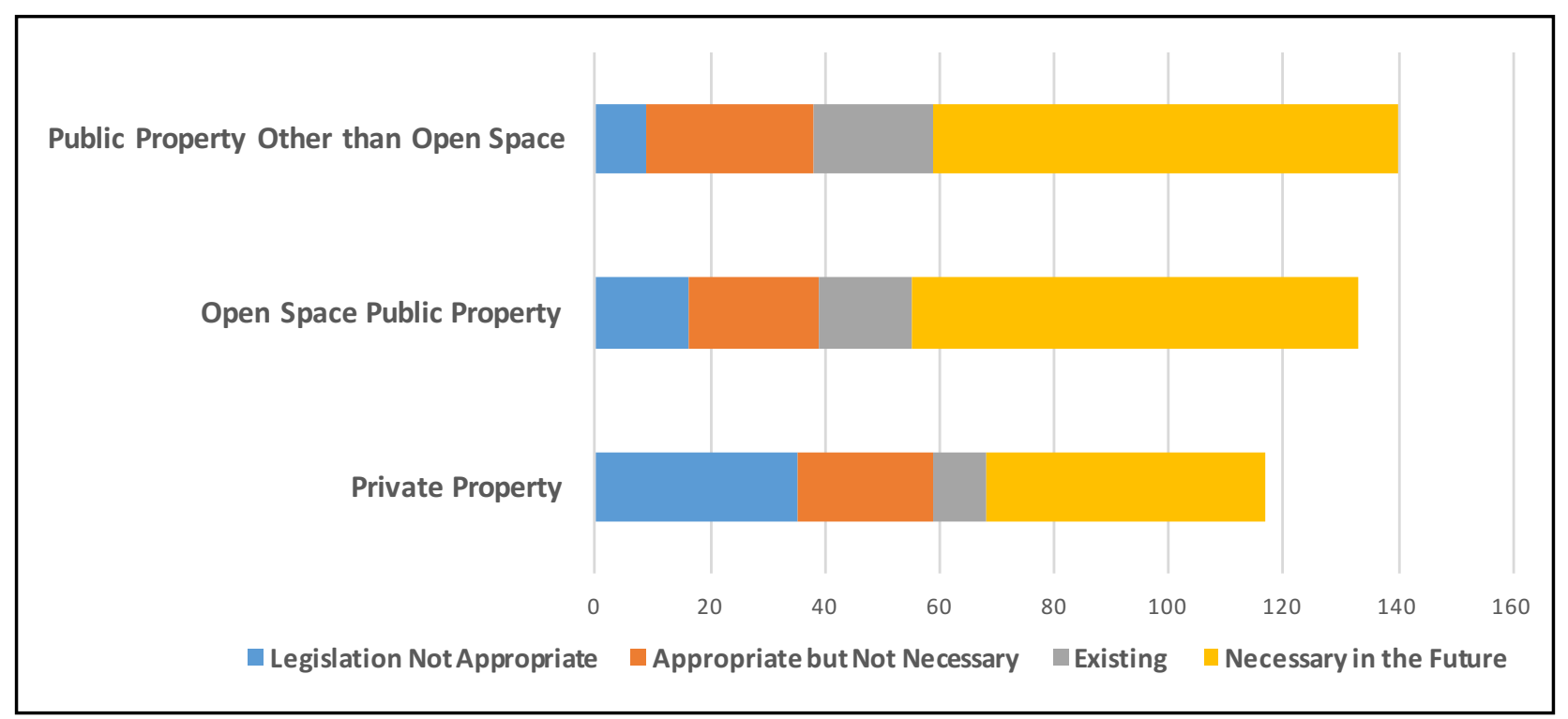

Figure 14. Legislation Forecast for Different Types of Location Restrictions 
Question: What is the expected volume of drones that you foresee within your jurisdiction?

The survey continued to explore the future volume expected by the local agencies, further requesting them to estimate whether commercial or recreational uses would represent a greater volume of use. This question began the final section of the survey, which targeted the future of drone applications, including drone deliveries and urban air mobility. Local agencies seem to expect a moderate amount of drone activity within the next 5 years, with recreational use having an edge over commercial use (Figure 15). This forecast matches the current estimates from NASA provided in Figure 1, which project that commercial use will remain at about a third of the recreational volume for the next 5 years.

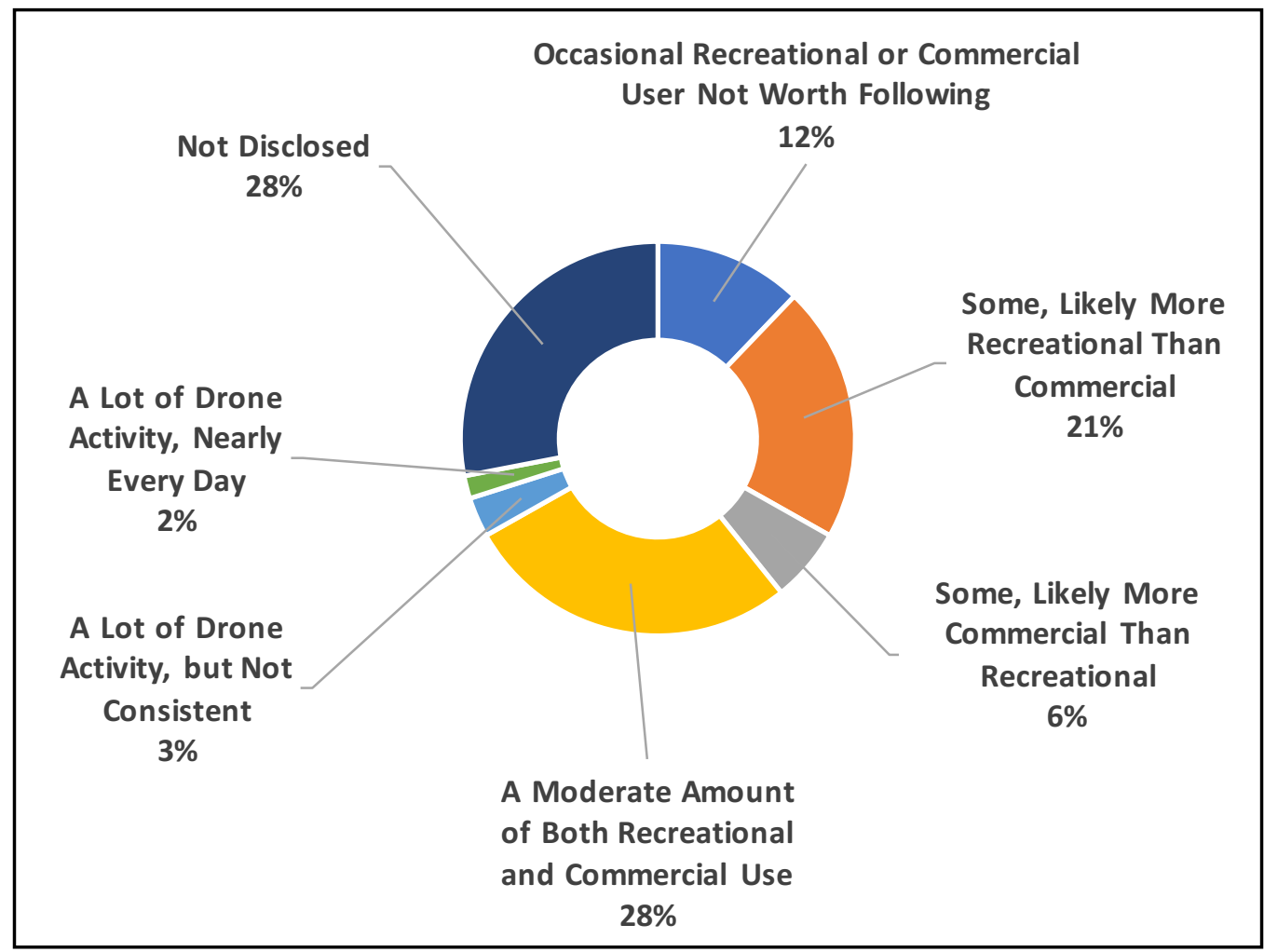

Figure 15. Forecasted UAS Activity and Type of Use (Recreational vs. Commercial) 
Question: Please indicate the likelihood of the following options based on your current expectations (drone delivery; urban air mobility)

Figure 16 reports the answers for estimated likelihood of drone delivery usage. Two possible timeframes of adoption were provided: medium-range (5 years) and long-range (10 years). While 5-year results were more spread out, there was a strong expectation that drone delivery applications would be likely to surface within the next 10 years of operations, showing different trends for the two timeframes.

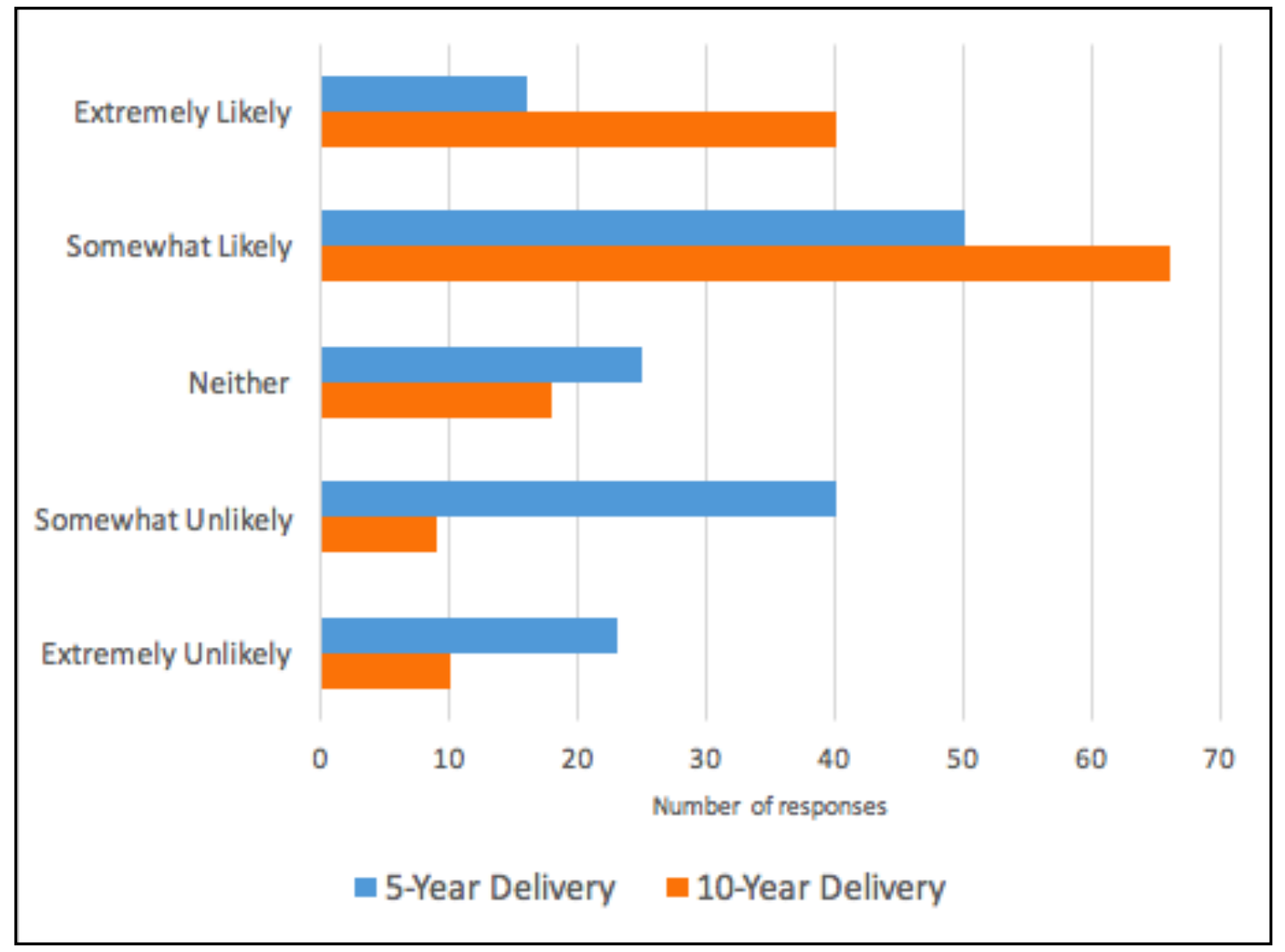

Figure 16. Estimated Timeframes for the Adoption of Drone Delivery

Furthermore, a similar question was proposed in relation to urban air mobility applications (i.e., transportation of people through vertical take-off and landing UAV for urban commuting purposes). Figure 17 reports the findings for the 10-year timeframe. There was no significant expectation that urban air mobility applications would surface before the next 10 years, so that the 5-year timeframe is not reported. Also, for the 10-year timeframe of Figure 17, results are scattered and show a low estimated likelihood. 


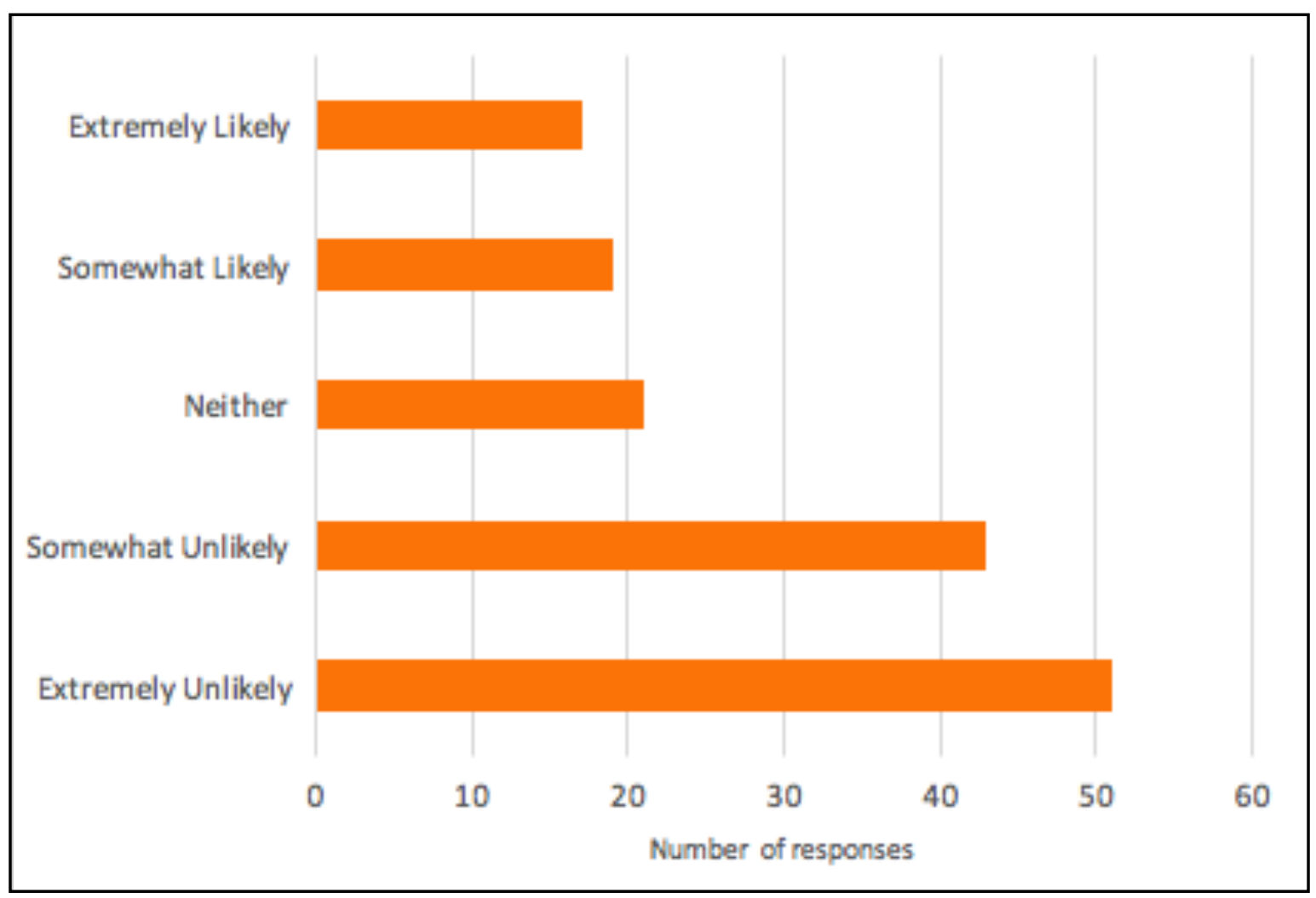

Figure 17. Likelihood Estimate Distribution for 10-year Timeframe Applications in Urban Air Mobility

Question: Please provide any additional comments related to regulation of drones within your jurisdiction that were not addressed above.

Finally, participants were queried for additional comments, and open-ended suggestions on the topic. Comments were left by $9 \%$ of the respondents and pointed to the following concerns:

- The fact that additional regulations might hamper the development of the technology

- The need of legal counsel not to waste the already scarce resources (Note: this concern most likely refers to previous regulatory efforts from local jurisdictions that got pre-empted in federal court. ${ }^{18,19}$ Local agencies may perceive this topic as "too cumbersome" to work with in the absence of clear legal counsel about the creation of policies that will fit within the FAA federal regulatory panorama.)

- The concern that privacy violations could be regarded as "subjective," so that regulations must be clear on what can or cannot be considered a violation.

- The need to produce interactive maps or current cartography to highlight current constructions sites and possible temporary flight restrictions (i.e., no-fly zones). 


\section{TIER TWO DATA ANALYSIS: FOCUS GROUP}

The online survey concluded with an option to leave contact information, for those participants who were interested in a more in-depth discussion about the survey findings as well as in providing direct feedback on local policy and usage concerns. Twenty-two respondents indicated that they were willing to participate in an in-person focus group. Of those respondents, 9 confirmed participation and successfully attended the event, which was held on July 31, 2019 in the Student Union of San José State University.

The focus group participants included representatives from both County and City levels. Table 2 summarizes the positions held by the focus group participants.

Table 2. Participants' Jurisdiction and Position Held

\begin{tabular}{cccc}
\hline Participant ID & Position Held & Jurisdiction Type & Field of Work \\
\hline 1 & Chief Deputy Counsel & County & Legal \\
2 & Lieutenant & City & Law Enforcement \\
3 & Director of Emergency Services & City & Law Enforcement / Operations \\
4 & City Engineer & City & Public Works \\
5 & Transportation Specialist & City & Public Works \\
6 & Sheriff & County & Law Enforcement \\
7 & Sheriff & County & Law Enforcement \\
8 & Superintendent of Airport Operations & City & Aviation Operations \\
9 & Park Ranger & County & Conservation / Operations \\
\hline
\end{tabular}

As gathered from Table 2, the focus group featured a fairly balanced representation from both City jurisdictions (55.6\%) and County jurisdictions (44.4\%). All participants came from the Santa Clara and San Mateo counties in northern California.

Each participant was provided with a handout (included in Appendix B) that summarized the major findings from the survey. Items for discussions were also highlighted in the handout, presented alongside with the specific prompts of the questions that would be discussed in person during the workshop.

The structure of the focus group revolved around three main activities:

1. General Discussion on Survey Findings: this activity was aimed at obtaining feedback on the results of the California survey and at exploring in more detail the observed trends. It featured a presentation of the results, together with $16 \mathrm{prompt}$ questions that had been provided ahead of time to the participants.

2. Debate Sessions: this activity was aimed at sparkling lively discussions on possibly controversial topics that were not included in the survey. Five debate sessions were included in the workshop on the topics of drone regulation authority (local versus federal); regulatory structures for various applications; public insurance; rogue operators; and exclusivity of airspace. 
3. Sticky Note Exercises: this activity was aimed at soliciting independent thoughts from each participant on various aspects of drone technology, use, and regulation. Three exercises were devised wherein participants were given color-coded sticky pads and asked to write down (without showing them to others) one keyword on a specified sticky-note color for each theme describing: general attitude towards drones; regulatory priorities; and visions for the future.

Each participant was provided with notepads, pens, sticky notes, and a summary of all question prompts. Figure 18 is a photograph from the even showing the layout of the room used for the workshop.

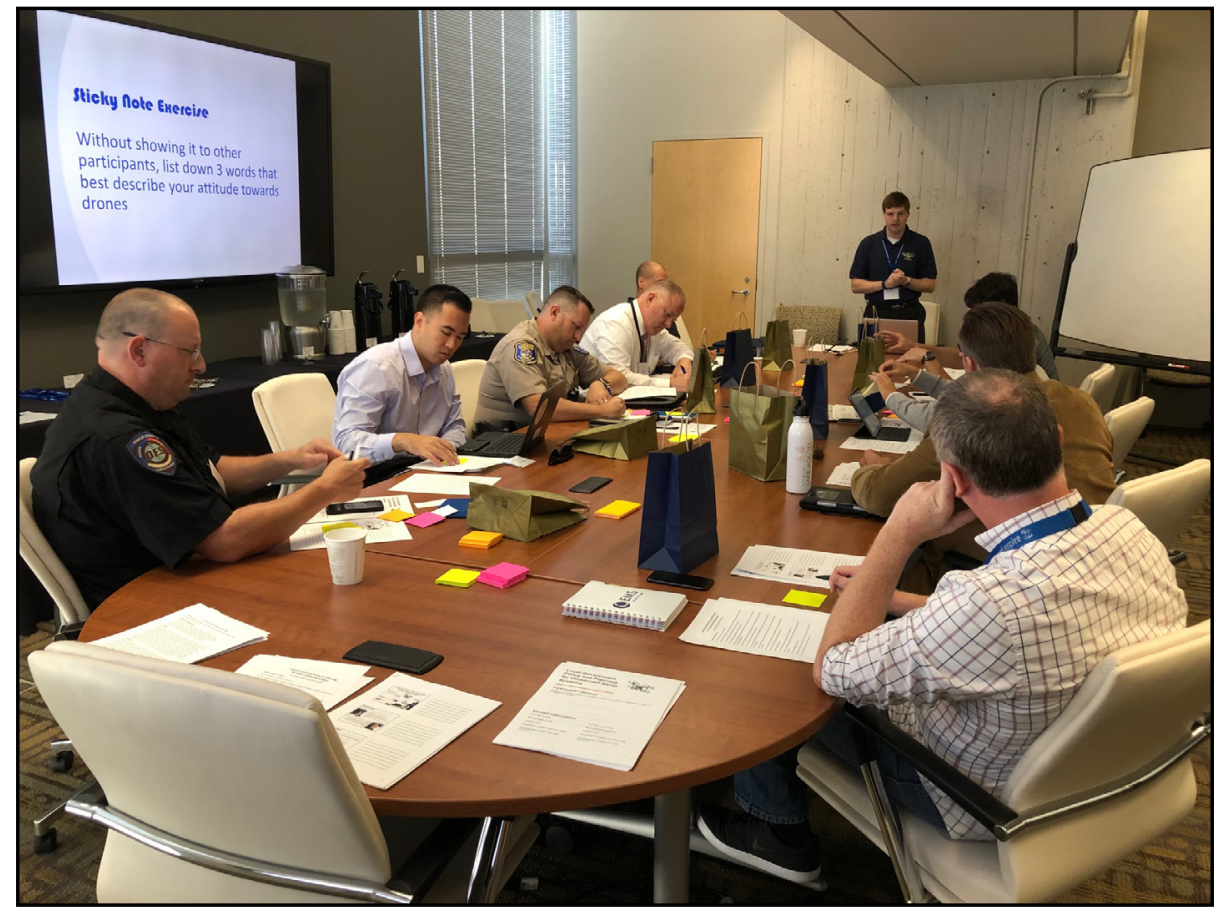

Figure 18. View of the Focus Group Setting

Before the beginning of the focus group, all participants were required to sign an informed consent form, as required by the SJSU IRB protocol for human subject testing. Answers given in the workshop were transcribed by two student assistants and an alternating one of the two main researchers, who took turns at leading the discussions. There was no video or audio recording of the event. The event took place over 4 hours and was made up of two sessions of $1 \mathrm{hr}$ and $45 \mathrm{~min}$ each, with a short $30 \mathrm{~min}$ break for lunch. The morning session revolved around the general discussion of the survey findings and a first sticky note exercise. The afternoon session involved further, focused discussion on the debates topic, with additional individual input collected though two more sticky note exercises. Results from the three activities are described next. 


\section{General Discussion on Survey Findings}

The general discussion questions, listed in Table 3, were integrated throughout the focus group workshop and presentation (workshop) through a guided PowerPoint presentation to facilitate continuous interaction with the participants and allow for thought evolution to occur throughout the focus group time. The workshop began with an initial "icebreaker" discussion about the status of UAS operations among the agencies represented by the participants in order to get the participants to think about the topic of the day and communicate with each other.

\section{Table 3. General Discussion Question Order}

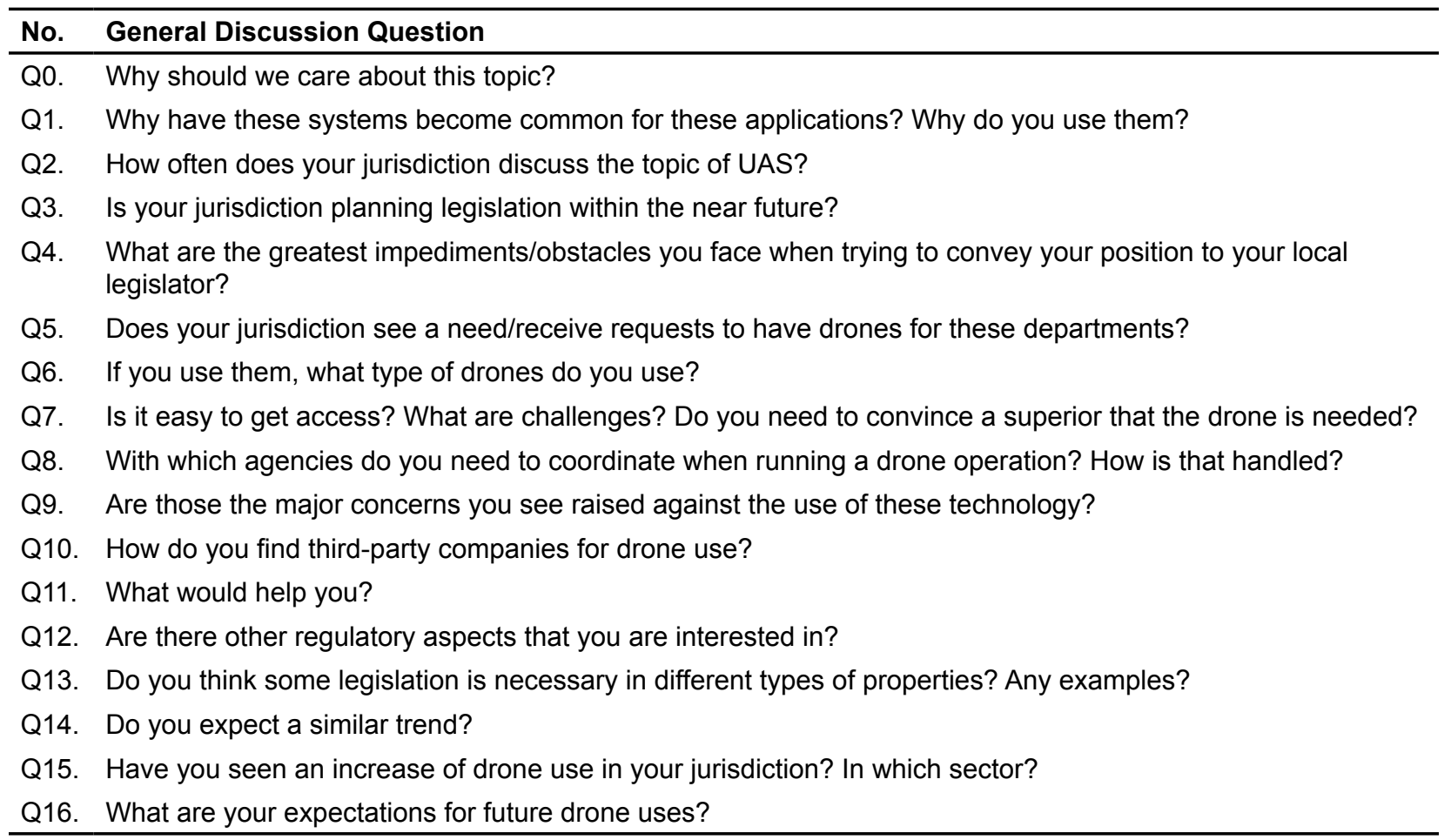

The initial question, Q0, prompted the participants to think about the importance of understanding the complexities surrounding the use of UAS from the various local level government agencies. Q1 asked the participants to make assessments, based on their own observations from within their communities, regarding the common uses of UAS they are witnessing. Participants agreed that these aircraft have already been used for a variety of operations from infrastructure inspections to crowd control monitoring to emergency response. The "Triple D" job description (i.e., dull, dirty, or dangerous) was identified through interactive discussion as a common reason UAS were being sought out for various applications; this included getting into locations people have a difficult time accessing, monitoring a location for increased situational awareness, or reducing risk to personnel. In addition, the participants noted that local governments are increasingly being tasked with finding ways to regulate UAS for public, recreational, and commercial use. 
The next series of questions, Q2-Q4, asked the participants to focus on the use of UAS within their own agency. Among the five work fields represented in the workshop, the law enforcement officers had most commonly witnessed or operated a UAS as a part of the job. These questions asked participants: to discuss how often the topic of UAS arises in meetings they attend (Q2); to recall if they discuss the topic of future UAS legislation at these meetings (Q3); and to discuss any obstacles to effective UAS policy planning by local legislators (Q4). City planning officials indicated that meetings have occurred regularly, often several times a month; however, they often do not discuss UAS issues from a regulatory perspective, because, as one participant indicated, there is no way to address the issue properly without all of the necessary information. For some operations in a local environment, a city may occasionally discuss a UAS project in collaboration with a community industry partner, but this is not standard for most operations. There was a consensus that, from a legislative perspective, discussions about UAS were more "wait and see," or reactive. There has not yet been any major accident of note due to an errant UAS in the United States, and regulators at all levels of government are still undecided on the extent to which operations need to be monitored. A challenge to regulators that was noted in the discussion is the constant change in regulatory structure from the Federal Aviation Administration (FAA). The rules or their associated interpretations are still fluctuating: one participant indicated that "we don't know the rules, or what they mean" and another participant stated, "the FAA changes continuously and without adequately informed notification about the changes." Law enforcement agencies did discuss UAS from an operational standpoint. They recognized the difficult position of attempting to enforce ordinances where children may not be cognizant of any regulation regarding operation, as well as of defining the boundary between local-level enforcement and federal enforcement. They viewed the issue from a perspective of threat mitigation, raising examples such as contingency plans to stop a professional sports game due to operation of a potentiallydangerous UAS in the vicinity of an active stadium.

After those discussions, the topic focus changed from a general discussion about the status of UAS in communities to ways in which the agencies were using UAS for their own purposes. The identification and discussion of the various operational UAS experiences were explored in Q5-Q8 and Q10-Q12 (Q9 will be discussed in the next paragraph, where its responses better fit the topics). When specifically asked about the need for UAS in the participants' own departments, most indicated that UAS had been used. The airport official stated that UAS use is now nearly an industry standard for runway inspection to spot vegetation and also as an airport monitoring tool such as perimeter fences for safety. The park ranger indicated that the equipment attached to the UAS was more important than the actual UAS itself, but that thermal camera-equipped quadcopter UAS have been used and they have a need for more routine operations. The city engineer specifically mentioned the use of UAS in post-earthquake bridge inspections to more easily find cracks or other structural deficiencies. Law enforcement and emergency management also noted similar uses: wildfire spotting, thermal sensor search and rescue, and emergency response. The specific type of UAS was not a primary concern for any of the participants, but rather the functions were the driving factor in choice. The airport official stated that they use "drones that look like eagles" because this causes other animals to stay away, thinking a predator is nearby. Lidar sensors and thermal cameras were important sensors that the participants saw as important for a variety of operations. The city engineer and park ranger thought 
a quadcopter would continue to be a preferred UAS type because of the small size and its durability with rough terrain operations (e.g., maneuvering in wooded areas or around cliffs). While all of these operations have been ongoing, only law enforcement officials indicated easy access to UAS, with one department managing a fleet. Coordination was therefore required for those who wanted to use UAS but did not have easy access. This required local agencies to either create Memorandums of Understanding (MOUs) with other agencies or hire private-sector consultants. One respondent indicated that their department was specifically thinking about third-party consultants, but that there were special circumstances and other regulatory hurdles involved due to the nature of involving civilians in law enforcement operations. A couple of potential solutions suggested to increase the availability and feasibility of acquiring UAS, in response to Q11, included an increased authority of local governments over their mission needs through better awareness and some approval abilities of operations in the local environment and an increase in their licensing mandates (suggested as being similar to those necessary to acquire a gun) so that awareness and training would be higher among those who purchased UAS. Some of the other regulatory aspects that were discussed and recommended for consideration by decision-makers included better understanding of land-use maps to easily facilitate approval of airspace use, and "zoning" for UAS. Discussion on airspace approval and what "zoning" would mean included a need to focus on better implementation of the Low Altitude Authorization and Notification Capability (LAANC) and establishment of a central repository for easy identification of local and federal restrictions in any given area.

The last series of discussion questions (Q9, Q13-Q16) were centered on things that need to change and on the future of UAS operations in the local area. There was much discussion about the lack of effectiveness and of general understanding surrounding the current regulations for UAS operation. A few major concerns raised were the lack of appropriate categorization of UAS, the ability for anyone to purchase a UAS without any prior knowledge (i.e., manufacturers selling UAS to anybody who is interested in buying one and placing the burden of ensuring competence entirely on the user), and the difficulty in understanding the regulatory and legal language required prior to operating an UAS. Among the participants, expectations regarding such changes tended to be pessimistic. A theme that was reiterated throughout the discussion was that, as one participant stated, "unless something huge happens and the media mentions it, there will be no discussion about drones." There was consensus around the idea that a similar trend will continue; however, there was a sense of hope that if the industry booms, as forecasts show, and money becomes a driving factor necessitating regulation, more consensus and cohesion may be formed. However, participants also made a comparison made with autonomous driving vehicles and the setbacks that have hindered that industry from taking advantage of the technology currently available, such that public perception has not grown at the rate that industry expected. That same public perception was believed to follow a similar pattern for the full-time use and acceptance of UAS technology. In other parts of the world, like Australia, package deliveries are already happening via UAS and there is greater acceptance of the technology; however, the same pattern is not evident in the United States, and the regulatory structure is not being pushed to adapt at the same rate. Urban Air Mobility - the operation of large-scale UAS for intracity and suburb-city passenger and cargo operations-was briefly mentioned in the focus group, but there was consensus that it will not be not be happening within the near future. 


\section{Debate Sessions}

At the conclusion of the series of brief general discussion topics just described, in which participants formulated general ideas about the full picture of UAS operations in the local area, a series of five debate questions was proposed to the participants. These questions were intended to elicit multiple points of view and to simulate the varying conflicts of interest that can arise when discussing the issue of operational UAS in a community. Table 4 presents the discussion questions in order as they were presented to the participants.

\section{Table 4. Debate Question Series}

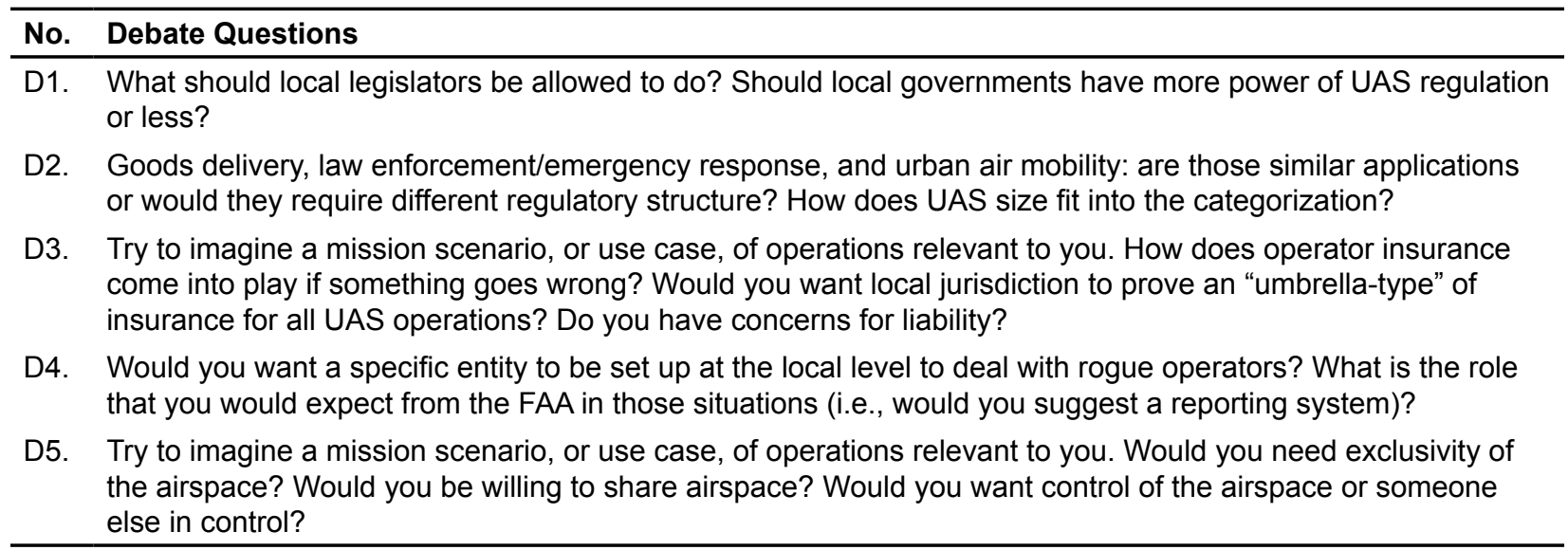

The first question (D1) resulted mostly in consensus among the group members. Many of the issues that keep local legislators from being able to effectively manage local problems with UAS activity were summarized earlier in the "challenges of legislation" series of general discussion questions. The regulatory and structural challenges of implementing UAS are generally local issues as the 107 regulations at a base level limit operations to local environments restricting UAS to within the line of sight of the remote pilot and below 400 feet in altitude (contrasted with the relative ease of interstate travel in a variety of weather conditions for manned aircraft and where manned aircraft typically have a cruising altitude limit of 500 to 1,000 feet above the ground), and the participants agreed that UAS operations impact local communities in ways that federal oversight does not reach ${ }^{92}$ However, the federal government has reacted to the growing forecast of UAS operations and considered the threat of UAS to other aircraft, therefore sweeping UAS under the arm of the FAA through the definition of aircraft. ${ }^{93}$ Currently, individuals use UAS in isolated environments compared to the intricate multi-layered context required for typical manned aircraft operations. Recreational users may want to go to an open space such as a park, or to fly in a backyard, or while walking down the sidewalk. These operations (even under Part 107 requirements if applicable) will not cross multiple air traffic control boundaries, use procedural knowledge of visibility and communication requirements for different airspace types, or require complex flight planning to determine fuel stops or weather diversion considerations to alternate airports. Local law enforcement recognized that requiring UAS operators to have the same level of regulatory understanding and application for local regulations was just as important as the required understanding of necessary federal regulations for the use of UAS. One issue 
identified by the participants where local governments could have better guidance on their regulatory allowance was public and private property divisions (and associated airspace authority). The participants discussed sidewalks and waterways as public property and not the property of an individual. However, they also stated there is very little guidance on how local law enforcement can better protect individuals from the encroachment on privacy from someone who is themselves on public property, but is controlling an aerial machine easily capable of intentionally or unintentionally encroaching on private property (e.g., a camera-mount on a UAS that sees over a tall fence). Another area local officials would like to have input on is the software development promoting UAS use. There are software applications and app developers attempting to create systems that aim to increase flight efficiencies and successful operations. However, these apps may have limitations on their accuracy and ability to provide adequate feedback on operation in a particular area within a community. There may be a local understanding established through informal means that would not be addressed through official documentation. One participant stated that it would be useful for local legislators to directly engage with these app developers, in ways that the FAA is not, in order to provide more context to local legislators about UAS issues. Partnership between software developers and local agencies could allow for collaboration that would improve solutions to community problems like response time inefficiencies for local emergency response. The local agency participants saw the need for more involvement of local governments in finding the best solutions, but they also wanted more clarity regarding the separation of powers between local, state, and federal levels. Another issue identified was the human staffpower available to effectively monitor and assess all of the UAS activity. Local agencies, particularly law enforcement, already have to work numerous tasks even without adding UAS enforcement activities. Without clear guidance from higher levels of government, there is much uncertainty about how local levels of government can appropriately handle additional tasks. This need for clarity was a consensus regarding the role of local government in creating UAS legislation and the power available to regulate the issue.

The second debate question, broadly titled "Apples or Oranges," initiated a discussion over the necessary regulatory structure required to appropriately categorize UAS. The variety of agencies and departments represented allowed for the discussion to explore the desires of public entities to drive the regulatory process of UAS technology, while also recognizing the various recreational and commercial industry needs for UAS. For instance, a few of the UAS uses frequently discussed include goods delivery, law enforcement/emergency response, and urban air mobility (the methods for low-altitude intra-metropolitan air travel for passengers and cargo). This particular question sparked a variety of answers on how a framework should be created to categorize UAS. Instead of simply registering UAS over a certain size, there was a suggestion that there should be a system for local licensing and registration divisions specifically for UAS, much like a Department of Motor Vehicles (DMV). Instead of having to appeal for a Certificate or Waiver of Authorization for specific operations, a local branch could provide a lasting certification, enabling applications to be processed much timelier and more efficiently. In addition, there was consensus among the participants that limitations to UAS operation cannot simply be one-size-fitsall. A commercial off-the-shelf UAS likely does not regularly need the same access to operational technology as search and rescue emergency operators. There should be distinct regulations for private users, public safety users, and others. It was also noted that 
location restrictions should not be uniform, either, such as requiring explicit and special operation for both law enforcement and private citizens. In addition, there should be more public notification and use transparency for public safety and law enforcement operations. There is public concern about who is using the UAS, the capacity of the UAS, and why they are flying. However, the airport representative believed that all aircraft operations should be able to know where a UAS is flying so they can be prepared to avoid it. This would require mandating a live flight path tracker and enabling an Unmanned Traffic Management (UTM) system. There was not much discussion about needing to limit the size of the UAS so much as there was about the intended capabilities of the devices and what can be attached to the UAS. The additional and compatible technologies available to a UAS were viewed as more of a threat to public safety than the actual vehicle portion of the UAS, which is contrasted with the emphasis the FAA places on collision hazards between unmanned and manned aircraft as a primary driver for regulation. ${ }^{94}$

The third discussion question, titled "Public Insurance," asked about liability and public agencies' concerns regarding the need for insurance in the case of an accident or incident with a UAS. This particular question did not spark much debate, as there was a lack of knowledge about whether or not current insurance policies would cover any liability regarding the use of the UAS. It did not seem to participants that there needed to be a separate and new type of insurance system specifically covering UAS operation for public use agencies. In contrast, they did think such a separate insurance system should exist for recreational and commercial users, but they still expected a need for a new insurance framework model that is distinct from current insurance structures, and then also an enforcement mechanism to coincide with such a requirement, or else the insurance system would not be viable. As one law enforcement officer participant noted, based on experiences, it did not seem possible to force people to buy insurance, and this participant continued to speculate that such a requirement would likely cost more than buying a new UAS. It was also suggested that an insurance requirement "would need teeth behind it," in terms of consequences for non-compliance, in order to have any effective quality. In general, there was not much debate or discussion, and the question generated a somewhat negative reaction regarding its impact on implementation and usefulness. An insurance mandate specific to UAS operations was treated by the participants as something that would just be a burden for compliance and would not work as a solution to foster safe operation of UAS.

The fourth debate question, titled "Dealing with Rogue Operators," was intended to detect any potential difference of opinion among those who were on the front lines of public safety (i.e., law enforcement) and the other participants. There was an initial discussion about the definition of a "rogue operator." Some took this term to refer to anyone who does not follow the intended rules of the air as defined by the FAA, while others were thinking about criminal activity and a specific threat to public safety. This difference shaped how the participants answered the question and the extent to which they believed there was indeed a problem that needed to be solved. For instance, when prompted with the term "rogue operators," one participant asked, "is rogue 'bad people'?" By the term "bad people," the participant was referring to those who behave with criminal intent and not the broader application of people who do not follow the standard norms and proper procedures for safe operations. The participant's solution to resolving the issues with this narrower definition of a rogue operator was simply to have a reporting system following an "if you see something, say 
something" model. Another participant from the law enforcement field thought a system of enforcement whereby officers could issue tickets would be a deterrent for improper activity, bluntly stating that rogue UAS activity was "not that big of a deal except to airline pilots." The threat of a rogue operator was more clearly defined in relation to aviation terms by the city airport representative. This participant was careful to note the nuance of the type of UAS that was operating in the vicinity of the airport, and the participant stated that as long as the operator followed prescribed procedures for operating in the airspace environment, then the operation was not a threat. However, the airport representative also stated that there is no specifically defined policy for how to handle an intruder and that it was up to the airport to figure out the best way to handle an observed UAS threat in an appropriate manner; in other words, officials like federal air marshals would not be the ones responsible for intervening in an errant UAS operation. ${ }^{95}$ For immediate threats, the airport approach was succinctly described as following the maxim, "do what you need to do and ask for forgiveness later."

The final discussion question, titled "Exclusivity of Airway," was asked in order to determine whether public agency UAS users foresaw instances where they would need to share certain airspace with other users, and whether local agencies needed explicit control over certain airspace. The answers from the participants showed that it depended on the purpose of their operation. For matters of homeland security and threats to public safety, law enforcement representatives were keen to state that they would like to be able to respond immediately, including by clearing the area of non-essential personnel and taking control of the immediate area while they handled the threat. Others who did not necessarily need immediate access to airspace for emergency purposes were more apt to state that the FAA could maintain control of the airways, and until there is a clear way to track UAS and enforce errant operations, then there is little that is currently available to control UAS activity in the airspace. However, law enforcement officials also noted that immediate and direct control of airspace would typically not be needed for routine operations and that being able to share airspace would be useful and beneficial. For non-security related reasons, there would not be any reason to hide an operation from the public or keep them entirely cordoned off from a designated area of operation laterally or vertically. This would mean there would need to be tiered approach for multi-use conditions. Education for UAS operators was seen as imperative in the immediate term to make sure that all operators understand their role in the National Airspace System as a UAS pilot. However, it was also noted that without an enforcement mechanism, education alone would likely still not be sufficient.

\section{Sticky Notes Exercises}

The sticky note exercises were aimed at collecting independent ideas from each participant. The notion behind this type of exercise is to have each participant draft one concept per sticky note based on a general prompt to the room. This visual methodology encourages active participation from participants ${ }^{96}$ each of whom had to write down 3 to 5 keywords per prompt and then stick their notes on a whiteboard. The researchers then worked, together with the participants, on clustering similar responses and on identifying underlying trends in the collected answers. As the group discussed the items and categories, additional comments were made to supplement what had been written by each participant. Once the members were satisfied with the categorizations of the ideas, the notes were recorded and 
the process was repeated for the next question. Figure 19 provides an example of how the initial distribution of the sticky notes was later structurally organized to highlight trends.

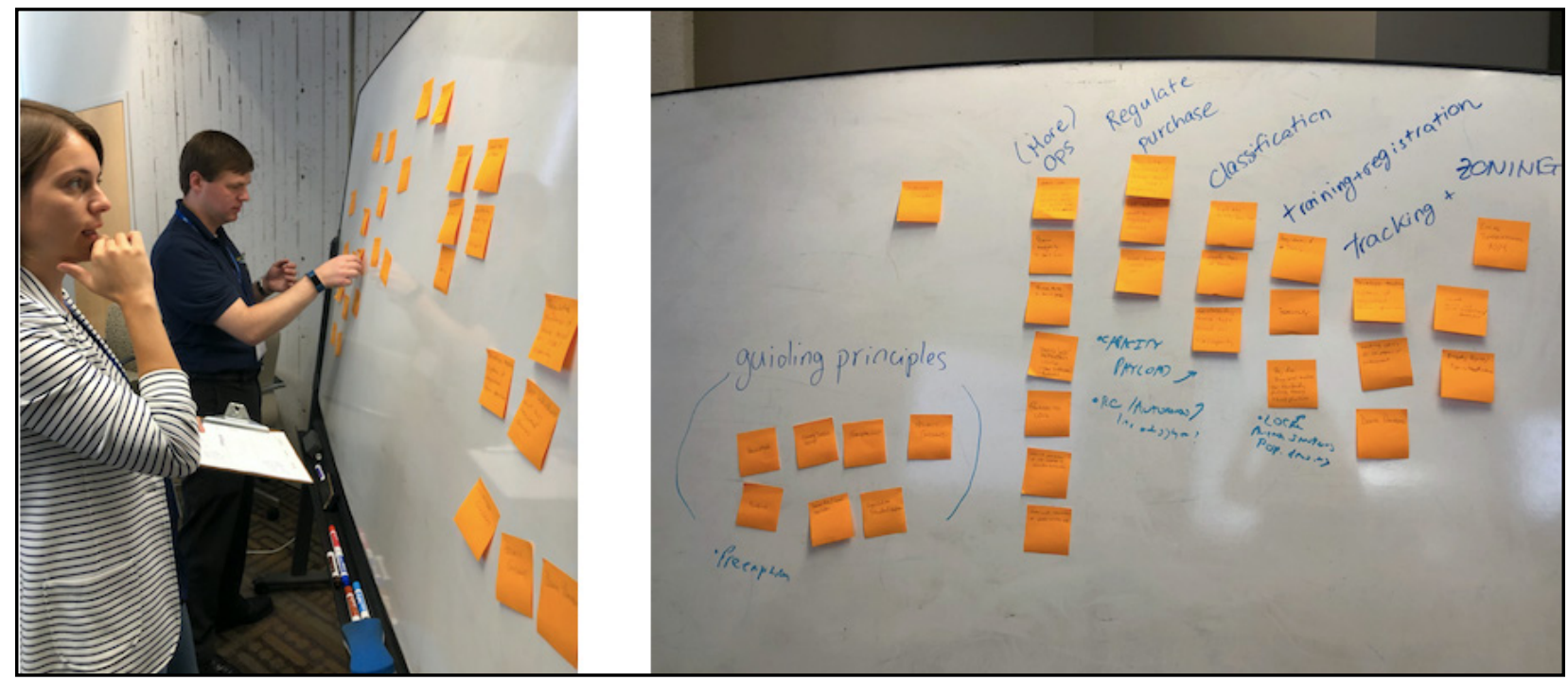

Figure 19. Example Organization of a Sticky Notes Exercise

The following three prompts were used during the event:

1. Without showing it to other participants, list down three words that best describe your attitude towards drones.

2. If you had the opportunity to dictate drone policy right now, what would be the top $3-5$ priorities that you would tackle first?

3. What are 3-5 things that you believe need to happen before we get to everyday drone deliveries and urban air mobility?

Each prompt took about 15 minutes of work, including 5 minutes for idea generation, 5 minutes for clustering and clarifications, and 5 minutes of concluding discussion.

\section{Exercise 1: "Attitude Towards Drones"}

1. Without showing it to other participants, list down 3 words that best describe your attitude towards drones.

The first prompt elicited a total of 29 sticky notes. Figure 20 provides an overview of the organized whiteboard after clustering and discussion were executed. 


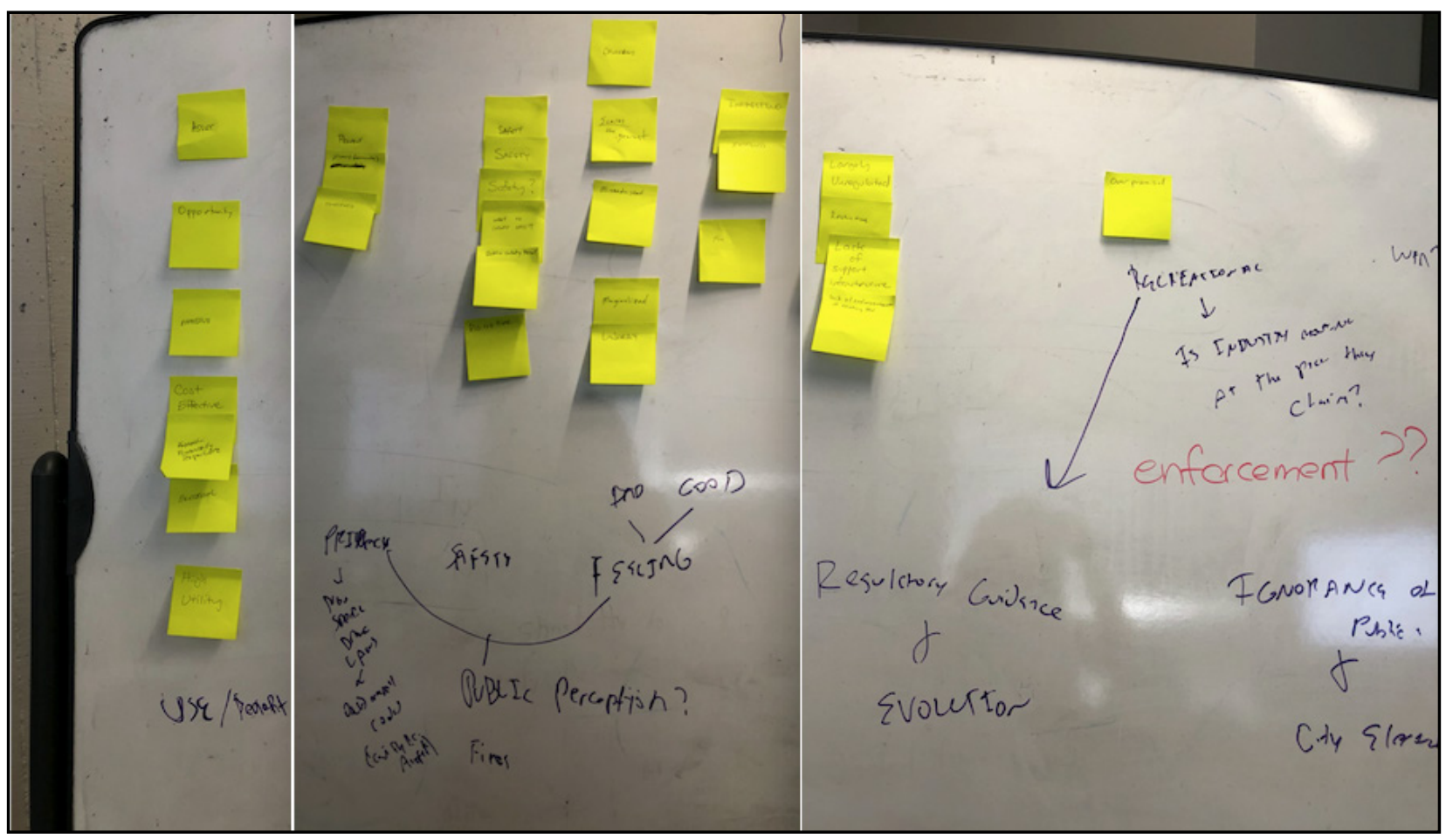

Figure 20. Overview of Finalized Board for Exercise 1

The notes were organized into six categories, but one macro-category including three of those was also later identified during discussion with the group. There was a general consensus from the group on the main categories for "attitudes towards drones" and what the overall concerns should be. Figure 21 summarizes the categories identified by the group, with an intuitive definition given for each.

\begin{tabular}{|l|l|}
\hline Use / Profit & $\begin{array}{l}\text { - Ideas related to advantages of the technology and } \\
\text { cost/benefit analysis }\end{array}$ \\
\hline Privacy & - Ideas related to concerns for the comunity related to privacy \\
\hline Safety & $\begin{array}{l}\text { - Ideas related to concerns for the overal safety of the } \\
\text { community }\end{array}$ \\
\hline Feelings & $\begin{array}{l}\text { - Ideas related to either "good" or "bad" attitudes to the general } \\
\text { concept of using drone technology }\end{array}$ \\
Regulatory & - Ideas related to the needed regulatory structure for drone \\
Guidance & usage
\end{tabular}

Figure 21. Identified Categories for Exercise 1 
Table 5 reports the bulk of the answers provided by the group, categorized per the identified areas of interest; it also reports the percentage of answers in each category.

Table 5. Sticky Notes Exercise 1: Summary of Answers

\begin{tabular}{|c|c|c|c|c|c|c|c|}
\hline \multirow[b]{3}{*}{ Counter } & \multirow[b]{3}{*}{ Use/Profit } & \multicolumn{4}{|c|}{ Public Perception } & \multirow{3}{*}{$\begin{array}{l}\text { Regulatory } \\
\text { Guidance }\end{array}$} & \multirow[b]{3}{*}{ Other } \\
\hline & & \multirow[b]{2}{*}{ Privacy } & \multirow[b]{2}{*}{ Safety } & \multicolumn{2}{|c|}{ Feelings } & & \\
\hline & & & & Bad & Good & & \\
\hline 1 & Asset & Privacy & Safety & Dangerous & Fun & $\begin{array}{c}\text { Largely } \\
\text { Unregulated }\end{array}$ & $\begin{array}{c}\text { Over- } \\
\text { promised }\end{array}$ \\
\hline 2 & Opportunity & $\begin{array}{c}\text { Privacy } \\
\text { (Community) }\end{array}$ & Safety & $\begin{array}{l}\text { Scares the } \\
\text { Ignorant }\end{array}$ & Interesting & Restrictions & \\
\hline 3 & Effective & Concerned $^{*}$ & Safety & Misunderstood & Intrigued & $\begin{array}{c}\text { Lack of } \\
\text { Supportive } \\
\text { Infrastructure }\end{array}$ & \\
\hline 4 & $\begin{array}{c}\text { Cost } \\
\text { Effective }\end{array}$ & & $\begin{array}{l}\text { Want to } \\
\text { Ensure } \\
\text { Safety }\end{array}$ & Marginalized & & $\begin{array}{l}\text { Lack of } \\
\text { Enforcement of } \\
\text { Existing Laws }\end{array}$ & \\
\hline 5 & $\begin{array}{l}\text { Financially } \\
\text { Responsible }\end{array}$ & & $\begin{array}{l}\text { Public } \\
\text { Safety } \\
\text { Threat }\end{array}$ & Worry & & $0.03 \%$ & \\
\hline 6 & Beneficial & & Disruptive & & & & \\
\hline 7 & High Utility & & & & & & \\
\hline Frequency & $7(24.1 \%)$ & $3(10.35 \%)$ & $6(20.7 \%)$ & $5(17.2 \%)$ & 3 (10.35\%) & $4(13.8 \%)$ & $1(3.5 \%)$ \\
\hline
\end{tabular}

* Note: the "concerned" sticky note was later clarified as referring to concern about privacy; this is the reason why it is not included under the category "feelings." Entries are represented by categories as agreed upon by the group based on live discussion.

As mentioned before, one macro-category termed "public perception" later emerged during the discussion of the identified categories. This macro-category encompassed the three areas of "privacy," "safety," and "feelings," and it would thus constitute the main area of interest from the participant input, with $58.6 \%$ of answers belonging to the "public perception" macro-category. This finding echoes what was discussed in the general questions as well as the debate sessions: although the interest in the technology was recognized by all (the "use/profit" category has a higher frequency [24.1\%] than any of the other non-macro categories), public perception understandings and concerns were identified at a greater frequency as important for determining proper uses and regulations of drone technology. In particular, two participants mentioned twice that "public perception" was intended to refer not only to the perceptions of the general community, but also to the perceptions of elected officials, as well as to how elected officials expect the surrounding community would react to a more substantial usage of drone technology. Note that "safety" was the overall most used word, appearing in a total of $5(17.2 \%)$ sticky notes.

The ensuing discussion revolved around three main areas of concern from the group: ignorance of the public; pace of industrial development; and regulatory enforcement. In particular, there was a consensus on the need to simplify the on-going evolution of federal regulations, so that they could be better tracked and better understood by the general public. Some participants noted that some of the very constraining restrictions imposed by federal regulations, as well as location-based restrictions imposed by local jurisdiction, 
have little value, since there is a general lack of enforcement from the federal level as well as from the local level. This issue further aggravates the perceptions of the public, which is left to believe that drone usage and the regulatory infrastructure is a "wild jungle," where users can go unpunished for any type of violation.

An overall trend of the discussion, as well as of the entire focus group event, was that participants started the debate with a optimistic perspective, recognizing advantages and benefits of the technology, but that ensuing concerns would drag the debate towards a more critical and hopeless view of unsurmountable obstacles to tapping into the real advantages of the technology. This trend was particularly true with respect to the need for local policy creation and implementation, as discussed next.

\section{Exercise 2: "Drone Policy Priorities"}

2. If you had the opportunity to dictate drone policy right now, what would be the top 3-5 priorities that you would tackle first?

The second prompt elicited a total of 30 responses. Figure 22 provides an overview of the whiteboard after clustering and discussion. The notes were organized into seven categories, including, as for exercise 1, an "other" category for those ideas that did not fit the trends that the group highlighted and agreed upon. In this situation, the participants provided more than simple keywords, but instead offered somewhat structured ideas that stemmed from the obstacles they were observing in the current regulatory structure. The specific prompt of exercise 2 had them imagine being in the role of the FAA and deciding what regulatory priorities they would set first. The group converged on highlighting the shortcomings of current regulations, which we discuss after the presentation of the answers and the identified categories, shown in Figure 23 and Table 6. The highest impact landed on the "Operations" category, with $23.33 \%$ of the answers pointing to the need for better regulating "special operations," which the group termed "public operations" (e.g., search and rescue, wildfire monitoring, etc.). 


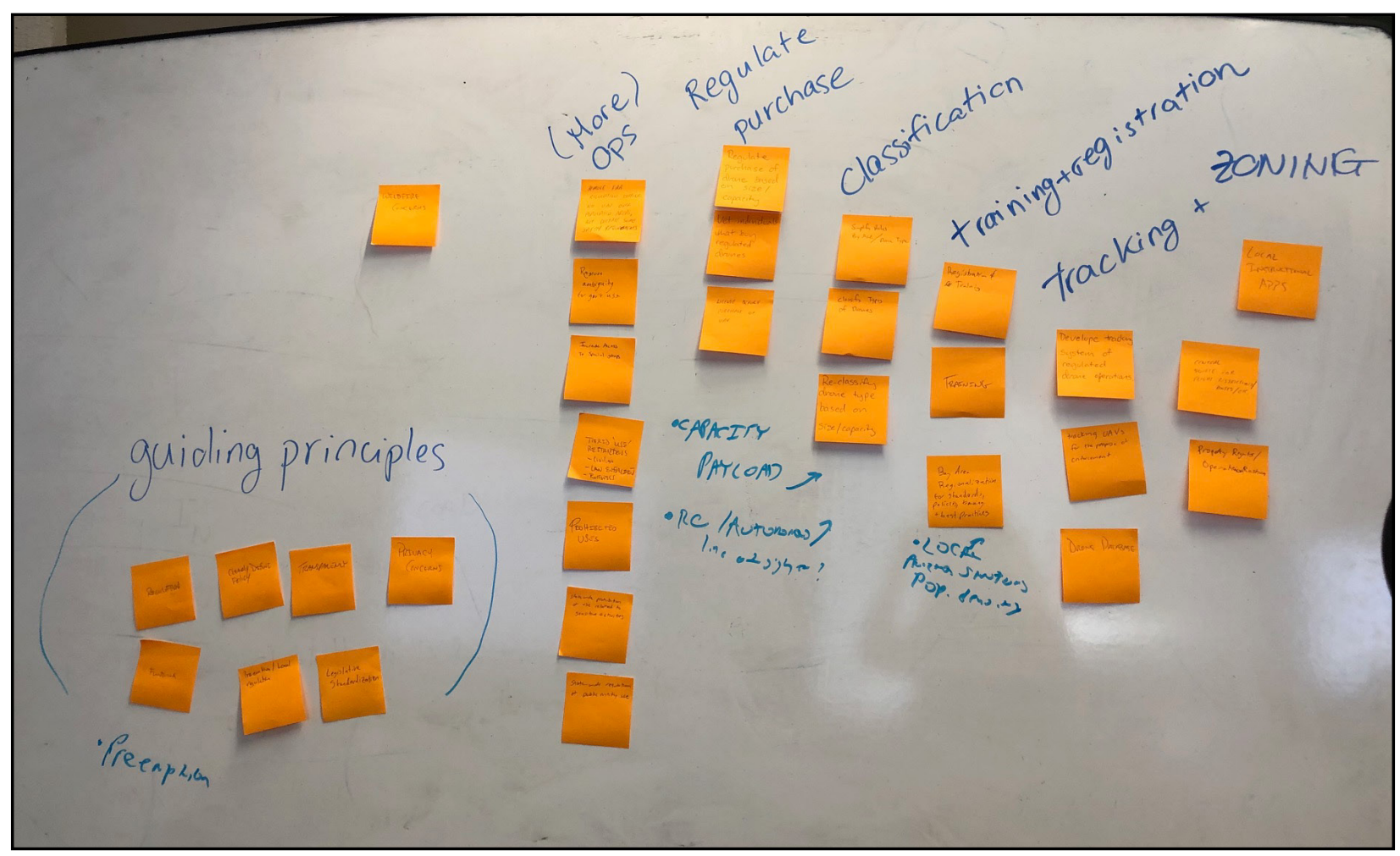

Figure 22. Overview of Finalized Board for Exercise 2

\begin{tabular}{|l|l|}
\hline $\begin{array}{l}\text { Guiding } \\
\text { Principles }\end{array}$ & $\begin{array}{l}\text { - Ideas related to how the endeavor of creating a new } \\
\text { regulations should be approached }\end{array}$ \\
\hline Operations & $\begin{array}{l}\text { - Ideas related to policy concerning how to regulate drone } \\
\text { operations }\end{array}$ \\
\hline Purchase & $\begin{array}{l}\text { Ideas related to policy concerning how to regulate drone } \\
\text { purchase }\end{array}$ \\
\hline Classification & $\begin{array}{l}\text { - Ideas related to policy aimed at establishing taxonomies and } \\
\text { classes of drones }\end{array}$ \\
\hline $\begin{array}{l}\text { Training and } \\
\text { Registration }\end{array}$ & $\begin{array}{l}\text { - Ideas related to policy for drone users' training and } \\
\text { registration }\end{array}$ \\
\hline Tracking and & $\begin{array}{l}\text { - Ideas related to policy for tracking drones and users and } \\
\text { Zestricting locations of operations }\end{array}$ \\
\hline Other & - Ideas that could not be categorized \\
\hline
\end{tabular}

Figure 23. Identified Categories for Exercise 2 
Table 6. Sticky Notes Exercise 2: Summary of Answers

\begin{tabular}{|c|c|c|c|c|c|c|c|}
\hline Counter & Guiding Principles & Operations & Purchase & Classification & $\begin{array}{c}\text { Training \& } \\
\text { Registration }\end{array}$ & Tracking \& Zoning & Other \\
\hline 1 & Regulation & $\begin{array}{c}\text { Remove } \\
\text { Ambiguity for } \\
\text { Government Use }\end{array}$ & $\begin{array}{l}\text { Regulate Purchase } \\
\text { Based on Size/ } \\
\text { Capacity }\end{array}$ & $\begin{array}{l}\text { Simplify Rules by } \\
\text { Age/ Drone Type }\end{array}$ & Training & $\begin{array}{c}\text { Develop Tracking } \\
\text { System of Regulated } \\
\text { Drone Ops }\end{array}$ & Wildfire Concerns \\
\hline 2 & $\begin{array}{l}\text { Clearly Define } \\
\text { Policy }\end{array}$ & $\begin{array}{c}\text { Increase } \\
\text { Access to } \\
\text { Special Groups }\end{array}$ & $\begin{array}{l}\text { Vet Individuals } \\
\text { Buying Regulated } \\
\text { Drones }\end{array}$ & $\begin{array}{l}\text { Classify Types of } \\
\text { Drones }\end{array}$ & $\begin{array}{l}\text { Training and } \\
\text { Registration }\end{array}$ & $\begin{array}{l}\text { Tracking UAVs } \\
\text { for Purpose of } \\
\text { Enforcement }\end{array}$ & \\
\hline 3 & Transparency & $\begin{array}{c}\text { Tiered "Use" } \\
\text { Restrictions: } \\
\text { Civilian, Law } \\
\text { enforcement, Business }\end{array}$ & $\begin{array}{l}\text { License Before } \\
\text { Purchase of UAV }\end{array}$ & $\begin{array}{l}\text { Reclassify Drone } \\
\text { Type Based on } \\
\text { Size/Capacity }\end{array}$ & $\begin{array}{l}\text { Bay Area } \\
\text { Regionalization for } \\
\text { Standard Policies, } \\
\text { Training, and Best } \\
\text { Practices }\end{array}$ & Drone Database & \\
\hline 4 & Funding & Prohibited Use & & & & $\begin{array}{l}\text { Local Instructional } \\
\text { Apps }\end{array}$ & \\
\hline 5 & $\begin{array}{l}\text { Pre-emption/Local } \\
\text { Regulation }\end{array}$ & $\begin{array}{c}\text { State-wide Prohibition of } \\
\text { Use Related to Sensitive } \\
\text { Activities }\end{array}$ & & & & $\begin{array}{l}\text { Central Source for } \\
\text { Flight Restrictions/ } \\
\text { Routes }\end{array}$ & \\
\hline 6 & $\begin{array}{l}\text { Legislative } \\
\text { Standardization }\end{array}$ & $\begin{array}{l}\text { State-wide Regulation of } \\
\text { Public Entity Use }\end{array}$ & & & & $\begin{array}{l}\text { Property Rights/ } \\
\text { Operations } \\
\text { Restrictions }\end{array}$ & \\
\hline 7 & Privacy Concerns & $\begin{array}{l}\text { Remove FAA Regulation } \\
\text { Stating no UAV Over } \\
\text { Populated Areas-but } \\
\text { Dictate Some Safety } \\
\text { Requirements }\end{array}$ & & & & & \\
\hline Frequency & $7(23.33 \%)$ & $7(23.33 \%)$ & $3(10 \%)$ & $3(10 \%)$ & $3(10 \%)$ & $6(20 \%)$ & $1(3.33 \%)$ \\
\hline
\end{tabular}


The discussion around regulatory priorities was lively. There were three main areas of discussion, which were related to licensing, current regulations, and current possibilities for users' locations to operate.

Firstly, with respect to licensing, a parallel was drawn to gun control and existing regulations for selling firearms and weapons only to those in possession of a state-issued or federallyissued license. In particular, various options were presented as to who would be the agent responsible for checking and enforcing the licensing of a customer, with the answer verging towards the specific seller/store location. It was suggested that only certain stores could sell drones, or that specialized stores (much like liquor stores) could sell this type of technology. Although probably a far-fetched vision (as it is not in agreement with the current market trends, with online retail being the most frequent platform of access to drones), this conclusion was reached by the participants as a result of general agreement that neither state legislators nor federal legislators would want the burden of carrying out the licensing process (due to lack of overall resources). Even if that happened, the store would still need to carry out the "checking/enforcing" side. Moreover, it was noted that effective lobbying from manufacturers had given them relative freedom from heavy regulation of sale permissions, with users being able to buy drones across the internet without any specific check being required.

Secondly, the topic of current regulations also re-surfaced, once more echoing the findings presented during the general discussion on survey findings. However, it should be noted that the researchers observed inconsistencies and misconceptions on the part of the participants of the current federal regulations, and in particular, of FAR Part 107. Not all participants seemed aware of the statutory requirements for public aircraft (49 U.S.C. $\S 40102(a)$ and $\S 40125$ ), which allows them to operate with a Certificate of Waiver or Authorization (COA). The COA allows the agency to self-certify their drones and operators for flights aimed at performing governmental functions. Even those aware of the COA indicated reluctance in submitting requests, due to the cumbersome process of (and the liability associated with) drafting a Public Declaration Intent letter to get begin the COA request with the FAA in the first place. Participants also seemed to agree that FAA enforcement was unlikely to be present in most situations, so that a "do now and ask later" philosophy seemed to be reaching consensus in the focus group-a couple members indicated they had run operations this way before. Although such philosophy was clearly targeted to emergency operations that hindered public safety, none of the participants mentioned or seemed aware of Part 107.21, which allows operators to "deviate from any rule of this part to the extent necessary to meet that emergency." This specific rule would of course be debatable in court, pertaining to what exactly the FAA considers an "in-flight emergency." Agreement was reached by all participants that the best approach would be that of a "tiered regulations with regards to use." In particular, they envisioned a threetier structure made of civilian use for recreational purposes; commercial/business use; and public entities/law enforcement use. Such a structure would allow public agencies a relaxation of federal regulations, and to remove the need to apply for a COA or for specific waiver to deviate from Part 107. Finally, as a more minor detail, the belief that "operations over populated areas are prohibited," raised by some participants, is incorrect, with Part 107.39 noting that flight over human beings who are not part of the operation is allowed provided that those individuals are "located under a covered structure or inside a stationary vehicle that can provide reasonable protection from a falling small unmanned aircraft." 
Thirdly, interesting suggestions came out of the idea of creating and encouraging forums for registered users. One participant mentioned the possibility of creating regional centers (physical or through online platforms) where users could share tips, best practices, and "dos and don'ts" for drone operations. The current existence of local amateur clubs was discussed, although participants pointed to the need of a better-structured network of licensed pilots across the region.

\section{Exercise 3: "Towards Drone Deliveries and Urban Air Mobility"}

3. What are 3-5 things that you believe need to happen before we get to everyday drone deliveries and urban air mobility?

The third and final prompt elicited a total of 25 entries. The general attitude of the group was somewhat hesitant: participants recognized limitations in the technology currently available and questioned the feasibility of public acceptance at this stage. Figure 24 provides an overview of the organized whiteboard after clustering and discussion were executed.

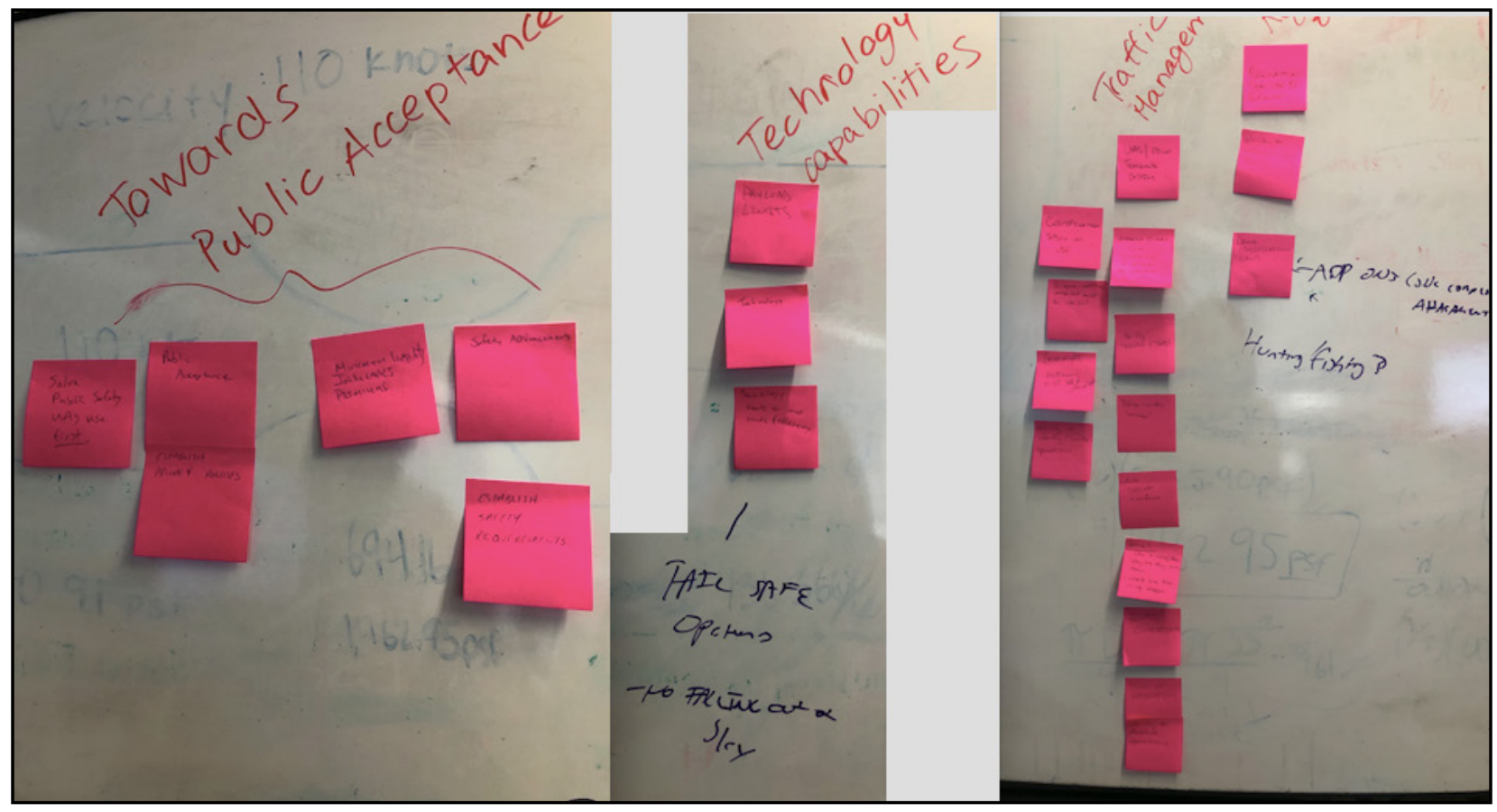

Figure 24. Overview of Finalized Board for Exercise 3 
The group converged on four categories, which are presented in Figure 25.

\begin{tabular}{|l|l|}
\hline $\begin{array}{l}\text { Public } \\
\text { Acceptance }\end{array}$ & $\begin{array}{l}\text { - Ideas related to concerns for operations acceptance by the } \\
\text { general public }\end{array}$ \\
$\begin{array}{l}\text { Technological } \\
\text { Capabilities }\end{array}$ & - Ideas related to the technology readiness level \\
$\begin{array}{l}\text { Traffic } \\
\text { Management }\end{array}$ & - Ideas related to the need to regulate and manage drone traffic \\
$\begin{array}{l}\text { Enforcement and } \\
\text { Policy }\end{array}$ & $\begin{array}{l}\text { - Ideas related to the creation of ad-hoc policy for these specific } \\
\text { applications }\end{array}$ \\
\hline
\end{tabular}

Figure 25. Identified Categories for Exercise 3

Table 7. Sticky Notes Exercise 3: Summary of Answers

\begin{tabular}{|c|c|c|c|c|}
\hline Counter & $\begin{array}{c}\text { Public } \\
\text { Acceptance }\end{array}$ & $\begin{array}{l}\text { Technological } \\
\text { Capabilities }\end{array}$ & $\begin{array}{c}\text { Traffic } \\
\text { Management }\end{array}$ & $\begin{array}{l}\text { Enforcement } \\
\text { \& Policy }\end{array}$ \\
\hline 1 & Public Acceptance & Payload Limits & $\begin{array}{l}\text { UAS / Pilot Tracking } \\
\text { System }\end{array}$ & $\begin{array}{l}\text { Regulations that Can } \\
\text { Be Enforced }\end{array}$ \\
\hline 2 & $\begin{array}{l}\text { Establish Privacy } \\
\text { Policies }\end{array}$ & Technology & $\begin{array}{l}\text { Establish Reliable UTM } \\
\text { (Centralized) and Require } \\
\text { all Operators to Use }\end{array}$ & $\begin{array}{l}\text { Ability to Enforce } \\
\text { Regulations Locally }\end{array}$ \\
\hline 3 & $\begin{array}{l}\text { Solve Public Safety } \\
\text { UAS Use First }\end{array}$ & $\begin{array}{l}\text { Technology Has to Meet } \\
\text { Needs \& Efficiency }\end{array}$ & "No Fly" Zones \& Times & $\begin{array}{l}\text { Drone Modifications } \\
\text { Law }\end{array}$ \\
\hline 4 & $\begin{array}{l}\text { Minimum Liability } \\
\text { Insurance Premiums }\end{array}$ & & $\begin{array}{l}\text { Define Corridors/ } \\
\text { "Volumes" }\end{array}$ & \\
\hline 5 & Safety Advancements & & Auto Collision Avoidance & \\
\hline 6 & $\begin{array}{l}\text { Establish Safety } \\
\text { Requirements }\end{array}$ & & $\begin{array}{l}\text { Define Who is Using } \\
\text { Them, Why, and Where }\end{array}$ & \\
\hline 7 & & & Route Limitations & \\
\hline 8 & & & Hours of Operations & \\
\hline 9 & & & $\begin{array}{l}\text { Ability to Schedule the } \\
\text { Operations }\end{array}$ & \\
\hline 10 & & & $\begin{array}{l}\text { Electronic Flight } \\
\text { Notification }\end{array}$ & \\
\hline 11 & & & $\begin{array}{c}\text { Ability to Identify/Locate } \\
\text { Operations }\end{array}$ & \\
\hline 12 & & & Certification Based on Use & \\
\hline 13 & & & $\begin{array}{l}\text { Airspace Restrictions/ } \\
\text { Management Must } \\
\text { Be Clarified }\end{array}$ & \\
\hline Frequency & $6(24 \%)$ & $3(12 \%)$ & $13(52 \%)$ & $3(12 \%)$ \\
\hline
\end{tabular}


As gathered from Table 7, the majority of the answers (52\%) were clustered in the Traffic Management category, followed by concerns about public acceptance (24\%). Two participants were aware of the NASA UTM program, with one of them having experienced it as part of a user-study. The discussion revolved around the need for a high-level framework (such as the one provided by NASA UTM) to assign corridors of operation to specific users, track drones' routes and hours of operation, and provide the ability to schedule or book time and airspace at the convenience of the operator. All parties agreed that this could be done through a "virtual centralized hub" and that neither local legislation nor the state should be in charge of managing the "right to occupy the airspace" unless under emergency procedure in a situation that threatened the public safety (a conclusion that echoed that of debate 5, see last paragraph of the previous section). Finally, the timeline for fielding of UAS delivery, UTM, and future UAS applications was discussed, with some participants indicating the 5- to 10-year range, and others believing an even longer timeline should be expected. The participants had reservations about the technology's readiness level, while at the same time seeming to be unaware of recent efforts such as Airbus's Vahana (https://www.airbus-sv.com/projects/1), Kitty Hawk's Cora and Flyer (https://kittyhawk.aero/), and Uber's Uber Elevate and Uber Air programs (https://www. uber.com/us/en/elevate/). All agreed that these applications had never been discussed from the local legislation perspective and were not under the radar of current elected decision-makers. 


\section{CONCLUDING SUMMARY OF FINDINGS}

The survey and the focus group activities showed broadly agreeing trends and conclusions. The following list highlights some of the major takeaways from the results.

- While a plurality of the participants recognized that the technology and associated concerns are already here, the majority showed only moderate/little interest in overall regulation of UAS.

- While there is a perception among local-level government representatives that there is little regulatory power at the moment due to rapidly changing federal rules and guidelines, many local agencies recognize that UAS can accomplish objectives with available technology where humans are limited or safety risk is high.

- The prompted discussions during the focus group showed that the environment in which department personnel interact with operational UAS shape their perspectives on the specific nature of the threats and their interpretations of the technology's impacts on society. As a result, clarification is needed to define terms, such as "rogue operator," that may have different meanings across agency sectors. Due to the FAA's role in leading UAS integration, special attention is needed for terms that have traditional aviation use.

- The authors observed a defeatist attitude towards understanding the regulatory approach: there was convergence on the feeling, "why keep track of federal regulations if, by the time we decide to act, those will be changed again?"

- Many answers provided by survey takers and focus group participants pointed to the need for specialized training at the local level for both drone usage and the associated regulatory processes, with a primary question being how to enforce such a regulatory structure. In this regard, programs offered by the FAA such as LEAP (the Law Enforcement Assistance Program) show promise to steer federal-local cooperation in the right direction.

- The authors observed that participants urged stronger licensing requirements with the purpose of tracking users. Potential regulation of purchase permits was explored and brought forward by the focus group participants (especially the law enforcement representatives), who drew a parallel with gun control laws for their future vision of drone regulation.

- The results collected pointed to a general feeling of the current regulatory structure being "too cumbersome" for public operations such as search and rescue, law enforcement, and wildfire monitoring. Both survey responses and the focus group pointed to limited resources (on the financial and the labor side), which prevented them from acquiring the necessary expertise to draft Public Intent Declaration letters for a COA or to request specific waivers to deviate from Part 107. The general consensus was that ad-hoc regulations for "special use" by public entities should be drafted. 
- At this stage, discussions about drone technology at the local legislative level still happen sporadically and are limited in scope. Overall, a "reactive" attitude is preferred over a "proactive" one, with results from both the survey and the focus group showing that legislation will most likely be implemented only in response to problems as they arise. There was consensus among the focus group participants that this status quo will not change until there is a tangible disaster that motivates a reaction. Participants of the focus group mentioned a "once a year" frequency of UAV-related talks within their respective offices. Moreover, all such discussions revolved around public operations, while advanced technology applications such as drone deliveries or urban air mobility were regarded as a concern for a future time, about 5 to 10 years away.

- While the approach to overall regulation was labeled as "reactive," there were specific suggestions where a proactive attitude was maintained. Specifically, participants in law enforcement suggested the need to ensure adequate spaces across the region where users could meet to fly drones, as well as to exchange tips and best practices for operations. Participants from the focus group recognized that too many restrictions could have a counterproductive effect on users and could stimulate the increase of rogue operators. They believed that in order to increase the likelihood UAS operators would comply with any use location restrictions, as certain locations are restricted for use, alternative locations should be clearly identified so that operators can still meet their needs.

- Local agencies showed an inclination towards hiring third-party companies to fulfill their needs rather than reaching out to aviation professionals to acquire in-house expertise. Moreover, participants expressed their overall assessment that local agencies in California only had low-levels of awareness of the current UAS regulatory structures, again echoing a defeatist attitude towards the idea of "catching up" with the evolving regulatory landscape.

- With respect to use and preferred applications, law enforcement showed the highest rate of current use and drone availability, followed by fire emergency response, and road inspection. There was consensus that all the investigated applications could make good use of drone technology.

- In terms of regulatory restrictions, location restrictions (i.e., zoning) were observed to be the only current area of interest as well as the only current area for which local regulations are already in place. Respondents from the survey indicated that their main concern was related to public property other than open spaces. Furthermore, focus group participants mentioned the existence of private property laws for the State of California that could already apply to drones preventing fly-bys in such locations. 


\section{APPENDIX A: SURVEY QUESTIONS}

1. Please describe your jurisdiction:

City

County

Town

Other

2. What is the approximate population of your jurisdiction?

Less than 10,000

10,000 to 49,999

50,000 to 99,999

100,000 to 249,999

250,000 to 499,999

500,000 to 990,999

$1,000,000$ or more

Don't know

3. How would you describe the predominant development in your jurisdiction? Urban (includes city or town)

Rural

Suburban

Mix of rural and urban or suburban

Other

4. Is the use and regulation of drones a topic of interest in your office?

0 - Not at all

1- Minor interest

2- Moderate interest

3- Major interest

4- Exceptional interest

5. In how many years do you think the use of drones and regulation of this activity will become a relevant topic with resources allocated in your office?

- Already here

- Within the next year

- Within the next 2-3 years

- Within the next 5 years

- More than 5 years 
6. To the best of your knowledge, which departments in your jurisdiction have used, accessed, or considered using a drone?

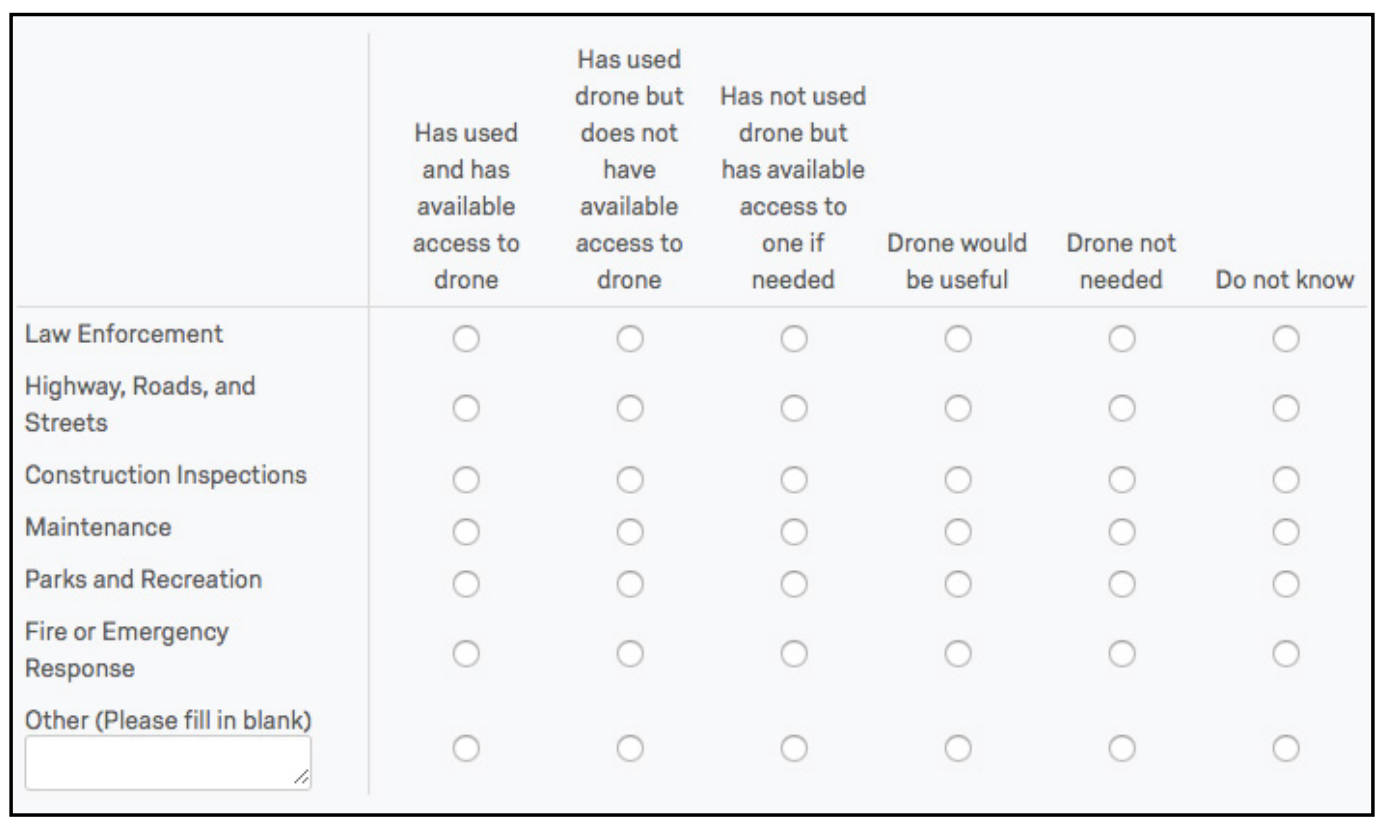

7. How do you rank the level of concern for each item listed below regarding drone use in your jurisdiction by either recreational or commercial operators?

\begin{tabular}{|l|ccccc|}
\hline & None at all & A little & $\begin{array}{c}\text { A moderate } \\
\text { amount }\end{array}$ & A lot & A great deal \\
\hline $\begin{array}{l}\text { Drones will threaten privacy } \\
\text { Drones will threaten safety }\end{array}$ & 0 & 0 & 0 & 0 & 0 \\
$\begin{array}{l}\text { Drones will threaten } \\
\text { property rights }\end{array}$ & 0 & 0 & 0 & 0 & 0 \\
$\begin{array}{l}\text { Drones will pollute the } \\
\text { environment } \\
\text { Other (Please fill in blank) }\end{array}$ & 0 & 0 & 0 & 0 & 0 \\
\hline
\end{tabular}


8. For each item listed below choose the appropriate category as it relates to UAS policy planning and operations for your office.

\begin{tabular}{|c|c|c|c|c|}
\hline & $\begin{array}{l}\text { Already } \\
\text { do }\end{array}$ & $\begin{array}{l}\text { Current plan } \\
\text { in place }\end{array}$ & $\begin{array}{l}\text { No current plan, but } \\
\text { likely in future }\end{array}$ & $\begin{array}{l}\text { Do not } \\
\text { foresee }\end{array}$ \\
\hline $\begin{array}{l}\text { The office will hire dedicated } \\
\text { aviation technical staff }\end{array}$ & 0 & 0 & 0 & 0 \\
\hline $\begin{array}{l}\text { The office will hire consultants as } \\
\text { needed }\end{array}$ & 0 & 0 & 0 & 0 \\
\hline $\begin{array}{l}\text { The office will take steps to } \\
\text { regulate drone operations within } \\
\text { local jurisdiction. }\end{array}$ & 0 & 0 & 0 & 0 \\
\hline $\begin{array}{l}\text { The office will have access to } \\
\text { drones and the required } \\
\text { technology }\end{array}$ & 0 & 0 & 0 & 0 \\
\hline $\begin{array}{l}\text { The office will hire third-party } \\
\text { companies for drones and the } \\
\text { required technology in the event } \\
\text { such equipment is needed. }\end{array}$ & 0 & 0 & 0 & 0 \\
\hline
\end{tabular}

9. Are you aware of the current federal aviation regulations (FAR) with regards to the use of drones?

- Yes fully aware and familiar with the content

- Yes, but it is hard to understand intricacies and applicability

- No, not aware

- Other (fill in the blank)

10. What is the expected framework for local legislation of drone use in the future? There is no need for local legislation since there are federal regulations for aircraft operations and air space

Local legislation would most likely be implemented in response to problems Local legislation would most likely be implemented proactively to avoid potential problems

Don't know 
11. Select the answer that best describes how you see your office involved in potential regulation of drones for each issue below?

\begin{tabular}{|c|c|c|c|c|}
\hline & Already do & $\begin{array}{l}\text { Current plan in } \\
\text { place }\end{array}$ & $\begin{array}{l}\text { No current plan, but } \\
\text { likely in future }\end{array}$ & Do not foresee \\
\hline $\begin{array}{l}\text { The office will work on } \\
\text { restricting locations where } \\
\text { drone use will be allowed } \\
\text { (e.g., no parks, no schools, } \\
\text { no corrective facilities). }\end{array}$ & 0 & 0 & 0 & 0 \\
\hline $\begin{array}{l}\text { The office will work on } \\
\text { restricting the types of } \\
\text { allowed drones (e.g. fixed- } \\
\text { wing or rotorcraft). }\end{array}$ & 0 & 0 & 0 & 0 \\
\hline $\begin{array}{l}\text { The office will work on } \\
\text { developing specialized } \\
\text { training for drone use. }\end{array}$ & 0 & 0 & 0 & 0 \\
\hline $\begin{array}{l}\text { The office will work on } \\
\text { developing a framework to } \\
\text { track drone routes/paths. }\end{array}$ & 0 & 0 & 0 & 0 \\
\hline $\begin{array}{l}\text { The office will work on } \\
\text { policies dictating drone } \\
\text { registration or other } \\
\text { ownership-tracking } \\
\text { systems. }\end{array}$ & 0 & 0 & 0 & 0 \\
\hline
\end{tabular}

12. Consider the following locations below and describe any expectations regarding local legislation or regulation to restrict drone use in your jurisdiction.

\begin{tabular}{|c|c|c|c|c|c|}
\hline & $\begin{array}{l}\text { Local legislation } \\
\text { exists }\end{array}$ & $\begin{array}{c}\text { Local legislation } \\
\text { not appropriate }\end{array}$ & $\begin{array}{l}\text { Local legislation } \\
\text { may be } \\
\text { appropriate, but } \\
\text { not necessary }\end{array}$ & $\begin{array}{l}\text { Local legislation } \\
\text { may be } \\
\text { necessary }\end{array}$ & Do not know \\
\hline $\begin{array}{l}\text { Restrict use on private } \\
\text { property }\end{array}$ & 0 & 0 & 0 & 0 & 0 \\
\hline $\begin{array}{l}\text { Restrict use on public } \\
\text { property other than open } \\
\text { spaces such as parks }\end{array}$ & 0 & 0 & 0 & 0 & 0 \\
\hline $\begin{array}{l}\text { Restrict use on open space } \\
\text { public property }\end{array}$ & 0 & 0 & 0 & 0 & 0 \\
\hline
\end{tabular}

13. What is the expected volume of drones that you foresee within your jurisdiction?

- Maybe an occasional recreational or commercial user, but nothing worth following

- Some, likely more recreational than commercial

- Some, likely more commercial than recreational

- A moderate amount of both recreational and commercial use

- A lot of drone activity, but not consistent

- A lot of drone activity nearly every day 
14. Please indicate the likelihood of the following options based on your current expectations

\begin{tabular}{|c|c|c|c|c|c|}
\hline & $\begin{array}{l}\text { Extremely } \\
\text { unlikely }\end{array}$ & $\begin{array}{c}\text { Somewhat } \\
\text { unlikely }\end{array}$ & $\begin{array}{c}\text { Neither likely } \\
\text { nor unlikely }\end{array}$ & $\begin{array}{l}\text { Somewhat } \\
\text { likely }\end{array}$ & Extremely likely \\
\hline $\begin{array}{l}\text { The first use that will } \\
\text { require local jurisdiction } \\
\text { regulation will be the } \\
\text { recreational use by private } \\
\text { citizens }\end{array}$ & 0 & O & 0 & 0 & O \\
\hline $\begin{array}{l}\text { The first use that will } \\
\text { require local jurisdiction } \\
\text { regulation will be the } \\
\text { commercial use by private } \\
\text { entities (e.g. business for } \\
\text { real estate, agricultural use, } \\
\text { mapping ad scanning } \\
\text { services, delivery) }\end{array}$ & 0 & 0 & 0 & 0 & O \\
\hline $\begin{array}{l}\text { Regulations will be } \\
\text { developed for each use } \\
\text { separately (recreational vs } \\
\text { public service vs } \\
\text { commercial) }\end{array}$ & O & 0 & 0 & 0 & 0 \\
\hline $\begin{array}{l}\text { Regulations will be } \\
\text { developed for all three uses } \\
\text { concurrently (recreational, } \\
\text { public service, commercial) }\end{array}$ & O & O & 0 & 0 & O \\
\hline $\begin{array}{l}\text { Regulations will be } \\
\text { developed for one use only } \\
\text { and then later on modified } \\
\text { for the other ones }\end{array}$ & 0 & 0 & 0 & 0 & 0 \\
\hline
\end{tabular}

15. Please indicate the likelihood of the following options based on your current expectations

\begin{tabular}{|c|c|c|c|c|c|}
\hline & Extremely likely & $\begin{array}{l}\text { Somewhat } \\
\text { likely }\end{array}$ & $\begin{array}{c}\text { Neither likely } \\
\text { nor unlikely }\end{array}$ & $\begin{array}{l}\text { Somewhat } \\
\text { unlikely }\end{array}$ & $\begin{array}{c}\text { Extremely } \\
\text { unlikely }\end{array}$ \\
\hline $\begin{array}{l}\text { The use of drones for } \\
\text { delivery purposes will be } \\
\text { relevant in your jurisdiction } \\
\text { within the next } 5 \text { years }\end{array}$ & 0 & 0 & 0 & 0 & 0 \\
\hline $\begin{array}{l}\text { The use of drones for } \\
\text { delivery purposes will be } \\
\text { relevant in your jurisdiction } \\
\text { within the next } 10 \text { years }\end{array}$ & 0 & O & O & 0 & 0 \\
\hline $\begin{array}{l}\text { The use of drones for urban } \\
\text { Air Mobility (e.g. air-taxis) } \\
\text { will be relevant in your } \\
\text { jurisdiction within the next } \\
10 \text { years }\end{array}$ & 0 & 0 & 0 & 0 & 0 \\
\hline
\end{tabular}

16. Please provide any additional comments related to regulation of drones within your jurisdiction that were not addressed above. 


\section{APPENDIX B: FOCUS GROUP HANDOUT}

\section{Local Government Policy and Planning for Unmanned Aerial Systems}

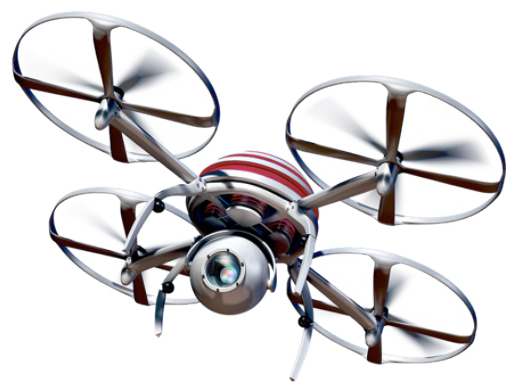

\section{PARTICIPANTS' HANDOUT}

Please refer to the following handout to follow with the active sessions of debates and discussion throughout the workshop.

\section{CONTACT INFORMATION:}

Prof. Tyler Spence

tyler.spence@sjsu.edu

408-924-3973

Department of Aviation and Technology

One Washington Square, San José

CA, 92192
Prof. Francesca Favaro

francesca.favaro@sjsu.edu

408-924-3215

Department of Aviation and Technology

One Washington Square, San José CA, 92192 


\section{Survey Results and Discussion}

Frequency of Discussion related to drone usage and regulation

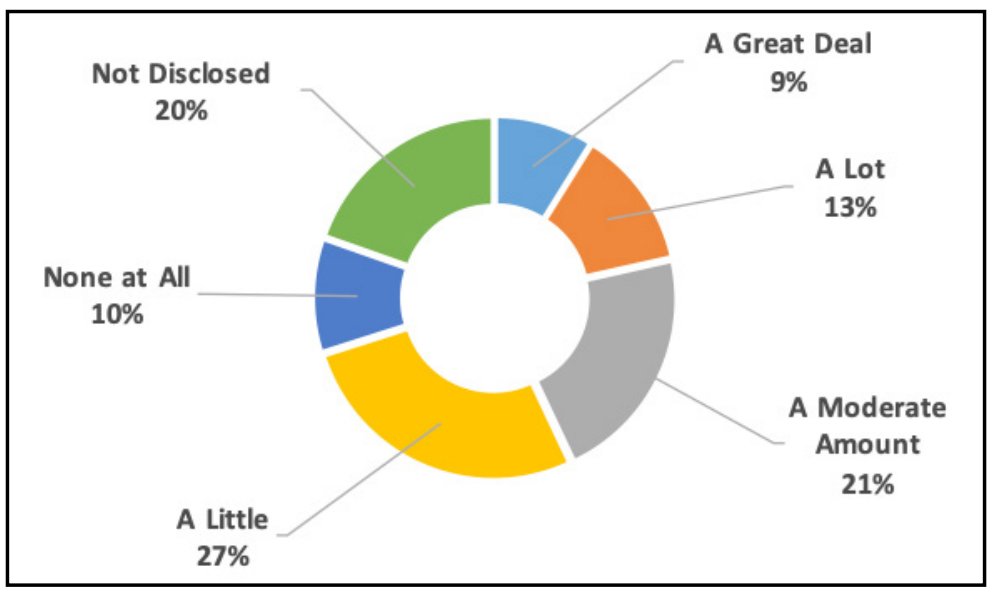

\section{Expected Time-Horizon}

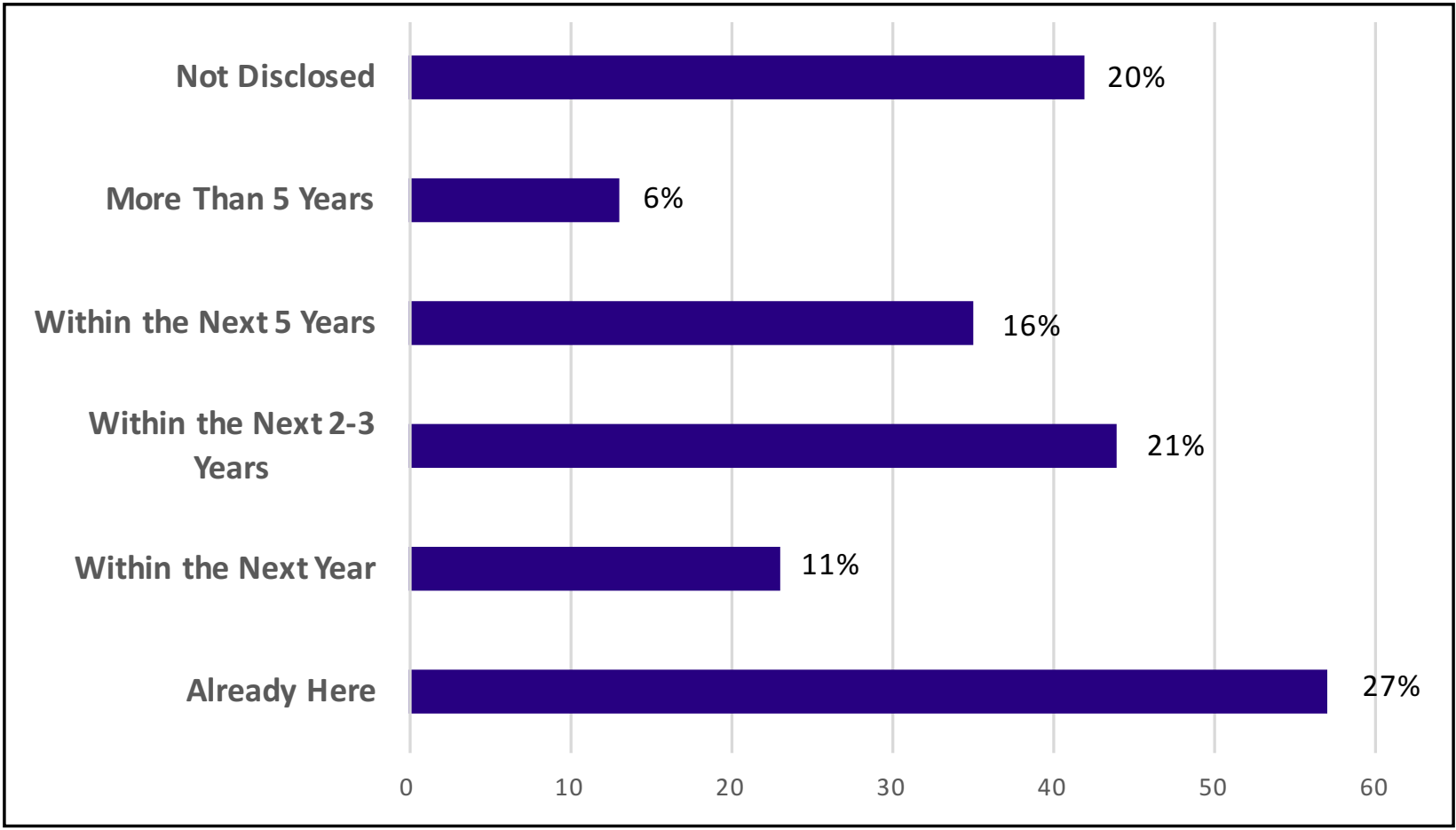

Question: How often does your jurisdiction discuss the topic of UAS?

Question: Are they planning legislation within the near future?

Question: What are the greatest impediments/obstacles you face when trying to convey your position to your local legislator? 


\section{UAS Usage}

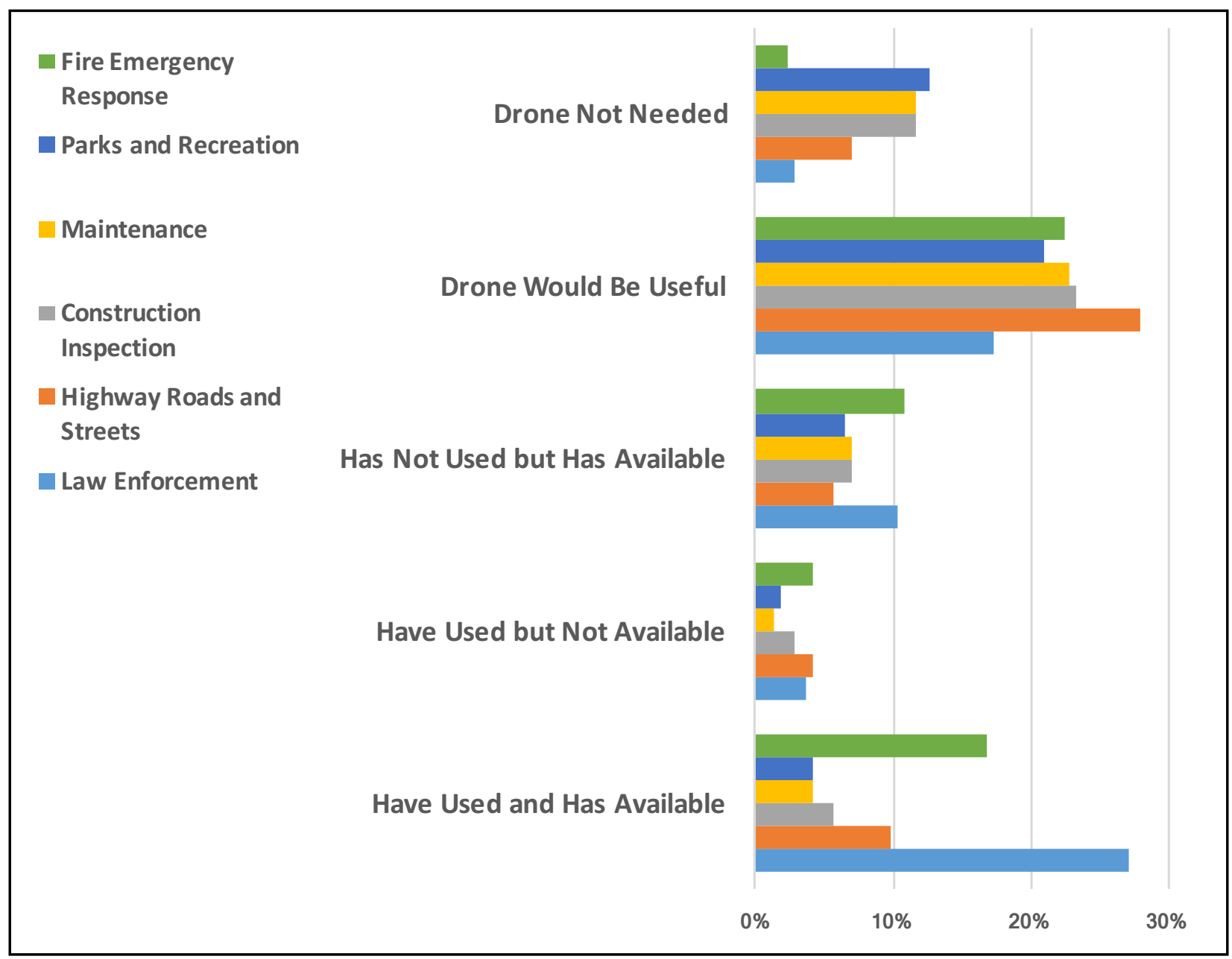

Question: Does your jurisdiction see a need/receives requests to have drones for these departments?

Question: If you used them, what type of drones do you use?

Question: Is it easy to get access? What are challenges? Do you need to convince a superior that the drone is needed?

Question: With which agencies do you need to coordinate when running a drone operation? How is that handled? 


\section{Perceived Threats}

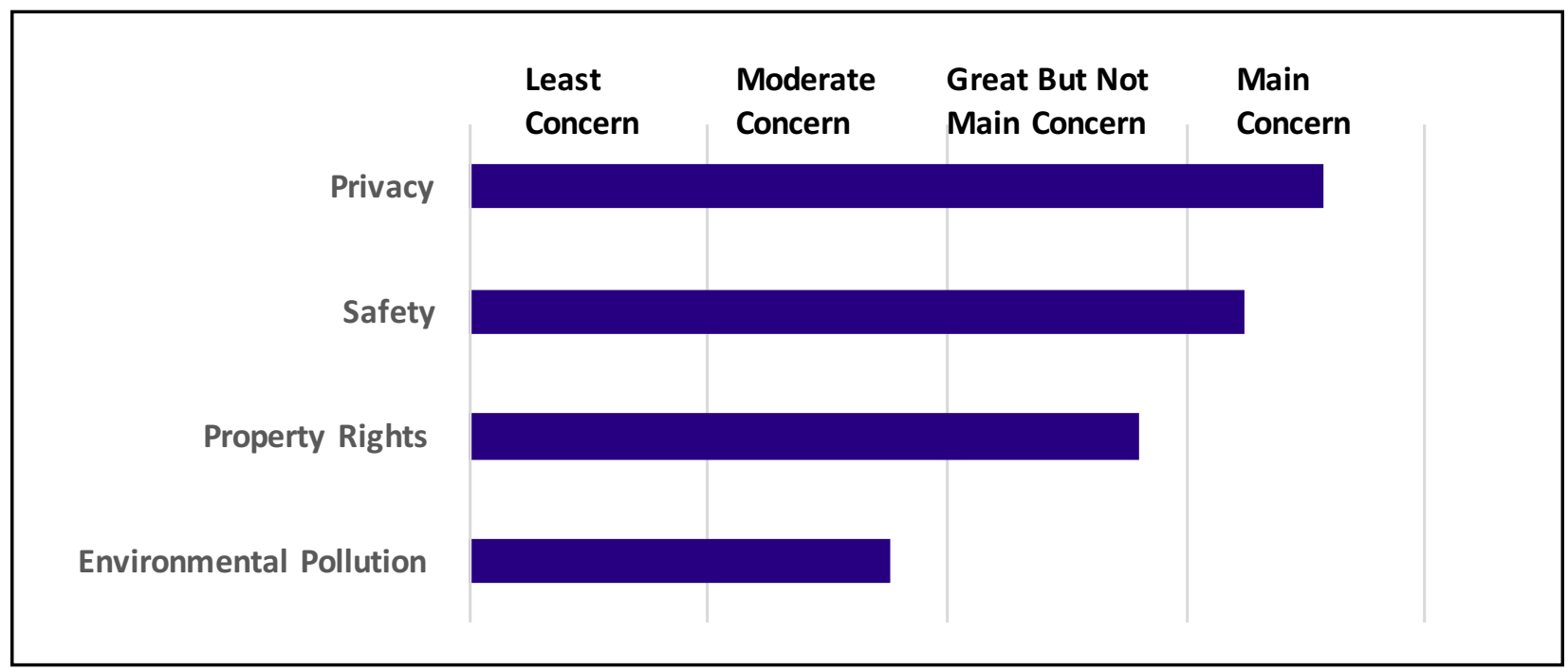

Question: Are those the major concerns you see raised against the use of these technology?

\section{Federal Regulation Awareness}

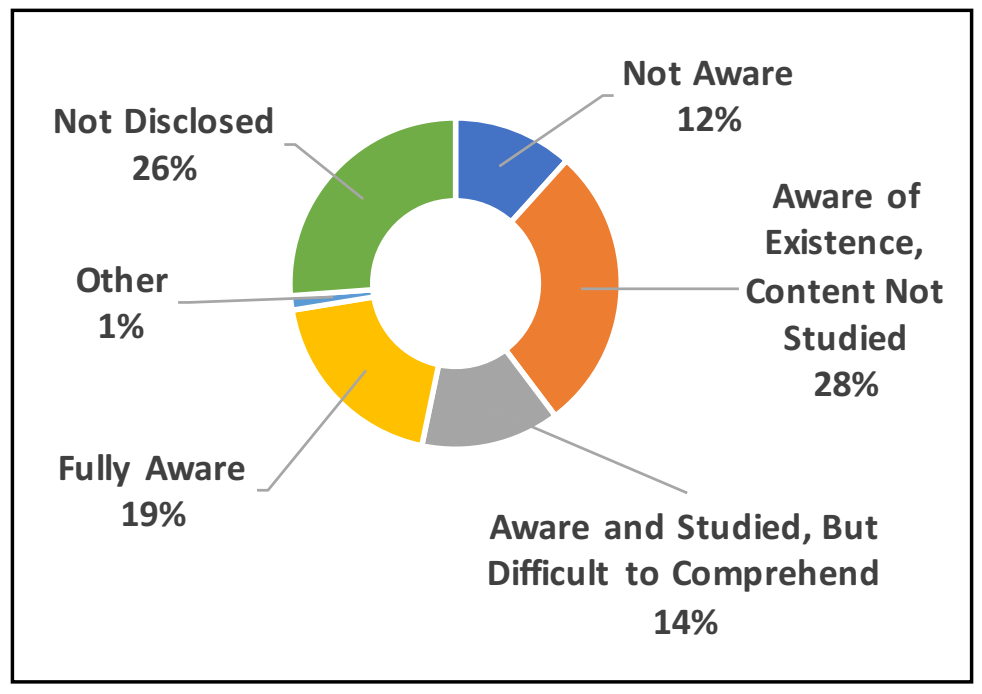

Question: What would help you? 
Current and Foreseen Regulatory Aspects: restrictions and tracking

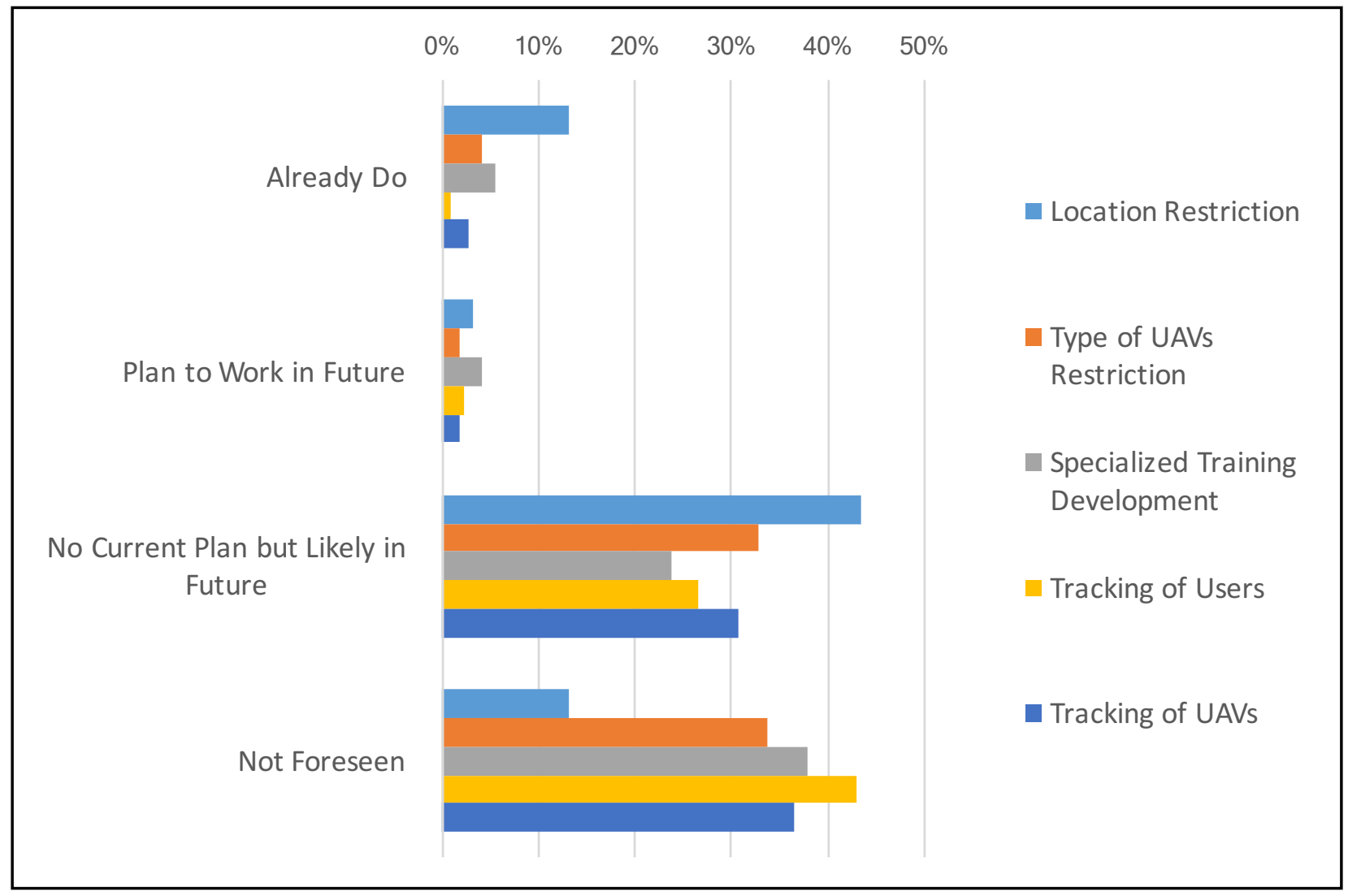

Question: Are there other regulatory aspects that you are interested in?

Restrictions: detail

Public Property Other than Open Space

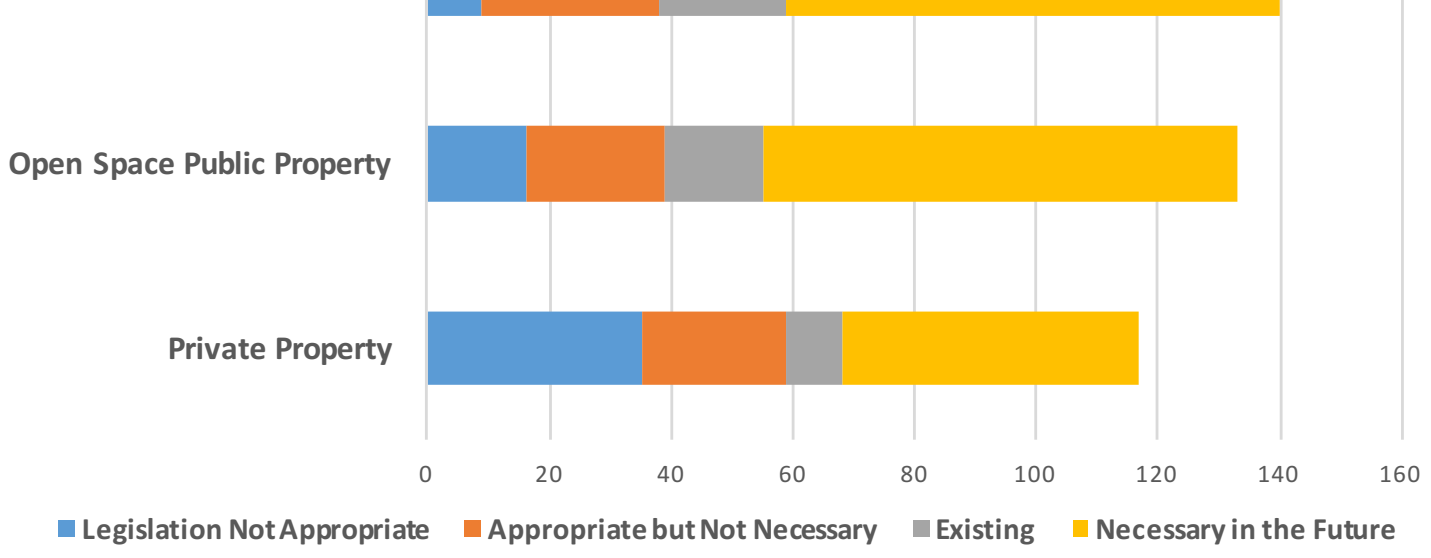

Question: Do you think some legislation is necessary in different types of properties? Do you have examples that sway your ideas otherwise? 
Expected Traffic Volume: recreational and commercial use

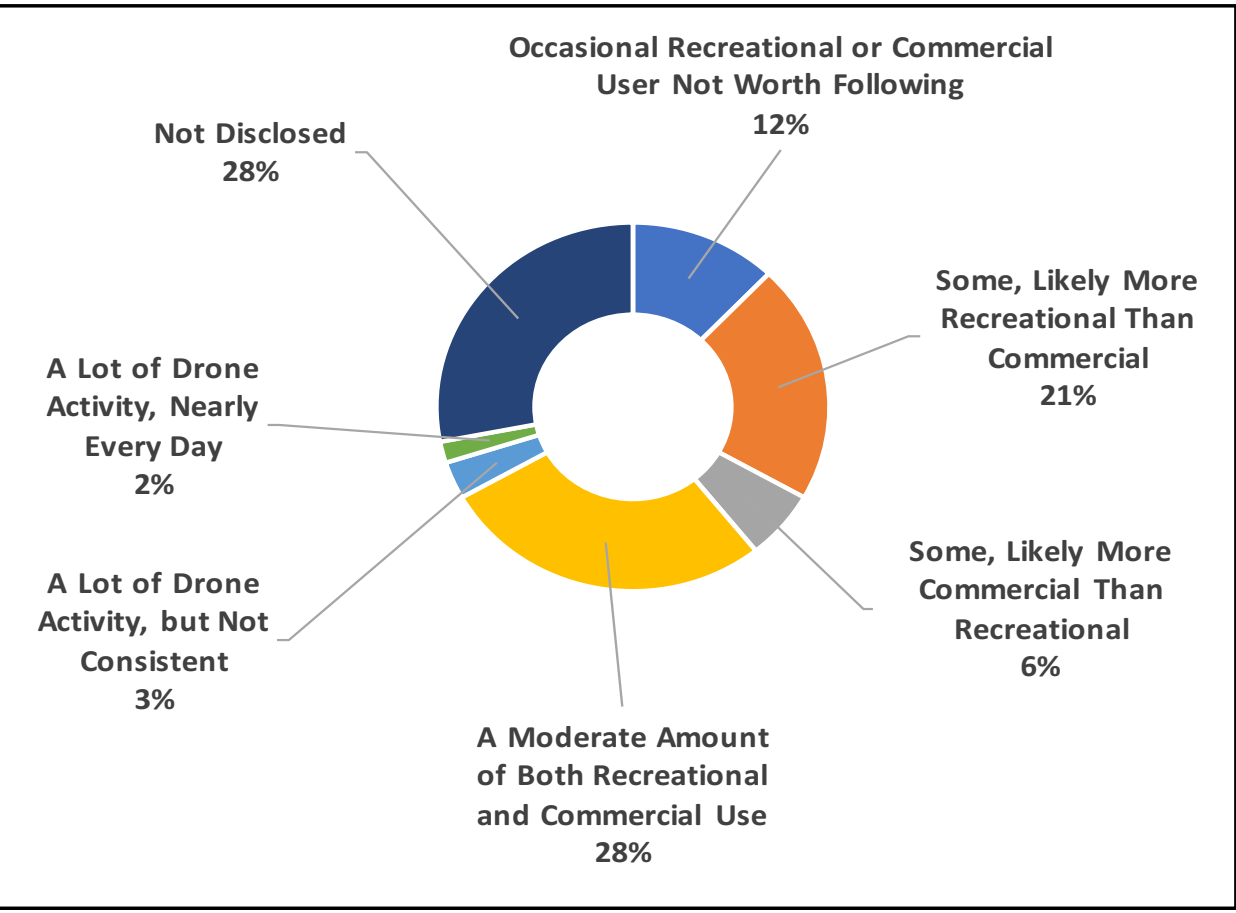

Question: Do you expect a similar trend?

Question: Have you seen an increase of drone use in your jurisdiction? In which sector?

Drone Delivery: comparing 5- to 10-year time horizons

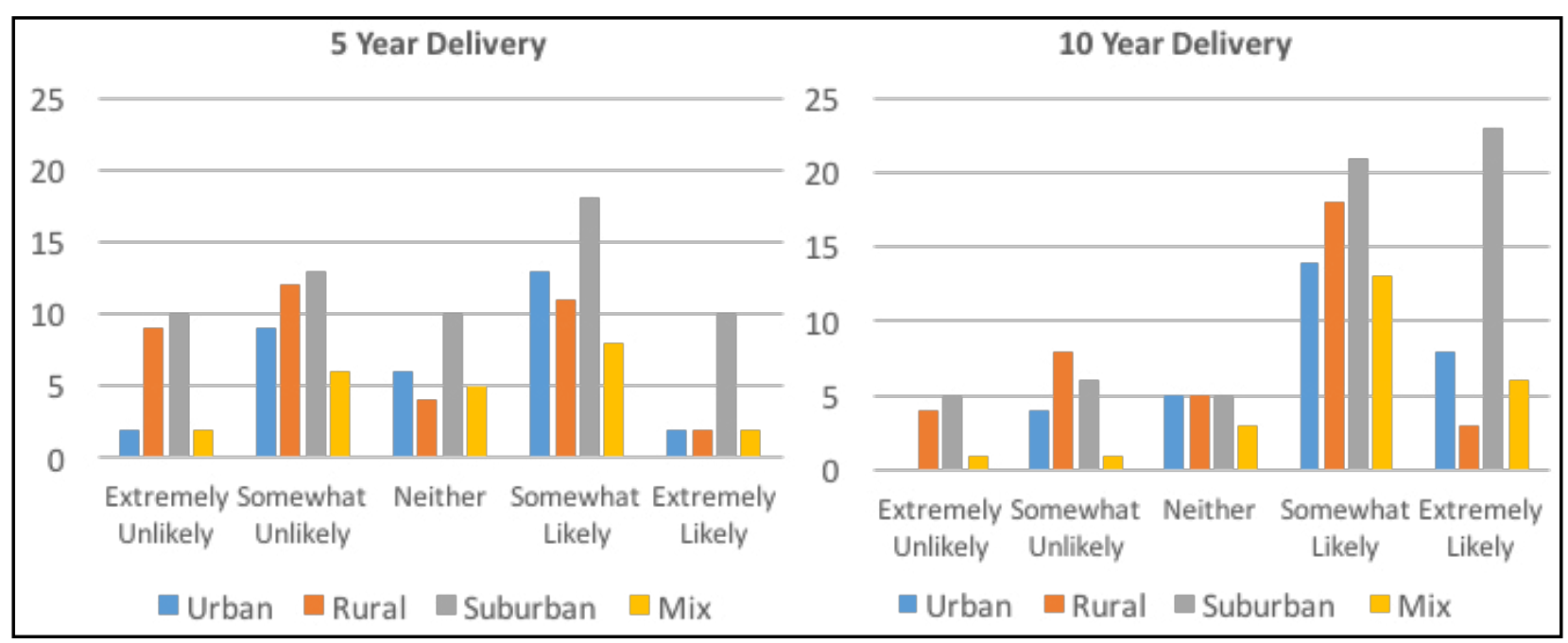

Question: What are your expectations for future drone uses? 


\section{Debate Sessions}

\section{General Debate:}

What Should Local Legislations Be Allowed to Do? Should Local Governments Have More Power Over UAV Regulation or Less?

\section{Apples and Oranges:}

Goods delivery, law enforcement/emergency response, and urban air mobility. Are those similar applications or would they require different regulatory structures? Does it go by size also?

\section{Public Insurance:}

Try to imagine a mission scenario, or use case, of operations relevant to you. How does personal insurance come into play if something goes wrong? Would you want local jurisdictions to provide an "umbrella-type" of insurance for all UAS operations? Do you have concerns for liability?

\section{Dealing with Rogue Operators:}

Would you want a specific entity to be set up at the local level to deal with rogue operators? What is the role that you would expect from the FAA in those situations (i.e., would you suggest a reporting system)?

\section{Exclusivity of Airspace:}

Try to imagine a mission scenario, or use case, of operations relevant to you. Would you need exclusivity of the airspace? Would you be willing to share airspace? Would you want control of the airspace or someone else in control? 


\section{ABBREVIATIONS AND ACRONYMS}

\begin{tabular}{ll}
\hline CHP & California Highway Patrol \\
COA & Certificate of Authorization \\
COW & Certificate of Waiver \\
DoT & Department of Transportation \\
FAA & Federal Aviation Administration \\
FAR & Federal Aviation Regulations \\
MTI & Mineta Transportation Institute \\
NASA & National Aeronautics and Space Administration \\
NAS & National Airspace System \\
SAP & Stakeholder Analysis Process \\
UAS & Unmanned Aircraft System \\
UAV & Unmanned Aircraft Vehicle \\
UTM & UAV Traffic Management \\
\hline
\end{tabular}




\section{ENDNOTES}

1. Federal Aviation Administration, "Unmanned Aerial System Traffic Management Concept of Operations (v1.0)(UTM CONOPS)", May 18, 2018, https://utm.arc.nasa. gov/docs/2018-UTM-ConOps-v1.0.pdf; Schaufele, Roger, Li Ding, Nick Miller, H. Anna Barlett, Michael Lukacs, and Disais Bhadra, "FAA Aerospace Forecast, Fiscal Years 2017-2037," 2017 (accessed October 11, 2019), https://www.faa.gov/data_research/ aviation/aerospace_forecasts/media/FY2017-37_FAA_Aerospace_Forecast.pdf.

2. DroneDeploy, "2018 Commercial Drone Industry Trends," 30 May 2018 (accessed October 10, 2019), https://dronedeploy-www.cdn.prismic.io/dronedeploywww\%2Fae535fda-dfc9-4bcf-9743-292df714e9fe_dd_2018_trends_report-f.pdf.

3. Global Market Insight, "UAV survey," May 2018 (accessed August 30, 2019), www. gminsights.com/industry-analysis/unmanned-aerial-vehicles-UAV-commercial-dronemarket.pdf.

4. Federal Aviation Administration, "Unmanned Aerial System Traffic Management Concept of Operations (v1.0)(UTM CONOPS)", May 18, 2018, https://utm.arc.nasa. gov/docs/2018-UTM-ConOps-v1.0.pdf

5. International Civil Aviation Organization, Safety Audit Results: USOAP Interactive Viewer (accessed October 11, 2019), https://www.icao.int/safety/pages/UsoapResults.aspx; Jansen, B. (2016, February 15), "2015 one of safest on record for airliners," USA Today, http://www.usatoday.com/story/news/2016/02/15/2015another-safe-year-airliners/80398194/.

6. Wallace, Ryan J., Kristy M. Kiernan, Tom Haritos, John Robbins, and Jon M. Loffi, "Evaluating Small UAS Operations and National Airspace System Interference Using AeroScope," Journal of Aviation Technology and Engineering 8 (May 2019), https:// doi.org/10.7771/2159-6670.1189; Flight Safety Foundation, "FAA Warns against Drone Interference with Firefighting," August 16, 2018 (accessed October 11, 2019), https://flightsafety.org/drone-interference/.

7. National Public Radio, interview by Tess Vigeland, "All Things Considered Radio Show," August 23, 2015 (accessed October 11, 2019), https://www.npr. org/2015/08/23/434088544/as-traffic-clots-the-skyways-officials-seek-ways-to-copewith-drones; Federal Aviation Administration, "Fact Sheet-International Aviation", July 30, 2018 (accessed October 11, 2019), https://www.faa.gov/news/fact_sheets/news_ story.cfm?newsld=22694.

8. Hume, Tim and Allen Greene, "Investigations launched after suspected drone strikes passenger jet in London”, April 18, 2016 (accessed August 15, 2019), http://www. cnn.com/2016/04/17/europe/london-heathrow-drone-strikes-plane/; Villeda, Ray, "4 Commercial planes report drone encounters at Newark airport," August 9, 2015 (accessed August 15, 2019), http://www.nbcnewyork.com/news/local/Drone-CrossesPath-of-Aircraft-at-Newark-Airport-Authorities-321181931.html. 
9. United States Government Accountability Office, "Unmanned Aircraft Systems—Issue Summary," no date (accessed October 11, 2019), https://www.gao.gov/key_issues/ unmanned_aerial_systems/issue_summary; Loffi, Jon M., Ryan J. Wallace, Jamey D. Jacob, and Jared C. Dunlap, "Seeing the Threat: Pilot Visual Detection of Small Unmanned Aircraft Systems in Visual Meteorological Conditions," International Journal of Aviation, Aeronautics, and Aerospace 3, https://commons.erau.edu/ijaaa/ vol3/iss3/13.

10. Government Accountability Office, "Small unmanned aircraft systems: FAA should improve its management of safety risks" (GAO-18-110), May 2018 (accessed August 31, 2019), https://www.gao.gov/assets/700/692010.pdf.

11. Rosenkarans, Wayne, "High Expectations," Flight Safety Foundation, May 31, 2017 (accessed August 31, 2019), https://flightsafety.org/asw-article/high-expectations/.

12. Neubaure, Kenneth, David Fleet, Filippo Grosoli, and Harry Verstynen, "Unmanned aircraft systems (UAS) at airports: A primer" (ACRP Report 144), Airport Cooperative Research Program, 2015, Washington, D.C.: Transportation Research Board.

13. Zickuhr, Kathryn, Elias Stahl, and Nicole DuPuis, Cities and Drones, What Cities Need to Know about Unmanned Aerial Vehicles (UAVs), National League of Cities Center for City Solutions and Applied Research, 2016 (accessed January 23, 2019), http:// uavs.insct.org/wp-content/uploads/2016/09/NLC-Drone-Report.pdf.

14. Flight Safety Foundation, "FAA Warns against Drone Interference with Firefighting," August 16, 2018 (accessed October 11, 2019), https://flightsafety.org/droneinterference/.

15. Restricted Entry and Minimum Tool Use-State Wilderness, Cultural Preserves, and Natural Preserves, California Code of Regulations Title 14, § 4351, no date (accessed October 10, 2019), http://www.parks.ca.gov/pages/1324/files/trail\%20use\%20 designation\%20and\%20minimum\%20tool\%20use_ccr_final_text_\%202-3-15.pdf.

16. Federal AviationAdministration, "Federal Aviation Regulation FAR Part 107-Operation and Certification of Small Unmanned Aerial Systems," no date (accessed October 9, 2019), https://www.faa.gov/uas/media/RIN_2120-AJ60_Clean_Signed.pdf.

17. Federal Aviation Administration, "Archive of granted Part 107 waivers," (accessed October 11, 2019), https://www.faa.gov/uas/request_waiver/waivers_granted/.

18. Federal Aviation Administration, Law Enforcement Guidance for Suspected Unauthorized UAS Operations," no date (accessed October 11, 2019), https://www. faa.gov/uas/resources/policy_library/media/FAA_UAS-PO_LEA_Guidance.pdf.

19. Diehl, Phil, "Police Using 'Drone Killers' to Disable Flying Devices in Emergency Situations," April 7, 2018 (accessed October 13, 2019), http://www.latimes.com/local/ lanow/la-me-drone-killers-20180407-story.html. 
20. May, Patrick, "Firefighters say drones interfered with theirwork—one pilot cited," October 16, 2017 (accessed October 7, 2019), https://www.mercurynews.com/2017/10/16/ firefighters-say-drones-interfered-with-their-work-one-pilot-arrested/.

21. Goglia, John, "Federal Judge Overturns City Drone Ordinance in First Ruling of its Kind," September 21, 2017 (accessed October 12, 2019), https://www.forbes.com/ sites/johngoglia/2017/09/21/federal-judge-overturns-city-drone-ordinance-in-firstruling-of-its-kind/.

22. Federal Aviation Administration, "State and Local Regulation of Unmanned Aircraft Systems Fact Sheet," December, 2015 (accessed August 30, 2019), https://www.faa. gov/uas/resources/policy_library/media/UAS_Fact_Sheet_Final.pdf.

23. Neubaure, Kenneth, David Fleet, Filippo Grosoli, and Harry Verstynen, "Unmanned aircraft systems (UAS) at airports: A primer" (ACRP Report 144), Airport Cooperative Research Program, 2015, Washington, D.C.: Transportation Research Board. P.1

24. Pathiyil, Lakshmi, L.H. low, Boon Hai Soon, and Shixin Mao, "Enabling Safe Operations of Unmanned Aircraft Systems in an Urban Environment: A Preliminary Study," in The International Symposium on Enhanced Solutions for Aircraft and Vehicle Surveillance Applications (ESAVS 2016), 2016.

25. Rice, Stephen, "Eyes in the Sky: The Public has Privacy Concerns about Drones," February 4, 2019 (accessed October 11, 2019), https://www.forbes.com/sites/ stephenrice1/2019/02/04/eyes-in-the-sky-the-public-has-privacy-concerns-aboutdrones/\#28ee6ca36984.

26. Rice, Stephen, "Eyes in the Sky: The Public has Privacy Concerns about Drones," February 4, 2019 (accessed October 11, 2019), https://www.forbes.com/sites/ stephenrice1/2019/02/04/eyes-in-the-sky-the-public-has-privacy-concerns-aboutdrones/\#28ee6ca36984; Jeffries, Robb, "Fourth Amendment Concerns Raised at Unmanned Aircraft Summit," McClatchy-Tribune Business News, June 1, 2013 (accessed October 11, 2019), https://www.grandforksherald.com/news/2194032fourth-amendment-concerns-raised-unmanned-aircraft-summit.

27. National Conference of State Legislatures, "Current Unmanned Aircraft State Law Landscape" May 22, 2015 (accessed October 11, 2019), http://www.ncsl.org/research/ transportation/current-unmanned-aircraft-state-law-landscape.aspx.

28. Blank, Peter, Sabrina Kirrane, and Sarah Spikerman, "Privacy-Aware Restricted Areas for Unmanned Aerial Systems," IEEE Security \& Privacy 16 (March-April 2018): 70 79.

29. Evangelista, Benny, "SF city agency halts use of drones amid concerns over China," December 2, 2017 (accessed October 13, 2019), https://www.sfchronicle. com/business/article/San-Francisco-city-agency-halts-use-of-drones-12399504. php; Shortell, David, 'DHS Warns of 'Strong Concerns' that Chinese-Made Drones 
are Stealing Data, May 20, 2019 (accessed October 11, 2019), https://www.cnn. com/2019/05/20/politics/dhs-chinese-drone-warning/index.html.

30. CBS13, "Why Is A Government Drone Flying Over A Sacramento Neighborhood?" May 16, 2018 (accessed October 13, 2019), https://sacramento.cbslocal.com/2018/05/16/ government-drones-neighborhood/.

31. Giaritelli, Anna, "Drones Swamp US-Mexico Border but Federal Agents Powerless to Stop Them," October 17, 2018 (accessed October 11, 2019), https://www. washingtonexaminer.com/news/drones-swamp-us-mexico-border-but-federalagents-powerless-to-stop-them.

32. Nguyen, Chris, "No Drone Zone' Campaign Launches in Santa Clara County." September 13, 2018 (accessed October 12, 2019), https://abc7news.com/no-dronezone-campaign-launches-in-santa-clara-co/4236940/.

33. Klauser, Francisco, and Silvana Pedrozo, "Big Data from the Sky: Popular perception of private drones in Switzerland," Institut de Géographie, June 2017; West, Jonathan P., Casey A. Klofstad, Joseph E. Uscinski, and Jennifer M. Connolly, "Citizen Support for Domestic Drone Use and Regulation," American Politics Research 47 (2019): 1-33, doi: 10.1177/1532673X18782208.

34. Klauser 2017 “Big Data.'

35. Connelly 2018 "Citizen Support."

36. Olivito, Jonathan, "Beyond the Fourth Amendment: Limiting Drone Surveillance Through the Constitutional Right to Informational Privacy," Ohio State Law Journal 74 (2013): 670-702.

37. Jenkins, Ben, "Watching the Watchmen: Drone Privacy and the Need for Oversight," Kentucky Law Journal 102 (2013): 160-182, https://uknowledge.uky.edu/klj/vol102/ iss $1 / 8$ (accessed October 13, 2019).

38. Jenkins, Ben, "Watching the Watchmen: Drone Privacy and the Need for Oversight," Kentucky Law Journal 102 (2013): 160-182, https://uknowledge.uky.edu/klj/vol102/ iss $1 / 8$ (accessed October 13, 2019).

39. Olivito, Jonathan, "Beyond the Fourth Amendment: Limiting Drone Surveillance Through the Constitutional Right to Informational Privacy," Ohio State Law Journal 74 (2013): 670-702.

40. West, Jonathan P., Casey A. Klofstad, Joseph E. Uscinski, and Jennifer M. Connolly, "Citizen Support for Domestic Drone Use and Regulation," American Politics Research 47; Olivito, Jonathan, "Beyond the Fourth Amendment: Limiting Drone Surveillance Through the Constitutional Right to Informational Privacy," Ohio State Law Journal 74 (2013): 670-702. 
41. Winter, Scott, Stephen Rice, Gajapriya Tamilselvan, and Rusell Tokarski, "Mission -Based Citizen Vies on UAV Usage and Privacy: An Affective Perspective," Journal of Unmanned Vehicle Systems 4 (2016): 125-135.

42. Cavoukain, Ann, "Privacy and Drones: Unmanned Aerial Vehicles," Information and Privacy Commissioner, August 2012 (accessed October 11, 2019), www. privacybydesign.ca; Olivito, Jonathan, "Beyond the Fourth Amendment: Limiting Drone Surveillance Through the Constitutional Right to Informational Privacy," Ohio State Law Journal 74 (2013): 670-702.

43. Clarridge, Christine, "Protesters Steal the Show at Seattle Police Gathering to Explain Intended Uses of Drones," Seattle Times, October 25, 2012 (accessed October 11, 2019), https://www.seattletimes.com/seattle-news/protesters-steal-the-showat-seattle-police-gathering-to-explain-intended-use-of-drones/; Granda, Carlos, "Protesters Opposed to LAPDs Use of Drones Disrupt Contention Police Commission Meeting," KABC, July 10, 2019 (accessed October 11, 2019), https://abc7.com/ protesters-opposed-to-lapds-use-of-drones-disrupt-meeting/5386310/.

44. Jenkins, Ben, "Watching the Watchmen: Drone Privacy and the Need for Oversight," Kentucky Law Journal 102 (2013): 160-182, https://uknowledge.uky.edu/klj/vol102/ iss1/8 (accessed October 13, 2019).

45. Olivito, Jonathan, "Beyond the Fourth Amendment: Limiting Drone Surveillance Through the Constitutional Right to Informational Privacy," Ohio State Law Journal 74 (2013): 670-702.

46. Sabatini, Joshua, "SF Ushering in a New Era with Drone Use by City Departments," San Francisco Examiner, May 4, 2017 (accessed October 8, 2019), https://www. sfexaminer.com/news/sf-ushering-in-new-era-with-drone-use-by-city-departments/; Cavoukain, Ann, "Privacy and Drones: Unmanned Aerial Vehicles," Information and Privacy Commissioner, August 2012 (accessed October 11, 2019), www. privacybydesign.ca.

47. Olivito, Jonathan, "Beyond the Fourth Amendment: Limiting Drone Surveillance Through the Constitutional Right to Informational Privacy," Ohio State Law Journal 74 (2013): 670-702.

48. Academy of Model Aeronautics, "AMA Government Relations Blog," January 18, 2016 (accessed October 12, 2019), https://amablog.modelaircraft.org/amagov/2016/01/18/ faa-advocacy-meeting-january-15-and-16/.

49. Olivito, Jonathan, "Beyond the Fourth Amendment: Limiting Drone Surveillance Through the Constitutional Right to Informational Privacy," Ohio State Law Journal 74 (2013): 670-702.

50. Federal Aviation Administration, "UAS by the Numbers," October 7, 2019 (accessed October 12, 2019), https://www.faa.gov/uas/resources/by_the_numbers/; Markowitz, 
Ezra M., Matthew C. Nisbet, Andy J. Danylchuk, Seth I. Engelbourg, "What's That Buzzing Noise? Public Opinion on the Use of Drones for Conservation Science, BioScience 67 (2017): 382-385, https://doi.org/10.1093/biosci/bix003; Academy of Model Aeronautics, "AMA Government Relations Blog," January 18, 2016 (accessed October 12, 2019), https://amablog.modelaircraft.org/amagov/2016/01/18/faaadvocacy-meeting-january-15-and-16/.

51. Markowitz, Ezra M., Matthew C. Nisbet, Andy J. Danylchuk, Seth I. Engelbourg, "What's That Buzzing Noise? Public Opinion on the Use of Drones for Conservation Science, BioScience 67 (2017): 382-385, https://doi.org/10.1093/biosci/bix003.

52. Nelson, Jake R., Tony H. Grubesic, Danielle Wallace, and Alyssa W. Chamberlain, "The View from Above: A Survey of the Public's Perception of Unmanned Aerial Vehicles," Journal of Urban Technology 26 (2017), doi: https://doi.org/10.1080/10630732.2018. 1551106; Marte, Daniel, A., Nathan Walters, Mattie Milner, Emily C. Anania, Stephen Rice, and Scott Winter, "Privacy Concerns about UAS Missions," Poster presented at Embry Riddle Aeronautical University Discovery Day 2018 (Daytona Beach, FL), April 10, 2018 (accessed October 12, 2019), https://commons.erau.edu/cgi/viewcontent.cg i?article=1249\&context=discovery-day; Rice, Stephen, "Eyes in the Sky: The Public has Privacy Concerns about Drones," February 4, 2019 (accessed October 11, 2019), https://www.forbes.com/sites/stephenrice1/2019/02/04/eyes-in-the-sky-the-publichas-privacy-concerns-about-drones/\#28ee6ca36984; Markowitz, Ezra M., Matthew C. Nisbet, Andy J. Danylchuk, Seth I. Engelbourg, "What's That Buzzing Noise? Public Opinion on the Use of Drones for Conservation Science, BioScience 67 (2017): 382-385, https://doi.org/10.1093/biosci/bix003.

53. UAV Coach, "Master List of Drone Laws (Organized by State \& Country)," 2019 (accessed October 11, 2019), https://uavcoach.com/drone-laws/.

54. Martinez, Kennedy, "Drone Laws in California," Dronethusiast, 2018 (accessed October 12, 2019), https://www.dronethusiast.com/california-drone-laws/.

55. UAV Coach, "Drone Laws in California (2019)," UAV Coach, 2019 (accessed October 12, 2019), https://uavcoach.com/drone-laws-california/.

56. UAV Coach, "Master List of Drone Laws (Organized by State \& Country)," 2019 (accessed October 11, 2019), https://uavcoach.com/drone-laws/.

57. UAV Coach, "Master List of Drone Laws (Organized by State \& Country)," 2019 (accessed October 11, 2019), https://uavcoach.com/drone-laws/.

58. Halstead, Richard, "Marin County, Calif., Explores Potential for Drone Program," Government Technology, July 16, 2018 (accessed October 13, 2019), https:// www.govtech.com/public-safety/Marin-County-Calif-Explores-Potential-for-DroneProgram.html. 
59. West, Jonathan P., Casey A. Klofstad, Joseph E. Uscinski, and Jennifer M. Connolly, "Citizen Support for Domestic Drone Use and Regulation," American Politics Research 47 (2019): 1-33, doi: 10.1177/1532673X18782208; Jenkins, Ben, "Watching the Watchmen: Drone Privacy and the Need for Oversight," Kentucky Law Journal 102 (2013): 160-182, https://uknowledge.uky.edu/klj/vol102/iss1/8 (accessed October 13, 2019).

60. Halstead, Richard, "Marin County, Calif., Explores Potential for Drone Program," Government Technology, July 16, 2018 (accessed October 13, 2019), https:// www.govtech.com/public-safety/Marin-County-Calif-Explores-Potential-for-DroneProgram.html; Greenway, Rebecca, "Local Park Orders Prohibit Drones on California State Parks and Beaches in San Mateo County," NBC Bay Area, June 13, 2017 (accessed October 11, 2019), https://www.nbcbayarea.com/news/local/Where-toDrone-in-the-Bay-Area-and-What-to-Know-Before-You-Fly-427297153.html.

61. Garrick, David, "San Diego Adopts Drone Regulations to Boost Enforcement, Safety," San Diego Union-Tribune, April 10, 2017 (accessed October 12, 2019), https://www. sandiegouniontribune.com/news/politics/sd-me-drone-council-20170410-story.html; Griffin, Dana, "Drones Banned at Sacramento County Parks," KCRA 3, April 13, 2017 (accessed October 12, 2019), https://www.kcra.com/article/drones-banned-atsacramento-county-parks/9274853; Klauser, Francisco, and Silvana Pedrozo, "Big Data from the Sky: Popular perception of private drones in Switzerland," Institut de Géographie, June 2017.

62. Ison, David, Brent Terwilliger, and Dennis Vincenzi, "Privacy, Restriction, and Regulation Involving Federal, State and Local Legislation: More Hurdles for Unmanned Aerial Systems (UAS) Integration?" Journal of Aviation/Aerospace Education \& Research 24 (2014): 41-80, doi: 10.15394/jaaer.2014.1606; Griffin, Dana, "Drones Banned at Sacramento County Parks," KCRA 3, April 13, 2017 (accessed October 12, 2019), https://www.kcra.com/article/drones-banned-at-sacramento-county-parks/9274853.

63. West, Jonathan P., Casey A. Klofstad, Joseph E. Uscinski, and Jennifer M. Connolly, "Citizen Support for Domestic Drone Use and Regulation," American Politics Research 47 (2019): 1-33, doi: 10.1177/1532673X18782208.

64. UAV Coach, "Master List of Drone Laws (Organized by State \& Country)," 2019 (accessed October 11, 2019), https://uavcoach.com/drone-laws/.

65. Martinez, Kennedy, "Drone Laws in California," Dronethusiast, 2018 (accessed October 12, 2019), https://www.dronethusiast.com/california-drone-laws/.

66. Trageser, Claire. "What are the Rules When it Comes to Flying a Drone in San Diego?" KPBS, July 17, 2017 (accessed October 11, 2019), https:// www.kpbs.org/news/2017/jul/17/what-are-rules-where-you-can-fly-dronessan-diego/; UAV Coach, "Master List of Drone Laws (Organized by State \& Country)," 2019 (accessed October 11, 2019), https://uavcoach.com/drone-laws/; Garrick, David, "San Diego Adopts Drone Regulations to Boost Enforcement, Safety," 
San Diego Union-Tribune, April 10, 2017 (accessed October 12, 2019), https://www. sandiegouniontribune.com/news/politics/sd-me-drone-council-20170410-story.html.

67. Garrick, David, "San Diego Adopts Drone Regulations to Boost Enforcement, Safety," San Diego Union-Tribune, April 10, 2017 (accessed October 12, 2019), https://www. sandiegouniontribune.com/news/politics/sd-me-drone-council-20170410-story.html.

68. Reyes, Emily A, "L.A. Fire Department Could Soon Seek Federal Permission to Fly Drones," LA Times, June 20, 2017 (accessed October 13, 2019), https://www.latimes. com/local/lanow/la-me-In-fire-drones-20170620-story.html.

69. Skyfire, "LAFD Drone Program Receives FAAApproval," January 25, 2019 (accessed October 12, 2019), https://www.skyfireconsulting.com/skyfire-drone-blog/lafd-droneprogramme-receives-faa-approval.

70. Evangelista, Benny, "Pending SF Policy Could Let City Agencies Launch Drones," SF Chronicle, May 4, 2017 (accessed October 13, 2019), https://www.sfchronicle.com/ business/article/New-San-Francisco-policy-could-let-city-agencies-11119712.php.

71. Metz, Sam, "Drones, a Vital California Wildfire-Fighting Tool, Hindered by Complex Approval Process," Desert Sun, July 18, 2018 (accessed October 11, 2019), https:// www.desertsun.com/story/news/politics/2018/07/17/riverside-county-californiawants-expand-use-drones-aircraft-fight-wildfires/794043002/; Olivera, Jason, "Drones Helping to Fight Wildfires in California," ABC 30, August 3, 2018 (accessed October 12, 2019), https://abc30.com/technology/drones-helping-to-fight-wildfires-incalifornia/3873400/.

72. Lakey, Pat, "Drone Technology Makes Jury Duty a Hot Ticket," Mountain Democrat, February 16, 2018 (accessed October 11, 2019), https://www.mtdemocrat.com/news/ drone-technology-makes-jury-duty-a-hot-ticket/.

73. CBS13, "Why Is A Government Drone Flying Over A Sacramento Neighborhood?" May 16, 2018 (accessed October 13, 2019), https://sacramento.cbslocal.com/2018/05/16/ government-drones-neighborhood/.

74. Quinton, Amy, "Two Drones Could be Flying over Placer County in Search for Mosquitoes," Capital Public Radio, April 11, 2017 (accessed October 13, 2019), http://www.capradio.org/articles/2017/04/11/two-drones-could-be-flying-over-placercounty-in-search-for-mosquitoes/.

75. Jiang, Tao, Jared Geller, Daihen Ni, and John Collura, "Unmanned Aircraft System Traffic Management: Concept of Operation and System Architecture," International Journal of Transportation Science and Technology 5 (2017): 123-135, doi: 10.1016/j. ijtst.2017.01.004.

76. Kopardekar, Parmial, "Unmanned Aerial System (UAS) Traffic Management (UTM): Enabling Low-Altitude Airspace and UAS Operations" (NASA/TM-2014-218299), 
2014 (accessed October 13, 2019), https://ntrs.nasa.gov/archive/nasa/casi.ntrs.nasa. gov/20140013436.pdf.

77. Balakrishnan, Karthik, Joe Polastre, Jessie Mooberry, Richard Golding, and Peter Sachs, "Blueprint for the Sky: The Roadmap for the Safe Operation of Autonomous Aircraft," Airbus, 2018 (accessed October 11, 2019), https://storage.googleapis.com/ blueprint/Airbus_UTM_Blueprint.pdf.

78. Balakrishnan, Karthik, Joe Polastre, Jessie Mooberry, Richard Golding, and Peter Sachs, "Blueprint for the Sky: The Roadmap for the Safe Operation of Autonomous Aircraft," Airbus, 2018 (accessed October 11, 2019), https://storage.googleapis.com/ blueprint/Airbus_UTM_Blueprint.pdf.

79. Balakrishnan, Karthik, Joe Polastre, Jessie Mooberry, Richard Golding, and Peter Sachs, "Blueprint for the Sky: The Roadmap for the Safe Operation of Autonomous Aircraft," Airbus, 2018 (accessed October 11, 2019), https://storage.googleapis.com/ blueprint/Airbus_UTM_Blueprint.pdf.

80. Rupprecht Law, "New FAA Recreational Drone Laws [May 2019]", no date (accessed October 13, 2019), https://jrupprechtlaw.com/recreational-drone-laws/.

81. Kesteloo, Haye, "FAA Issues New Rules for Hobbyist Drone Pilots," Drone DJ, May 20, 2019 (accessed October 12, 2019), https://dronedj.com/2019/05/20/faa-new-ruleshobbyist-drone-pilots/; Rupprecht Law, "New FAA Recreational Drone Laws [May 2019]", no date (accessed October 13, 2019), https://jrupprechtlaw.com/recreationaldrone-laws/.

82. Rupprecht Law, "FAA's LAANC System-Low Altitude Authorization \& Notification Capability," no date (accessed October 12, 2019), https://jrupprechtlaw.com/lowaltitude-authorization-notification-capability-laanc-system/.

83. Federal Aviation Administration, "Unmanned Aerial System Traffic Management Concept of Operations (v1.0)(UTM CONOPS)", May 18, 2018, https://utm.arc.nasa. gov/docs/2018-UTM-ConOps-v1.0.pdf; Lakey, Pat, "Drone Technology Makes Jury Duty a Hot Ticket," Mountain Democrat, February 16, 2018 (accessed October 11, 2019), https://www.mtdemocrat.com/news/drone-technology-makes-jury-duty-a-hotticket/

84. Levin, Alan, "Drone Hobbyists May Soon Lose Their Freedom from Regulation," Insurance Journal, September 28, 2018 (accessed October 13, 2019), https://www. insurancejournal.com/news/national/2018/09/28/502849.htm.

85. Ashford, Nicholas A, "Technology-focused Regulatory Approaches for Encouraging Sustainable Industrial Transformations: Beyond green, beyond the dinosaurs, and beyond evolutionary theory," presented at the $3^{\text {rd }}$ Blueprint Workshop on Instrument for Integrating Environmental and Innovation Policy, Brussels, Belgium. September 26-27, 2002; Virtanen, Mikko, Ismo Heimonen, and Mari Hukkalainen, 
"Stakeholder Analysis and Questionnaire Showing the Way for Development of Business and Service Models," Energy Procedia 58 (2014): 51-57, doi: 10.1016/j. egypro.2014.10.408; Li, Hongyan, S. Thomas Ng, and Martin Skitmore, "Stakeholder Impact Analysis During Post-Occupancy Evaluation of Green Buildings- A Chinese Context," Building and Environment 128 (January 2018): 89-95, doi: https://doi. org/10.1016/j.buildenv.2017.11.014; Brugha, Ruairí, and Zsuzsa Varvasovszky, "Stakeholder Analysis: A review," Health Policy and Planning 15 (2000): 239-246.

86. Brugha, Ruairí, and Zsuzsa Varvasovszky. "Stakeholder Analysis: A review." Health Policy and Planning 15 (2000): 239-246, https://www.ncbi.nlm.nih.gov/ pubmed/11012397.

87. Hubbard, Sarah M., Tyler B. Spence, and Brian J. Hubbard, "UAS Considerations for Local Transportation Agencies and Other Local Agencies," Presented at the 2017 Mid-Continent Transportation Research Symposium, Ames, IA, August 16, 2017.

88. Kahan, James P, "Focus Groups as a Tool for Policy Analysis," Analyses of Social Issues and Public Policy 1 (2004): 129-146, doi: https://doi.org/10.1111/15302415.00007; Breen, Rosanna L, "A Practical Guide to Focus-Group Research," Journal of Geography in Higher Education 30 (2007): 463-475, doi: https://doi. org/10.1080/03098260600927575.

89. Brugha, Ruairí, and Zsuzsa Varvasovszky. "Stakeholder Analysis: A review." Health Policy and Planning 15 (2000): 239-246, https://www.ncbi.nlm.nih.gov/ pubmed/11012397.

90. Varavasovszky, Zsusza and Martin Mckee, "An Analysis of Alcohol Policy in Hungary. Who is in Charge?" Addiction 93 (2002): 1815-1827, doi: https://doi.org/10.1046/ j.1360-0443.1998.931218157.x.

91. Varavasovszky, Zsusza and Martin Mckee, "An Analysis of Alcohol Policy in Hungary. Who is in Charge?" Addiction 93 (2002): 1815-1827, doi: https://doi.org/10.1046/ j.1360-0443.1998.931218157.x.

92. Rupprecht Law, "Section 107.51 Operating Limitations for Small Unmanned Aircraft," no date (accessed October 11, 2019), https://jrupprechtlaw.com/section-107-51operating-limitations-for-small-unmanned-aircraft/.

93. Federal Aviation Administration, Law Enforcement Guidance for Suspected Unauthorized UAS Operations," no date (accessed October 11, 2019), https://www. faa.gov/uas/resources/policy_library/media/FAA_UAS-PO_LEA_Guidance.pdf.

94. Federal Aviation Administration, Unmanned Aircraft Systems Safety Risk Management Policy (Order 8040.6), October 4, 2019 (accessed October 11, 2019), https://www.faa. gov/documentLibrary/media/Order/FAA_Order_8040.6.pdf. 
95. Federal Aviation Administration, Law Enforcement Guidance for Suspected Unauthorized UAS Operations," no date (accessed October 11, 2019), https://www. faa.gov/uas/resources/policy_library/media/FAA_UAS-PO_LEA_Guidance.pdf.

96. Sibbet, David, Visual Meetings: How Graphics, Sticky Notes and Idea Mapping can Transform Group Productivity, Hoboken, New Jersey: John Wiley \& Sons, 2010. 


\section{BIBLIOGRAPHY}

Academy of Model Aeronautics. "AMA Government Relations Blog." January 18, 2016 (accessed October 12, 2019). https://amablog.modelaircraft.org/ amagov/2016/01/18/faa-advocacy-meeting-january-15-and-16/.

Ashford, Nicholas A. "Technology-focused Regulatory Approaches for Encouraging Sustainable Industrial Transformations: Beyond green, beyond the dinosaurs, and beyond evolutionary theory." Presented at the $3^{\text {rd }}$ Blueprint Workshop on Instrument for Integrating Environmental and Innovation Policy, Brussels, Belgium. September 26-27, 2002.

Balakrishnan, Karthik, Joe Polastre, Jessie Mooberry, Richard Golding, and Peter Sachs. "Blueprint for the Sky: The Roadmap for the Safe Operation of Autonomous Aircraft." Airbus, 2018 (accessed October 11, 2019). https://storage.googleapis. com/blueprint/Airbus_UTM_Blueprint.pdf.

Blank, Peter, Sabrina Kirrane, and Sarah Spikerman. Privacy-Aware Restricted Areas for Unmanned Aerial Systems. IEEE Security \& Privacy 16 (March-April 2018): 70-79.

Breen, Rosanna L. "A Practical Guide to Focus-Group Research." Journal of Geography in Higher Education 30 (2007): 463-475. doi: https://doi. org/10.1080/03098260600927575.

Brugha, Ruairí, and Zsuzsa Varvasovszky. "Stakeholder Analysis: A review." Health Policy and Planning 15 (2000): 239-246, https://www.ncbi.nlm.nih.gov/ pubmed/11012397.

Cavoukain, Ann. "Privacy and Drones: Unmanned Aerial Vehicles." Information and Privacy Commissioner August 2012 (accessed October 11, 2019). www. privacybydesign.ca.

CBS13. "Why Is A Government Drone Flying Over A Sacramento Neighborhood?" May 16, 2018 (accessed October 13, 2019). https://sacramento.cbslocal. com/2018/05/16/government-drones-neighborhood/.

Clarridge, Christine. "Protesters Steal the Show at Seattle Police Gathering to Explain Intended Uses of Drones." Seattle Times, October 25, 2012 (accessed October 11, 2019). https://www.seattletimes.com/seattle-news/protesters-steal-the-showat-seattle-police-gathering-to-explain-intended-use-of-drones/.

Diehl, Phil. "Police Using 'Drone Killers' to Disable Flying Devices in Emergency Situations." April 7, 2018 (accessed October 13, 2019). http://www.latimes.com/ local/lanow/la-me-drone-killers-20180407-story.html. 
DroneDeploy. "2018 Commercial Drone Industry Trends." May 30, 2018 (accessed October 10, 2019). https://dronedeploy-www.cdn.prismic.io/dronedeploywww\%2Fae535fda-dfc9-4bcf-9743-292df714e9fe_dd_2018_trends_report-f.pdf.

Evangelista, Benny. "SF city agency halts use of drones amid concerns over China." December 2, 2017 (accessed October 13, 2019). https://www.sfchronicle.com/ business/article/San-Francisco-city-agency-halts-use-of-drones-12399504.php.

Evangelista, Benny. "Pending SF Policy Could Let City Agencies Launch Drones." SF Chronicle, May 4, 2017 (accessed October 13, 2019). https://www.sfchronicle. com/business/article/New-San-Francisco-policy-could-let-city-agencies-11119712. php.

Federal Aviation Administration. "Archive of granted Part 107 waivers." October 11, 2019 (accessed October 11, 2019). https://www.faa.gov/uas/request_waiver/waivers_ granted/.

Federal Aviation Administration. "Fact Sheet—International Aviation." July 30, 2018 (accessed October 11, 2019). https://www.faa.gov/news/fact_sheets/news_story. cfm?newsld=22694.

Federal Aviation Administration. "Federal Aviation Regulation FAR Part 107-Operation and Certification of Small Unmanned Aerial Systems." no date (accessed October 9, 2019). https://www.faa.gov/uas/media/RIN_2120-AJ60_Clean_Signed.pdf.

Federal Aviation Administration. "State and Local Regulation of Unmanned Aircraft Systems Fact Sheet." December 2015 (accessed August 30, 2019). https://www. faa.gov/uas/resources/policy_library/media/UAS_Fact_Sheet_Final.pdf.

Federal Aviation Administration. "UAS by the Numbers." October 7, 2019 (accessed October 12, 2019). https://www.faa.gov/uas/resources/by_the_numbers/.

Federal Aviation Administration. "Unmanned Aerial System Traffic Management Concept of Operations (v1.0)(UTM CONOPS)." May 18, 2018 (accessed October 12, 2019). https://utm.arc.nasa.gov/docs/2018-UTM-ConOps-v1.0.pdf.

Federal Aviation Administration. Law Enforcement Guidance for Suspected Unauthorized UAS Operations." no date (accessed October 11, 2019). https://www.faa.gov/uas/ resources/policy_library/media/FAA_UAS-PO_LEA_Guidance.pdf.

Federal Aviation Administration. "Law Enforcement Guidance for Suspected Unauthorized UAS Operations." no date (accessed October 11, 2019). https:// www.faa.gov/uas/resources/policy_library/media/FAA_UAS-PO_LEA_Guidance. pdf.

Federal Aviation Administration. Unmanned Aircraft Systems Safety Risk Management Policy (Order 8040.6). October 4, 2019 (accessed October 11, 2019). https://www. faa.gov/documentLibrary/media/Order/FAA_Order_8040.6.pdf. 
Flight Safety Foundation. "FAA Warns against Drone Interference with Firefighting." August 16, 2018 (accessed October 11, 2019). https://flightsafety.org/droneinterference/.

Garrick, David. "San Diego Adopts Drone Regulations to Boost Enforcement, Safety." San Diego Union-Tribune, April 10, 2017 (accessed October 12, 2019). https:// www.sandiegouniontribune.com/news/politics/sd-me-drone-council-20170410story.html.

Giaritelli, Anna. "Drones Swamp US-Mexico Border but Federal Agents Powerless to Stop Them." October 17, 2018 (accessed October 11, 2019). https://www. washingtonexaminer.com/news/drones-swamp-us-mexico-border-but-federalagents-powerless-to-stop-them.

Global Market Insight. "UAV survey." May 2018 (accessed August 30, 2019). www. gminsights.com/industry-analysis/unmanned-aerial-vehicles-UAV-commercialdrone-market.pdf.

Goglia, John. "Federal Judge Overturns City Drone Ordinance in First Ruling of its Kind." September 21, 2017 (accessed October 12, 2019). https://www.forbes.com/sites/ johngoglia/2017/09/21/federal-judge-overturns-city-drone-ordinance-in-first-rulingof-its-kind/.

Government Accountability Office. "Small unmanned aircraft systems: FAA should improve its management of safety risks" (GAO-18-110). May 2018 (accessed August 31, 2019). https://www.gao.gov/assets/700/692010.pdf.

Granda, Carlos. "Protesters Opposed to LAPDs Use of Drones Disrupt Contention Police Commission Meeting." KABC, July 10, 2019 (accessed October 11, 2019). https:// abc7.com/protesters-opposed-to-lapds-use-of-drones-disrupt-meeting/5386310/.

Greenway, Rebecca. "Local Park Orders Prohibit Drones on California State Parks and Beaches in San Mateo County." NBC Bay Area, June 13, 2017 (accessed October 11, 2019). https://www.nbcbayarea.com/news/local/Where-to-Drone-inthe-Bay-Area-and-What-to-Know-Before-You-Fly-427297153.html.

Griffin, Dana. "Drones Banned at Sacramento County Parks." KCRA 3, April 13, 2017 (accessed October 12, 2019). https://www.kcra.com/article/drones-banned-atsacramento-county-parks/9274853.

Halstead, Richard. "Marin County, Calif., Explores Potential for Drone Program." Government Technology, July 16, 2018 (accessed October 13, 2019). https:// www.govtech.com/public-safety/Marin-County-Calif-Explores-Potential-for-DroneProgram.html.

Hubbard, Sarah M., Tyler B. Spence, and Brian J. Hubbard. "UAS Considerations for Local Transportation Agencies and Other Local Agencies." Presented at the 2017 Mid-Continent Transportation Research Symposium, Ames, IA, August 16, 2017. 
Hume, Tim and Allen Greene. "Investigations launched after suspected drone strikes passenger jet in London." April 18, 2016 (accessed August 15, 2019). http://www. cnn.com/2016/04/17/europe/london-heathrow-drone-strikes-plane/.

International Civil Aviation Organization, Safety Audit Results: USOAP Interactive Viewer, accessed October 11, 2019. https://www.icao.int/safety/pages/UsoapResults.aspx.

Ison, David, Brent Terwilliger, and Dennis Vincenzi. "Privacy, Restriction, and Regulation Involving Federal, State and Local Legislation: More Hurdles for Unmanned Aerial Systems (UAS) Integration?" Journal of Aviation/Aerospace Education \& Research 24 (2014): 41-80. doi: 10.15394/jaaer.2014.1606.

Jansen, B. (2016, February 15). "2015 one of safest on record for airliners." USA Today. http://www.usatoday.com/story/news/2016/02/15/2015-another-safe-yearairliners/80398194/.

Jeffries, Robb. "Fourth Amendment Concerns Raised at Unmanned Aircraft Summit." McClatchy_Tribune Business News, June 1, 2013 (accessed October 11, 2019). https://www.grandforksherald.com/news/2194032-fourth-amendment-concernsraised-unmanned-aircraft-summit.

Jenkins, Ben. "Watching the Watchmen: Drone Privacy and the Need for Oversight." Kentucky Law Journal 102 (2013): 160-182. https://uknowledge.uky.edu/klj/ vol102/iss 1/8 (accessed October 13, 2019).

Jiang, Tao, Jared Geller, Daihen Ni, and John Collura. "Unmanned Aircraft System Traffic Management: Concept of Operation and System Architecture." International Journal of Transportation Science and Technology 5 (2017): 123-135. doi: 10.1016/j.jitst.2017.01.004.

Kahan, James P. "Focus Groups as a Tool for Policy Analysis." Analyses of Social Issues and Public Policy 1 (2004): 129-146. doi: https://doi.org/10.1111/15302415.00007.

Kesteloo, Haye. "FAA Issues New Rules for Hobbyist Drone Pilots." Drone DJ, May 20, 2019 (accessed October 12, 2019). https://dronedj.com/2019/05/20/faa-newrules-hobbyist-drone-pilots/.

Klauser, Francisco, and Silvana Pedrozo. "Big Data from the Sky: Popular perception of private drones in Switzerland." Institut de Géographie, June 2017.

Kopardekar, Parmial. "Unmanned Aerial System (UAS) Traffic Management (UTM): Enabling Low-Altitude Airspace and UAS Operations" (NASA/TM-2014-218299). 2014 (accessed October 13, 2019). https://ntrs.nasa.gov/archive/nasa/casi.ntrs. nasa.gov/20140013436.pdf. 
Lakey, Pat. "Drone Technology Makes Jury Duty a Hot Ticket." Mountain Democrat, February 16, 2018 (accessed October 11, 2019). https://www.mtdemocrat.com/ news/drone-technology-makes-jury-duty-a-hot-ticket/.

Levin, Alan. "Drone Hobbyists May Soon Lose Their Freedom from Regulation." Insurance Journal, September 28, 2018 (accessed October 13, 2019). https:// www.insurancejournal.com/news/national/2018/09/28/502849.htm.

$\mathrm{Li}$, Hongyan, S. Thomas Ng, and Martin Skitmore. "Stakeholder Impact Analysis During Post-Occupancy Evaluation of Green Buildings: A Chinese Context." Building and Environment 128 (January 2018): 89-95. doi: https://doi.org/10.1016/j. buildenv.2017.11.014.

Loffi, Jon M., Ryan J. Wallace, Jamey D. Jacob, and Jared C. Dunlap. "Seeing the Threat: Pilot Visual Detection of Small Unmanned Aircraft Systems in Visual Meteorological Conditions." International Journal of Aviation, Aeronautics, and Aerospace 3 (accessed October 11, 2019). https://commons.erau.edu/ijaaa/vol3/ iss $3 / 13$.

Markowitz, Ezra M., Matthew C. Nisbet, Andy J. Danylchuk, Seth I. Engelbourg. "What's That Buzzing Noise? Public Opinion on the Use of Drones for Conservation Science." BioScience 67 (2017): 382-385. https://doi.org/10.1093/biosci/bix003.

Marte, Daniel, A., Nathan Walters, Mattie Milner, Emily C. Anania, Stephen Rice, and Scott Winter. "Privacy Concerns about UAS Missions." Poster presented at Embry Riddle Aeronautical University Discovery Day 2018 (Daytona Beach, FL). April 10, 2018 (accessed October 12, 2019). https://commons.erau.edu/cgi/viewcontent.cgi ?article $=1249 \&$ context $=$ discovery-day.

Martinez, Kennedy. "Drone Laws in California." Dronethusiast, 2018 (accessed October 12, 2019). https://www.dronethusiast.com/california-drone-laws/.

May, Patrick. "Firefighters say drones interfered with their work-one pilot cited." October 16, 2017 (accessed October 7, 2019). https://www.mercurynews.com/2017/10/16/ firefighters-say-drones-interfered-with-their-work-one-pilot-arrested/.

Metz, Sam. "Drones, a Vital California Wildfire-Fighting Tool, Hindered by Complex Approval Process." Desert Sun, July 18, 2018 (accessed October 11, 2019). https://www.desertsun.com/story/news/politics/2018/07/17/riverside-countycalifornia-wants-expand-use-drones-aircraft-fight-wildfires/794043002/.

National Conference of State Legislatures. "Current Unmanned Aircraft State Law Landscape." May 22, 2015 (accessed October 11, 2019). http://www.ncsl.org/ research/transportation/current-unmanned-aircraft-state-law-landscape.aspx. 
National Public Radio. Interview by Tess Vigeland. "All Things Considered Radio Show." August 23, 2015 (accessed October 11, 2019). https://www.npr. org/2015/08/23/434088544/as-traffic-clots-the-skyways-officials-seek-ways-tocope-with-drones.

Nelson, Jake R., Tony H. Grubesic, Danielle Wallace, and Alyssa W. Chamberlain. "The View from Above: A Survey of the Public's Perception of Unmanned Aerial Vehicles." Journal of Urban Technology 26 (2017). doi: https://doi.org/10.1080/106 30732.2018.1551106.

Neubaure, Kenneth, David Fleet, Filippo Grosoli, and Harry Verstynen. "Unmanned Aircraft Systems (UAS) at Airports: A primer" (ACRP Report 144), Airport Cooperative Research Program. 2015, Washington, D.C.: Transportation Research Board.

Nguyen, Chris. "No Drone Zone' Campaign Launches in Santa Clara County." September 13, 2018 (accessed October 12, 2019). https://abc7news.com/nodrone-zone-campaign-launches-in-santa-clara-co/4236940/.

Olivera, Jason. "Drones Helping to Fight Wildfires in California." ABC 30, August 3, 2018 (accessed October 12, 2019). https://abc30.com/technology/drones-helping-tofight-wildfires-in-california/3873400/.

Olivito, Jonathan. "Beyond the Fourth Amendment: Limiting Drone Surveillance Through the Constitutional Right to Informational Privacy." Ohio State Law Journal 74 (2013): 670-702.

Pathiyil, Lakshmi, L.H. low, Boon Hai Soon, and Shixin Mao. "Enabling Safe Operations of Unmanned Aircraft Systems in an Urban Environment: A Preliminary Study." In The International Symposium on Enhanced Solutions for Aircraft and Vehicle Surveillance Applications (ESAVS 2016), 2016.

Quinton, Amy. "Two Drones Could be Flying over Placer County in Search for Mosquitoes." Capital Public Radio, April 11, 2017 (accessed October 13, 2019). http://www.capradio.org/articles/2017/04/11/two-drones-could-be-flying-overplacer-county-in-search-for-mosquitoes/.

Restricted Entry and Minimum Tool Use-State Wilderness, Cultural Preserves and Natural Preserves. California Code of Regulations Title 14, § 4351, no date (accessed October 10, 2019). http://www.parks.ca.gov/pages/1324/files/trail\%20 use $\% 20$ designation\%20and\%20minimum $\% 20$ tool\%20use_ccr_final_text_\%20 2-3-15.pdf.

Reyes, Emily A."L.A. Fire Department Could Soon Seek Federal Permission to Fly Drones." LA Times, June 20, 2017 (accessed October 13, 2019). www.latimes. com/local/lanow/la-me-In-fire-drones-20170620-story.html. 
Rice, Stephen. "Eyes in the Sky: The Public has Privacy Concerns about Drones." February 4, 2019 (accessed October 11, 2019). https://www.forbes.com/sites/ stephenrice1/2019/02/04/eyes-in-the-sky-the-public-has-privacy-concerns-aboutdrones/\#28ee6ca36984.

Rosenkarans, Wayne. "High Expectations." Flight Safety Foundation, May 312017 (accessed August 31, 2019). https://flightsafety.org/asw-article/high-expectations/.

Rupprecht Law. "FAA's LAANC System (Low Altitude Authorization \& Notification Capability." no date (accessed October 12, 2019). https://jrupprechtlaw.com/lowaltitude-authorization-notification-capability-laanc-system/.

Rupprecht Law. "New FAA Recreational Drone Laws [May 2019]." no date (accessed October 13, 2019). https://jrupprechtlaw.com/recreational-drone-laws/.

Rupprecht Law. "Section 107.51 Operating Limitations for Small Unmanned Aircraft." no date (accessed October 11, 2019). https://jrupprechtlaw.com/section-107-51operating-limitations-for-small-unmanned-aircraft/.

Sabatini, Joshua. "SF Ushering in a New Era with Drone Use by City Departments." San Francisco Examiner, May 4, 2017 (accessed October 8, 2019). https:// www.sfexaminer.com/news/sf-ushering-in-new-era-with-drone-use-by-citydepartments/.

Schaufele, Roger, Li Ding, Nick Miller, H. Anna Barlett, Michael Lukacs, and Disais Bhadra. "FAA Aerospace Forecast, Fiscal Years 2017-2037." 2017 (accessed October 11, 2019). https://www.faa.gov/data_research/aviation/aerospace_ forecasts/media/FY2017-37_FAA_Aerospace_Forecast.pdf.

Shortell, David. "DHS Warns of 'Strong Concerns' that Chinese-Made Drones are Stealing Data." May 20, 2019 (accessed October 11, 2019). https://www.cnn. com/2019/05/20/politics/dhs-chinese-drone-warning/index.html.

Sibbet, David. Visual Meetings: How Graphics, Sticky Notes and Idea Mapping can Transform Group Productivity. Hoboken, New Jersey: John Wiley \& Sons, 2010.

Skyfire. "LAFD Drone Program Receives FAA Approval." January 25, 2019 (accessed October 12, 2019). https://www.skyfireconsulting.com/skyfire-drone-blog/lafddrone-programme-receives-faa-approval.

Trageser, Claire. "What are the Rules When it Comes to Flying a Drone in San Diego?" KPBS, July 17, 2017 (accessed October 11, 2019). https://www.kpbs.org/ news/2017/jul/17/what-are-rules-where-you-can-fly-drones-san-diego/.

UAV Coach. "Drone Laws in California (2019)." UAV Coach, 2019 (accessed October 12, 2019). https://uavcoach.com/drone-laws-california/. 
UAV Coach. "Master List of Drone Laws (Organized by State \& Country)." 2019 (accessed October 11, 2019). https://uavcoach.com/drone-laws/.

United States Government Accountability Office. "Unmanned Aircraft Systems-Issue Summary." no date (accessed October 11, 2019). https://www.gao.gov/key_ issues/unmanned_aerial_systems/issue_summary.

Varavasovszky, Zsusza and Martin Mckee. "An Analysis of Alcohol Policy in Hungary. Who is in Charge?" Addiction 93 (2002): 1815-1827. doi: https://doi.org/10.1046/ j.1360-0443.1998.931218157.x.

Villeda, Ray. "4 Commercial planes report drone encounters at Newark airport." August 9, 2015 (accessed August 15, 2019). http://www.nbcnewyork.com/news/local/ Drone-Crosses-Path-of-Aircraft-at-Newark-Airport-Authorities-321181931.html.

Virtanen, Mikko, Ismo Heimonen, and Mari Hukkalainen. "Stakeholder Analysis and Questionnaire Showing the Way for Development of Business and Service Models." Energy Procedia 58 (2014): 51-57. doi: doi.org/10.1016/j. egypro.2014.10.408.

Wallace, Ryan J., Kristy M. Kiernan, Tom Haritos, John Robbins, and Jon M. Loffi. "Evaluating Small UAS Operations and National Airspace System Interference Using AeroScope." Journal of Aviation Technology and Engineering 8 (May 2019). https://doi.org/10.7771/2159-6670.1189.

West, Jonathan P., Casey A. Klofstad, Joseph E. Uscinski, and Jennifer M. Connolly. "Citizen Support for Domestic Drone Use and Regulation." American Politics Research 47 (2019): 1-33. doi: 10.1177/1532673X18782208.

Winter, Scott, Stephen Rice, Gajapriya Tamilselvan, and Rusell Tokarski. "Mission-Based Citizen Vies on UAV Usage and Privacy: An Affective Perspective." Journal of Unmanned Vehicle Systems 4 (2016): 125-135.

Zickuhr, Kathryn, Elias Stahl, and Nicole DuPuis. Cities and Drones, What Cities Need to Know about Unmanned Aerial Vehicles (UAVs). National League of Cities Center for City Solutions and Applied Research, 2016 (accessed January 23, 2019). http://uavs.insct.org/wp-content/uploads/2016/09/NLC-Drone-Report.pdf. 


\section{ABOUT THE AUTHORS}

\section{TYLER SPENCE, PH.D.}

Dr. Tyler Spence is an Assistant Professor in the Department of Aviation and Technology in the College of Engineering at San José State University. Prior to joining SJSU, he was a Postdoctoral Policy Fellow for the Purdue Policy Research Institute (PPRI). With his background in aviation, both as a researcher and certified flight instructor, he has experienced many of the problems associated with aviation infrastructure, airports' and airlines' safety systems, and the growth of UAS activities in the national airspace. He also brings policy expertise, having completed the social policy graduate certificate in the Department of Political Science and having conducting research at the intersection of aviation and public policy. Dr. Spence collaborated on the development of the Drone Regulatory Research Initiative at PPRI and was an integral part of the teams in the Office of Aviation Negotiations and the Office of Transportation Policy when he worked at the U.S. Department of State in the Transportation Affairs Bureau. Dr. Spence was acting co-chair for the bilateral discussions on an Open Skies agreement. He also researched the impact of aviation on the Mexican and U.S. economies and created a presentation for the Assistant Secretary of Transportation for Aviation and International Affairs comparing the historical trends in cargo and passengers between the U.S., Japan, South Korea, and China. Dr. Spence is also a FAA certified single engine instrument rated flight instructor and also holds a multi-engine commercial certificate and an advanced ground instructor certificate. Dr. Spence holds a PhD in Aviation from Purdue University.

\section{FRANCESCA FAVARO, PH.D.}

Dr. Favaro is an Assistant Professor in the Department of Aviation and Technology in the College of Engineering at San José State University. Prior to joining SJSU, she earned a $\mathrm{PhD}$ and MS in Aerospace Engineering at the Georgia Institute of Technology and an MS and BS in Space Engineering at Politecnico di Milano, Italy. Dr. Favaro's research interests lie in the broad field of system safety and risk analysis, with an emphasis on system engineering concepts and the safe integration and embedding of new technologies and the consistent update of regulations and certification practices. In 2016, she funded the RiSA ${ }^{2} S$ lab, which

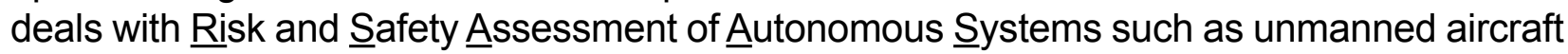
systems and self-driving cars. In 2017 she became an MTI research associate and started collaborating as an expert in the realm of autonomous vehicles. Her interests are currently focused on the safe integration of autonomous systems within U.S. public roads as well as national airspace. She particularly focuses on bridging the gap between the technological world and the current regulatory panorama. Dr. Favaro has authored several journal publications and conference proceedings on a variety of topics, ranging from UAS mishaps to risk assessment and regulatory compliance for nuclear power plants. Dr. Favaro serves on the Board of Directors of the Aero Club of Northern California and acts as Secretary for CAAPSO (Community and Airport Partnership for Safe Operations), an aviation interest group that safeguards safe and efficient operations at the local airport of Reid-Hillview, San José. She is an FAA certified Advanced Ground Instructor, a certified Remote Pilot for UAS commercial operations, and a solo-endorsed pilot. 


\section{KALLY YEUNG}

Ms. Yeung's research interests focus on sustainable air transportation planning and policy. In particular, she wrote her master's report on how to implement green roofs at San Francisco International Airport while not increasing the threat of bird strikes. She holds a BS degree in Aviation concentrated in aviation management and a Master's degree in Urban Planning, both from San José State University. 


\section{PEER REVIEW}

San José State University, of the California State University system, and the MTI Board of Trustees have agreed upon a peer review process required for all research published by MTI. The purpose of the review process is to ensure that the results presented are based upon a professionally acceptable research protocol. 


\author{
Founder, Honorable \\ Norman Mineta (Ex-Officio) \\ Secretary (ret.), \\ US Department of Transportation \\ Chair, \\ Abbas Mohaddes (TE 202I) \\ President \& COO \\ Econolite Group Inc. \\ Vice Chair, \\ Will Kempton (TE 2022) \\ Retired \\ Executive Director, \\ Karen Philbrick, PhD \\ (Ex-Officio) \\ Mineta Transportation Institute \\ San José State University \\ Richard Anderson \\ (Ex-Officio) \\ President \& CEO \\ Amtrak \\ David Castagnetti (TE 202 I) \\ Co-Founder \\ Mehlman Castagnetti \\ Rosen \& Thomas \\ Maria Cino (TE 202 I) \\ Vice President \\ America \& U.S. Government \\ Relations Hewlett-Packard Enterprise
}

\author{
Grace Crunican* \\ (TE 2022) \\ Retired
}

Donna DeMartino (TE 202I)

General Manager \& CEO

San Joaquin Regional Transit District

Nuria Fernandez* (TE 2020)

General Manager \& CEO

Santa Clara Valley

Transportation Authority (VTA)

John Flaherty (TE 2020)

Senior Fellow

Silicon Valley American

Leadership Form

Rose Guilbault (TE 2020)

Board Member

Peninsula Corridor

Joint Powers Board

Ian Jefferies (Ex-Officio)

President \& CEO

Association of American Railroads

Diane Woodend Jones

(TE 2022)

Principal \& Chair of Board

Lea + Elliott, Inc.
Therese McMillan

(TE 2022)

Executive Director

Metropolitan Transportation

Commission (MTC)

Bradley Mims (TE 2020)

President \& CEO

Conference of Minority

Transportation Officials (COMTO)

Jeff Morales (TE 2022)

Managing Principal

InfraStrategies, LLC

Dan Moshavi, PhD

(Ex-Officio)

Dean, Lucas College and

Graduate School of Business

San José State University

Takayoshi Oshima (TE 202 I)

Chairman \& CEO

Allied Telesis, Inc.

Toks Omishakin

(Ex-Officio)

Director

California Department of

Transportation (Caltrans)
Paul Skoutelas (Ex-Officio)

President \& CEO

American Public Transportation

Association (APTA)

Dan Smith (TE 2020)

President

Capstone Financial Group, Inc.

Beverley Swaim-Staley (TE 2022)

President

Union Station Redevelopment

Corporation

\section{Jim Tymon (Ex-Officio)}

Executive Director

American Association of

State Highway and Transportation

Officials (AASHTO)

\section{Larry Willis (Ex-Officio)}

President

Transportation Trades

Dept., AFL-CIO

$(\mathrm{TE})=$ Term Expiration

* = Past Chair, Board of Trustees

\section{Directors}

Karen Philbrick, Ph.D.

Executive Director

Hilary Nixon, Ph.D.

Deputy Executive Director

\section{Asha Weinstein Agrawal,}

\section{Ph.D.}

Education Director

National Transportation Finance

Center Director

\section{Brian Michael Jenkins}

National Transportation Security

Center Director

\title{
Research Associates Policy Oversight Committee
}

Jan Botha, Ph.D.

Civil \& Environmental Engineering

San José State University

Katherine Kao Cushing,

\section{Ph.D.}

Enviromental Science

San José State University

Dave Czerwinski, Ph.D. Marketing and Decision Science San José State University
Frances Edwards,

Ph.D.

Political Science

San José State University

Taeho Park, Ph.D.

Organization and Management

San José State University

\section{Christa Bailey}

Martin Luther King, Jr. Library

San José State University

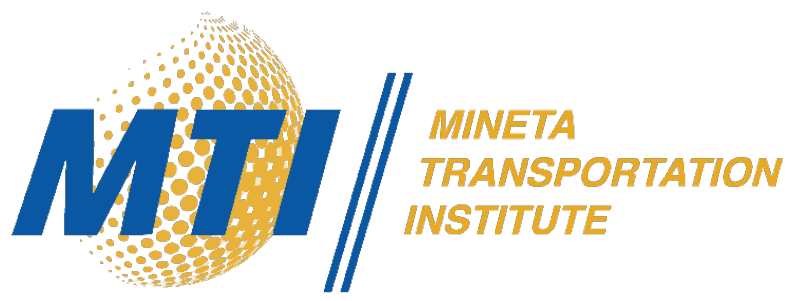

